\title{
Status of Healthcare
}

Michael Weißer, Ute Zerwes, Simon Krupka, Tonio Schönfelder, Silvia Klein, Hans-Holger Bleß

\subsection{Basis of the Study -42}

3.2 Ambulatory Care -43

3.3 Inpatient Care -45

3.3.1 Primary Arthroplasty -45

3.3.2 Revision Total Arthroplasty -53

3.3.3 Accompanying Measures during Inpatient Stay -59

3.3.4 Complications -61

3.4 Rehabilitation - 65

3.4.1 Therapy Recommendations and Standards -66

3.4.2 Provision of Care -67

3.4.3 Utilization of Services - 67

3.4.4 Implementation of Therapeutic Measures - 69

3.4.5 Effectiveness of Subsequent Rehabilitation - 71

3.4.6 Post-Rehabilitation Care -71

3.4.7 Challenges - 71

3.4.8 Outlook -72

3.5 Quality Aspects of Care - 73

3.5.1 Materials -73

3.5.2 Surgery and Perioperative Management -73

3.5.3 Surgeon -76

3.5.4 Hospital -76

3.5.5 Patient -76

3.5.6 Post-Discharge Treatment Outcomes - 78

3.5.7 Indications -81

3.5.8 Regional Differences -81

References -83 


\section{Summary}

Approximately half of all hospitals in Germany perform primary hip and knee arthroplasty. Symptomatic osteoarthritis is the cause of $80 \%$ of primary hip replacements and $96 \%$ of primary knee replacements. In accordance with mandatory external quality assurance measures for hospitals, an increase in the documentation of appropriate indications has been observed for a growing proportion of patients over the last few years and reached $96 \%$ for both types of surgery in 2014. A limiting factor, however, is that some of the relevant indication criteria do not yet exist in a standardized or evidence-based format. Hip and knee replacements are amongst the most commonly performed inpatient procedures. Patients who undergo primary hip or knee replacement account for approximately $2 \%$ of all full-time inpatients. Over the past years, the length of hospital stay for arthroplasty patients has been declining continuously with a greater decline relative to the average length of stay for all other types of hospital treatments. In 2014, the average length of stay was approximately 11.8 days and 10.6 days for total hip and for total knee arthroplasty respectively. Surgical complications during inpatient stays for primary arthroplasty have been declining for years and are now in the lower single-digit percentage range. Routine statutory health insurance data between 2005 and 2006 show that that $3.5 \%$ of primary hip arthroplasty patients and $3.8 \%$ of primary knee arthroplasty patients underwent premature revision total replacement within the first 2 years after surgery. The risk of complications from endoprosthetic surgery depends on numerous factors. Influencing factors include the implant itself and the type surgery performed (including the surgeon's experience, surgical techniques, the duration of surgery, etc.), the patient's medical characteristics (concomitant diseases, compliance, etc.) as well as the type of rehabilitation care and ambulatory follow-up care. To date, no relevant data on service lives and influencing factors have been systematically collected in Germany. However, this is expected to change thanks to the German arthroplasty registry »Endoprothesenregister Deutschland" which was established in 2011. Rehabilitation treatment should start soon after surgery and in the majority of cases this is commenced a few days after discharge from hospital. However, due to shorter lengths of hospital stays, patients in rehabilitation clinics have greater care requirements. Older multimorbid patients in particular, require targeted geriatric, interdisciplinary care. Surveys carried out on statutory health insurees have indicated that most patients show a significant reduction in symptoms after surgery and that this is still the case even 5 years after surgery. In addition, a large majority of patients are satisfied with the procedure. These effects are more pronounced in hip surgery patients than in patients who have undergone knee replacements. The vast majority of patients return to work following the procedure.

Quality of care cannot be ascribed to an implant alone as a number of other factors need to be taken into consideration. To a greater degree, the entire ambulatory medical care chain, including medical care before admission into hospital, acute care, follow-up care and rehabilitation, are crucial to the quality of care. Nationwide quality initiatives in Germany aim at improving the transparency and analysis of medical services as well as improving the quality in the provision of care. The following chapter describes the chain of care and quality aspects of care.

\subsection{Basis of the Study}

Illustrations of the use and quality aspects of replacement surgery in Germany are founded on numerous expert reviews and reports, as well as on different data sources. The expert reviews refer to three data sources:

1. Data based on $\$ 21$ of the German Hospital Remuneration Law.

2. Routine data from individual statutory health insurances.

3. Routine data on the prevalence of all reported procedures according to the German procedure classification »Operationen- und Prozedurenschlüssel (OPS) « compiled by the Federal Statistical Office of Germany.

On the whole, different primary and secondary data studies based on the volume and quality of care exist (•Tab. 3.1). 
Tab. 3.1 Overview of selected publications, focusing on case numbers and database analysis of hip and knee arthroplasty

\begin{tabular}{|c|c|c|c|c|c|}
\hline Author & Publication & Analysis topic & Sample & Period & Focus \\
\hline $\begin{array}{l}\text { AQUA } \\
\text { Institute }\end{array}$ & $\begin{array}{l}\text { Bundesaus- } \\
\text { wertungen }\end{array}$ & $\begin{array}{l}\text { Hip and knee } \\
\text { endoprostheses }\end{array}$ & $\begin{array}{l}\text { Accounting data acc. to } \\
\S 301 \text { Volume V of the Ger- } \\
\text { man Social Security Code }\end{array}$ & 2009-2014 & Quality indicators \\
\hline $\begin{array}{l}\text { AQUA } \\
\text { Institute }\end{array}$ & $\begin{array}{l}\text { Hüftendopro- } \\
\text { thesenversorgung } \\
\text { Abschlussbericht }\end{array}$ & $\begin{array}{l}\text { Hip endo- } \\
\text { prostheses }\end{array}$ & $\begin{array}{l}\text { Settlement data acc. to } \\
\S 301 \text { Volume V German } \\
\text { Social Security Code }\end{array}$ & 2004-2010 & $\begin{array}{l}\text { Development of } \\
\text { quality indicators }\end{array}$ \\
\hline $\begin{array}{l}\text { AQUA } \\
\text { Institute }\end{array}$ & $\begin{array}{l}\text { Knieendoprothe- } \\
\text { senversorgung } \\
\text { Abschlussbericht }\end{array}$ & $\begin{array}{l}\text { Knee endo- } \\
\text { prostheses }\end{array}$ & $\begin{array}{l}\text { Accounting data acc. to } \\
\S 301 \text { Volume V German } \\
\text { Social Security Code }\end{array}$ & 2004-2010 & $\begin{array}{l}\text { Development of } \\
\text { quality indicators }\end{array}$ \\
\hline $\begin{array}{l}\text { Barmer } \\
\text { GEK }\end{array}$ & $\begin{array}{l}\text { Barmer GEK Kran- } \\
\text { kenhaus-Report } \\
2010\end{array}$ & $\begin{array}{l}\text { Hip and knee } \\
\text { endoprostheses }\end{array}$ & $\begin{array}{l}\text { SHI routine data, patient } \\
\text { survey approx. } 8 \text { million } \\
\text { patients }\end{array}$ & 2003-2009 & $\begin{array}{l}\text { Case number } \\
\text { development }\end{array}$ \\
\hline Braun & $\begin{array}{l}\text { hkk-Gesund- } \\
\text { heitsreport } 2013\end{array}$ & $\begin{array}{l}\text { Hip and knee } \\
\text { endoprostheses }\end{array}$ & $\begin{array}{l}\text { hkk routine data; Federal } \\
\text { Statistical Office data }\end{array}$ & $\begin{array}{l}2008-2012 / \\
2006-2011\end{array}$ & $\begin{array}{l}\text { Development of } \\
\text { revision surgery } \\
\text { over time; services } \\
\text { associated with } \\
\text { joint replacements }\end{array}$ \\
\hline $\begin{array}{l}\text { Haas } \\
\text { et al. }\end{array}$ & $\begin{array}{l}\text { EndoCert }^{\circledR} \text {-Zertifi- } \\
\text { zierung von endo- } \\
\text { prothetischen } \\
\text { Zentren in } \\
\text { Deutschland } 2013\end{array}$ & $\begin{array}{l}\text { Hip and knee } \\
\text { endoprostheses }\end{array}$ & $\begin{array}{l}\text { Federal Statistical Office } \\
\text { data }\end{array}$ & 2004-2010 & $\begin{array}{l}\text { Factors influenc- } \\
\text { ing the quality of } \\
\text { care }\end{array}$ \\
\hline $\begin{array}{l}\text { Lüring } \\
\text { et al. }\end{array}$ & $\begin{array}{l}\text { Report der } \\
\text { DGOOC/Bertels- } \\
\text { mann Stiftung } \\
2013\end{array}$ & $\begin{array}{l}\text { Knee endopros- } \\
\text { theses }\end{array}$ & $\begin{array}{l}\text { AOK routine data; approx. } \\
25 \text { million insurees }\end{array}$ & 2005-2011 & $\begin{array}{l}\text { Regional differ- } \\
\text { ences }\end{array}$ \\
\hline $\begin{array}{l}\text { Raben- } \\
\text { berg }\end{array}$ & $\begin{array}{l}\text { Robert Koch } \\
\text { Institut, Arthrose } \\
2013\end{array}$ & $\begin{array}{l}\text { Hip and knee } \\
\text { endoprostheses }\end{array}$ & $\begin{array}{l}\text { Federal Statistical Office } \\
\text { data (in addition to GEK } \\
\text { and AOK) }\end{array}$ & 2010 & $\begin{array}{l}\text { Endoprostheses } \\
\text { prevalence (case } \\
\text { number develop- } \\
\text { ment) }\end{array}$ \\
\hline $\begin{array}{l}\text { Schäfer } \\
\text { et al. }\end{array}$ & $\begin{array}{l}\text { Krankenhaus } \\
\text { Report } 2012\end{array}$ & $\begin{array}{l}\text { Hip and knee } \\
\text { endoprostheses }\end{array}$ & $\begin{array}{l}\text { AOK routine data; approx. } \\
25 \text { million insurees }\end{array}$ & 2005-2009 & $\begin{array}{l}\text { Regional differ- } \\
\text { ences }\end{array}$ \\
\hline
\end{tabular}

\subsection{Ambulatory Care}

Different groups of specialist physicians are involved in the ambulatory care of patients who have undergone hip and knee replacements. The chain of care comprises primary care physicians (general practitioners and internists working as primary care physicians), orthopedic and trauma surgery specialists in as well as radiologists. Physio- therapists and occupational therapists are also involved.

The indication for joint replacement surgery is made by specialists in orthopedics and trauma surgery, based on clinical and radiological criteria that take into consideration the related benefits and risks (Section 1.2).

Usually, patients suffering from arthrosis have been in ambulatory medical care for years before a 


\begin{tabular}{|c|c|}
\hline $\begin{array}{c}\text { Physiotherapy } \\
\text { e.g. (conventional) } \\
\text { movement therapy }\end{array}$ & $\begin{array}{c}\text { Physical therapy } \\
\text { e. g. massages, cold and } \\
\text { heat therapy }\end{array}$ \\
\hline $\begin{array}{c}\text { Occupational therapy } \\
\text { e. g. information on } \\
\text { appropriate joint } \\
\text { protection }\end{array}$ & $\begin{array}{l}\text { Orthopedic aids } \\
\text { e. g. walking aids, } \\
\text { orthopedic show } \\
\text { finishings/insoles }\end{array}$ \\
\hline
\end{tabular}

- Fig. 3.1 Factors of conservative, non-drug treatment of osteoarthritis. (Source: IGES - Claes et al. 2012 and Wirtz 2011)

hip or knee replacement becomes necessary. Conservative arthrosis therapy comprises the use of therapeutic products and medical aids (- Fig. 3.1) as well as pain management drugs (AWMF 2009a, b).

In many cases, joint replacement constitutes the primary treatment of femoral neck fractures. In contrast to the case of osteoarthritis, surgical care here is urgent (acute), i.e. should take place shortly after the event as otherwise an imminent and considerable deterioration of the patient's state of health is to be expected (Claes et al. 2012).

- Tab. 3.2 shows the use of ambulatory treatment of statutory health insurance patients prior to joint replacement for the period 2003 to 2009. According to patient reports, e.g. 74 to $85 \%$ of patients who received a hip or knee joint replacement had taken medication for joint pain prior to surgery (Barmer GEK 2010).
An analysis of routine data from the SHI Handelskrankenkasse (hkk) found that ambulatory services prior to joint replacement surgery accounted for around two thirds of all ambulatory services (i.e. pre- and postoperative, for 6 months each). This was the case for both total hip and total knee arthroplasty (Braun 2013).

Owing to the remuneration and visiting consultant system, the orthopedic specialist who treated the patient in ambulatory care and who made the recommendation for surgical inpatient care has the option of performing the surgery.

Visiting consultants with admission privileges are »(...) statutory health insurance physicians who are not employed by the hospital and are entitled to treat their patients in hospital as inpatients or daycare patients using the services, facilities and materials available without receiving any remuneration from the hospital (\$121 [2] Volume V German Social Security Code). Fee-based physicians are also not employed by the hospital but make their services available to the hospital for a fee.

The number of cases of hip joint replacements and revisions (including partial replacements) and knee joint replacements in visiting consultant wards are declining (• Fig. 3.2).

Tab. 3.2 Annual patient use of ambulatory treatment services prior to joint replacement (questionnaire survey)

\begin{tabular}{|c|c|c|c|c|}
\hline Joint & \multicolumn{2}{|l|}{ Hip } & \multicolumn{2}{|l|}{ Knee } \\
\hline Population & \multicolumn{4}{|c|}{ Barmer GEK insurees } \\
\hline Evaluation period & $2003(n=555)$ & $2009(n=1,080)$ & $2003(n=301)$ & $2009(n=940)$ \\
\hline $\begin{array}{l}\text { Pain management } \\
\text { with drugs }\end{array}$ & $76.4 \%$ & $74.1 \%$ & $82.4 \%$ & $85.0 \%$ \\
\hline Physiotherapy & $50.6 \%$ & $46.4 \%$ & $39.5 \%$ & $40.2 \%$ \\
\hline Massage & $19.8 \%$ & $14.3 \%$ & $14.6 \%$ & $12.3 \%$ \\
\hline Physical therapy & $20.0 \%$ & $13.4 \%$ & $17.6 \%$ & $9.3 \%$ \\
\hline
\end{tabular}




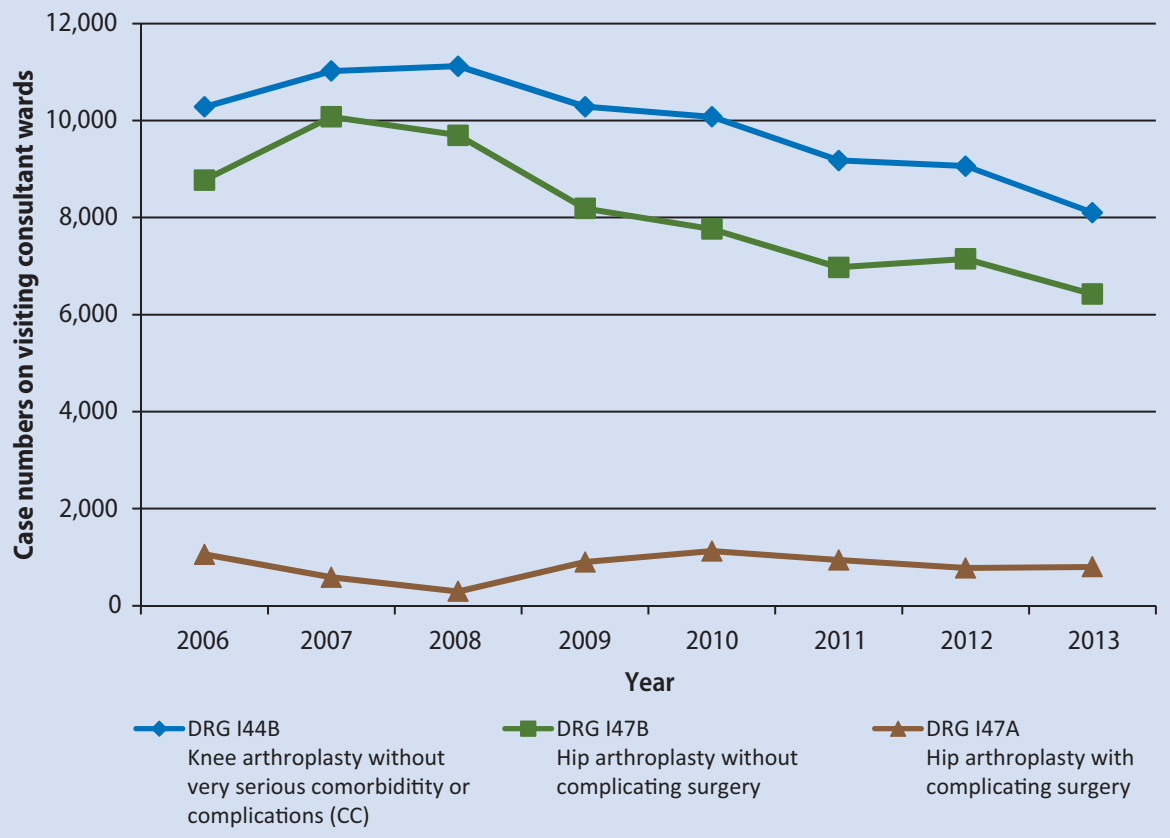

- Fig. 3.2 Number of cases of the most common DRGs for hip and knee joint replacements in visiting consultant wards, patients with normal length of stays, 2006-2013. (Source: IGES - InEK 2015)

\subsection{Inpatient Care}

\subsubsection{Primary Arthroplasty}

Capacity of care, proximity to domicile and waiting times

Hip and knee joint replacements rank amongst the most common procedures performed in the inpatient care sector. According to 2013 DRG statistics, out of a total of $18,531,819$ patients in inpatient care, approximately $2 \%$ of these underwent primary hip and knee joint replacements (Destatis 2014).

The AQUA Institute conducted a national »External Quality Assurance for Inpatient Care« assessment for elective primary total hip arthroplasty (THA), recorded 1,075 hospitals performing primary THA (AQUA-Institut 2013a). 1,031 hospitals performed primary total knee arthroplasty (TKA) (AQUA-Institut 2013c). In total, more than half of all German hospitals performed primary hip or knee joint replacement surgery in 2013 (Destatis 2015a). Between 2009 and 2013, there was a decline in the number of hospitals that performed total hip arthroplasty. It must be noted, however, that there was a decline in the overall number of hospitals as well (- Tab. 3.3).

Between 2009 and 2010, the number of hospitals that performed primary TKA increased slightly, after which it remained relatively steady until 2013 (AQUA-Institut 2012c, 2013c, 2014c, 2015d, 2010c, 2014c). The percentage of centers performing endoprosthetic surgery in relation to the total number of hospitals increased from $49.0 \%$ to $51.7 \%$.

In 2014, the method used to count hospitals for inpatient quality care assurance purposes changed, whereby additional locations of each hospital were also included in the count. Hence, as of 2014, the number of recorded hospitals performing THA replacement surgery increased to 1,229 hospitals (AQUA-Institut 2015b) and to 1,160 hospitals performing TKA (AQUA-Institut 2015d).

A study evaluated the distance patients traveled to hospitals for hip joint replacements (OPS 5-820, including partial prostheses), for both elective surgery and emergency treatment, based on data from hospital cases of 71,870 AOK insurees in 2006 (Fried- 
- Tab. 3.3 Total number of hospitals in Germany, centers that performed hip and knee joint replacements, and percentage of hospitals performing endoprosthetic surgery 2009-2014

\begin{tabular}{|c|c|c|c|c|c|}
\hline & 2009 & 2010 & 2011 & 2012 & 2013 \\
\hline Number of hospitals in Germany ${ }^{1)}$ & 2,084 & 2,064 & 2,045 & 2,017 & 1,996 \\
\hline Number of hospitals that performed primary $\mathrm{THA}^{2)}$ & 1,156 & 1,149 & 1,112 & 1,091 & 1,075 \\
\hline $\begin{array}{l}\text { Proportion of hospitals that perform THA out of all } \\
\text { hospitals in Germany'1), 2) }\end{array}$ & $55.5 \%$ & $55.7 \%$ & $54.4 \%$ & $54.1 \%$ & $53.9 \%$ \\
\hline Number of hospitals that performed primary TKA ${ }^{3)}$ & 1,022 & 1,036 & 1,030 & 1,033 & 1,031 \\
\hline $\begin{array}{l}\text { Proportion of hospitals that perform TKA out of all } \\
\text { hospitals in Germany1), 3) }\end{array}$ & $49.0 \%$ & $50.2 \%$ & $50.4 \%$ & $51.2 \%$ & $51.7 \%$ \\
\hline
\end{tabular}

Source: IGES calculations - 1) Destatis 2015a, 2) AQUA-Institut 2010b, 2011b, 2012a, 2013a, 2014a, 3) 2010c, 2011c, 2012c, 2013c, 2014c

rich and Beivers 2009). The average distance to the service-providing hospitals was 17.6 kilometers (elective surgery $19.7 \mathrm{~km}$, emergency procedures $12.4 \mathrm{~km})$. A total of $41 \%$ of the patients had the procedure performed in the hospital closest to their domicile (elective surgery $34.3 \%$, emergency procedures $56.8 \%$ ). Older patients in particular were treated close to their homes and had the lowest average travel distances. For elective surgery, the patient travel distances in rural areas were the longest. Moreover, patients in urban areas often did not choose the nearest hospital. On the whole, the study results indicate that hospital care close to the domicile of the patient becomes more important with increasing age. Hospitals located further away are particularly chosen for specific elective surgery. These are usually smaller establishments specialized in performing specific procedures (Friedrich and Beivers 2009).

Waiting times for surgery are not systematically recorded in Germany (Finkenstädt and Niehaus 2013). A telephone survey conducted in 2010 by the American foundation »Commonwealth Fund « found that patients in Germany have a waiting time of 4 months at most for elective surgery (of any kind). $78 \%$ of those surveyed had this surgery performed within one month (The Commonwealth Fund 2010).

Overviews of health economic data show broad spans of waiting times for hip joint replacements. In 2008, the waiting time in Germany and Austria was between 1 month and 12 months. In Switzerland, the waiting period was between less than 1 month and 6 months, and in Great Britain approximately 8 months (Effenberger et al. 2008).

More up-to-date data on waiting times, provision of care close to the patient's domicile and waiting times specifically for patients with indications for knee replacements could not be sourced. Overall, the decision with regard to waiting times for hip or knee joint replacements must take into consideration minimizing the time the patient has to live with diminished quality of life and avoiding revision surgery over their lifetime and/or an as long as possible service life of the endoprosthesis. Additionally, study results suggest that a realistic waiting period as well as regular and transparent communication during the waiting period have a positive influence on patient satisfaction with regard to waiting times (Conner-Spady 2011).

\section{- Indication (underlying disease)}

Symptomatic osteoarthritis constitutes the most common underlying disease in patients who are admitted to hospital for hip or knee joint replacements. A study based on routine data from a statutory health insurance fund found that osteoarthritis of the hip joint accounted for $80.1 \%$ of all procedures and osteoarthritis of the knee joint accounted for $96 \%$ (-Tab. 3.4). Femoral neck fractures constituted $12.5 \%$ of all indications for hip joint replacements (Barmer GEK 2010). 
- Tab. 3.4 Frequency of treatment diagnosis for hip or knee joint replacements (primary replacement) amongst statutory health insurees (Barmer GEK, 2007-2009)

\begin{tabular}{|l|l|l|}
\hline Diagnosis & Description & Percentage \\
\hline Hip & & \\
\hline M16 & Osteoarthritis of hip & $80.1 \%$ \\
\hline M87 & Fracture of femur & $12.5 \%$ \\
\hline T84 & Osteonecrosis & $3.1 \%$ \\
\hline M & $\begin{array}{l}\text { Complications of inter- } \\
\text { nal orthopedic pros- } \\
\text { thetic devices }\end{array}$ & $2.1 \%$ \\
\hline C & $\begin{array}{l}\text { Other diseases of the } \\
\text { musculoskeletal system }\end{array}$ & $1.0 \%$ \\
\hline Knee & Malignant neoplasms & $0.5 \%$ \\
\hline M17 & Other diagnoses $0.6 \%$ & \\
\hline T84 & Osteoarthritis of knee & $96.0 \%$ \\
\hline M & $\begin{array}{l}\text { Complications of inter- } \\
\text { nal orthopedic pros- } \\
\text { thetic devices }\end{array}$ & $2.0 \%$ \\
\hline Other diseases of the \\
musculoskeletal system
\end{tabular}

However, with the patients « increasing age, an increase in the percentage of hip joint replacements due to fractures can be observed. In the 65 to 74 years age group, femoral neck fractures were the surgical indication for hip joint replacement in $8.6 \%$ of cases and in the 75 to 84 years age group femoral neck fractures accounted for $26.8 \%$. In addition, it was found that $66.1 \%$ of those receiving hip joint replacements due to femoral neck fractures were over the age of 85 (Barmer GEK 2010) (• Fig. 3.3).

\section{- Comorbidity and perioperative risk}

The most common concomitant diseases of patients undergoing hip or knee joint replacement were determined by several studies based on administrative data from statutory health insurances (•Tab. 3.5).
- Tab. 3.5 Examples of common concomitant diseases of hip and knee joint replacement patients $(n=149,717)$

\begin{tabular}{|c|c|c|}
\hline Concomitant disease & \multicolumn{2}{|l|}{ Prevalence } \\
\hline Diabetes mellitus & \multicolumn{2}{|l|}{$16.0 \%$} \\
\hline Heart failure & \multicolumn{2}{|l|}{$7.7 \%$} \\
\hline Chronic renal failure & \multicolumn{2}{|l|}{$5.9 \%$} \\
\hline COPD & \multicolumn{2}{|l|}{$5.2 \%$} \\
\hline Asthma & \multicolumn{2}{|l|}{$1.9 \%$} \\
\hline Arteriosclerosis & \multicolumn{2}{|l|}{$1.7 \%$} \\
\hline Malignant neoplasms & \multicolumn{2}{|l|}{$1.0 \%$} \\
\hline Acute renal failure & \multicolumn{2}{|l|}{$0.4 \%$} \\
\hline $\begin{array}{l}\text { Barmer GEK (2010), Initial } \\
\text { survey } 2009\end{array}$ & $\begin{array}{l}\text { Hip } \\
(n=1,120)\end{array}$ & $\begin{array}{l}\text { Knee } \\
(n=1,033)\end{array}$ \\
\hline Diabetes mellitus & $10 \%$ & $12.7 \%$ \\
\hline Cancer excluding leukemia & $9 \%$ & $8.6 \%$ \\
\hline COPD & $7.7 \%$ & $8.7 \%$ \\
\hline Stomach ulcer & $7.6 \%$ & $9.9 \%$ \\
\hline Heart failure & $7.1 \%$ & $10.2 \%$ \\
\hline
\end{tabular}

The studies showed that patients with hip or knee replacements suffered from diseases such as diabetes mellitus and heart failure, which are particularly common at an older age (RKE 2015).

In the survey for TKA care documented in the "2010 Barmer GEK Hospital Report « (Barmer GEK Krankenhaus-Report 2010), 46.5 \% (initial survey 2009 ) and $56.6 \%$ (follow-up survey 2009) of patients reported suffering from at least one concomitant disease. Amongst the patients with THA, $39.8 \%$ (initial survey 2009) and $50.2 \%$ (follow-up survey 2009) suffered from at least one concomitant disease. The prevalence of individual concomitant diseases was comparable for patients with THA and TKA (Barmer GEK 2010).

Each surgical procedure involves certain risks that are not only related to the operation itself but also the required anesthesia. These added risks prevail for the duration of the surgery as well as for a certain period subsequent to the surgery (perioperative com- 


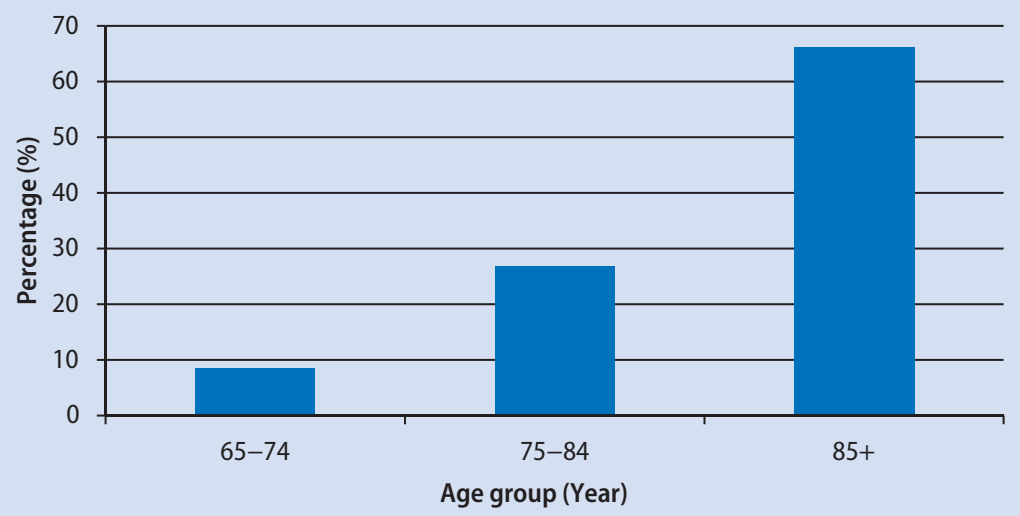

Fig. 3.3 Age distribution of femoral neck fractures (S72) treated with hip joint replacements (Source: IGES Barmer GEK 2010)

plication risk). Amongst other things, surgical risk depends on the extent of the surgery, the expected duration, anatomical conditions, blood loss and patient positioning. Anesthetic risk is described as the risk associated with the anesthetic method applied. For elective surgery in particular, the benefits must be carefully weighed against the risks of the surgery and anesthesia (Claes et al. 2012; Wirtz 2011).

Furthermore, the comorbidity of patients who undergo endoprosthetic surgery constitutes a significant influencing factor for the overall risk associated with the procedure (Singh 2013, Lau 2016). The American Society of Anesthesiology classifica- tion (ASA classification system) has been used to estimate patients " perioperative risks for a long time. The treating anesthetist documents the ASA classification during premedication, based on the American Society of Anesthesiology (ASA) classification requirements. The ASA classification groups patients into up to six classes ( $\downarrow$ Chapter 1 ). $\mathrm{Pa}$ tients" ASA classifications were also included in the external quality assurance conducted by the AQUA Institute (AQUA-Institut 2015d). The majority of patients were assigned to ASA class 2 (with mild systemic disease) or class 3 (with severe systemic disease and functional limitations) (• Tab. 3.6).

- Tab. 3.6 ASA classification for primary THA $(n=160,559)$ and TKA $(n=130,802)(2014)$ documented for External Quality Assurance for Inpatient Care

\begin{tabular}{|c|l|l|l|}
\hline ASA & Description & THA classification [\%] & TKA classification [\%] \\
\hline ASA 1 & A normal, healthy patient & 8.4 & 5.5 \\
\hline ASA 2 & A patient with mild systemic disease & 61.3 & 61.1 \\
\hline ASA 3 & $\begin{array}{l}\text { A patient with severe systemic disease and functional } \\
\text { limitations }\end{array}$ & 29.8 & 33.0 \\
\hline ASA 4 & $\begin{array}{l}\text { A patient with severe systemic disease that is a } \\
\text { constant threat to life }\end{array}$ & 0.5 & 0.4 \\
\hline ASA 5 & A moribund patient & 0.01 & 0.01 \\
\hline
\end{tabular}


This seems plausible in view of the fact that only healthy patients are classified into ASA 1 and patients who undergo hip or knee joint replacement already have an underlying symptomatic disease. Over the period 2009 to 2014, the distribution of the documented patient population within the ASA classifications remained almost constant (AQUA-Institut 2010b, c, 2011b, c, 2012a, c, 2013a, c, 2014a, c, 2015b, d).

A limiting factor, however, is that the ASA classification has been subject to strong criticism for several decades. One particular point of criticism is the lack of distinct criteria for classifying patients into the ASA categories. This especially affects ASA classes 2 and 3, to which most patients are assigned. Study results suggest that the allocation to a given ASA class is often undertaken subjectively and physicians' evaluations often differ in this respect (Shah et al. 2013). In addition, the ASA classification is hardly relevant to later patient pathways.

In contrast, specific comorbidities or clinical parameters, such as blood sugar values, tachypnea and lack of sinus rhythm, are of much higher importance for clinical decision-making and perioperative risk assessment. With regard to the long-term complication risks and/or the long-term success of treatment following endoprosthetic surgery, other specific concomitant diseases seem to have a significant influence. For example, it was demonstrated that obesity, diabetes mellitus and hyperglycemia are associated with an increased risk of joint inflammation during the first post-operative year (Jämsen et al. 2012).

On the whole, studies suggest that using scores which enable differentiated and objective assessments of a patient's general comorbidity, such as the Charlson Comorbidity Score (Charlson et al. 1987), enable good predictions of postoperative mortality and morbidity (Singh et al. 2013, Lau et al. 2016).

In addition, analyses of mortality after endoprosthetic surgery do exist. Based on Barmer GEK routine data, patients who received primary joint replacements were identified and analyzed with regard to cases of death (Barmer GEK 2010). The study shows that $1.0 \%$ of patients who underwent a hip joint replacement died during the inpatient stay. $4.3 \%$ of the patients died within 365 days after discharge from hospital, but distinct differences in the underlying diseases were observed. $21.4 \%$ of patients with a femoral fracture died within one year after discharge from hospital. In contrast, only $0.7 \%$ of the patients with osteoarthritis of the hip died within one year after discharge from hospital (Barmer GEK 2010).

An inpatient mortality of $0.1 \%$ was observed in patients who had undergone knee joint replacements. $1.3 \%$ of the patients died within one year after discharge from hospital. In individual sub populations, hardly any differences could be identified with regard to mortality (Barmer GEK 2010).

\section{- Surgical procedures}

Jaschinski et al. (2014) conducted a nationwide survey in Germany on elective total hip and knee arthroplasty based on data from hospitals that recorded a minimum of 100 primary operations in their 2010 quality reports. Chief physicians from 694 orthopedics/trauma surgery departments and the respective anesthetists were contacted in writing with the aim of gaining insight into treatment processes and medical approaches as well as obtaining suggestions for optimizing care. $31.8 \%$ of the hospitals contacted responded. 303 questionnaires from 221 hospitals were statistically evaluated, based on which the authors concluded that the study was representative (Jaschinski et al. 2014).

$50 \%$ of the surgery was performed by the chief physicians, $40 \%$ by senior physicians and approximately $10 \%$ by other physicians in senior positions (heads of division, lead physicians, assistant physicians) on the day of admission or no later than one day after admission (Jaschinski et al. 2014). Other study results show that the duration of surgery was on average 75 minutes (hip) or 85 minutes (knee) (AQUA-Institut 2012a, c, 2013a, c, 2014a, c, 2010b, c, 2011b, c). Postoperative pain management and perioperative antibiotic prophylaxis were documented for almost all patients (-Tab. 3.7; Jaschinski et al. 2014; AQUA-Institut 2012a, c, 2013a, c, 2014a, c, 2010b, c, 2011b, c).

\section{- Length of stay}

According to a nationwide analysis conducted in Germany by the AQUA Institute, the length of stay and the length of postoperative stay for primary THA and TKA surgery have been declining for 
Tab. 3.7 Description of inpatient care for THA and TKA

\begin{tabular}{|c|c|c|}
\hline Description & $\begin{array}{l}\text { THA (per- } \\
\text { centage of } \\
\text { patients) }\end{array}$ & $\begin{array}{l}\text { TKA (per- } \\
\text { centage of } \\
\text { patients) }\end{array}$ \\
\hline \multicolumn{3}{|l|}{ Jaschinski et al. (2014) } \\
\hline $\begin{array}{l}\text { Surgery on day of } \\
\text { admission }\end{array}$ & $16 \%$ & $17 \%$ \\
\hline $\begin{array}{l}\text { Surgery one day after } \\
\text { admission }\end{array}$ & $84 \%$ & $83 \%$ \\
\hline $\begin{array}{l}\text { Drainage of the surgical } \\
\text { site }\end{array}$ & $93 \%$ & $94 \%$ \\
\hline $\begin{array}{l}\text { Removal of drain on the } \\
\text { second postoperative day }\end{array}$ & $80 \%$ & $83 \%$ \\
\hline \multicolumn{3}{|l|}{ Pain management: } \\
\hline - Opiates & $97 \%$ & $91 \%$ \\
\hline - NSA & $85 \%$ & $85 \%$ \\
\hline - COX-2 inhibitors & $60 \%$ & $58 \%$ \\
\hline - Paracetamol & $20 \%$ & $19 \%$ \\
\hline - Epidural catheter & $10 \%$ & $12 \%$ \\
\hline - Peripheral nerve blocks & $30 \%$ & $91 \%$ \\
\hline - Cooling & $0 \%$ & $37 \%$ \\
\hline \multicolumn{3}{|l|}{ AQUA-Institut 2014} \\
\hline $\begin{array}{l}\text { Medium duration of } \\
\text { surgery }\end{array}$ & $74.5 \mathrm{~min}$ & $85.2 \mathrm{~min}$ \\
\hline $\begin{array}{l}\text { Use of special navigation } \\
\text { systems }\end{array}$ & $1.3 \%$ & $10 \%$ \\
\hline $\begin{array}{l}\text { Perioperative antibiotic } \\
\text { prophylaxis }\end{array}$ & $99.7 \%$ & $99.7 \%$ \\
\hline $\begin{array}{l}\text { Application of minimally } \\
\text { invasive surgical } \\
\text { techniques }\end{array}$ & $13.9 \%$ & $1.8 \%$ \\
\hline $\begin{array}{l}\text { Application of surgery } \\
\text { robots }\end{array}$ & 1 case & 4 cases \\
\hline
\end{tabular}

Source: IGES - AQUA-Institut (2012c, 2013c, 2014C, 2015d, 2010c, 2014c)

years. In Germany, the average length of stay for a patient who has undergone a hip or knee replacement is about 5 days longer than that of a patient admitted to hospital for other reasons. From 2009 to
2013, the length of stay for THA and TKA showed a greater decline than the average length of stay for all other types of hospital treatment in Germany (• Fig. 3.4 and - Fig. 3.5).

\section{- Discharge from hospital}

The AQUA Institute's External Quality Assurance for Inpatient Care assessment examines quality indicators for treatment (nationwide). One of the predetermined quality goals for at the time of hospital discharge is that $80 \%$ of the primary TKA patients are able to bend the knee joint by $>90^{\circ}$ in addition to being able to fully stretch it. In addition, two parameters for patient independence were examined: independent walking and autonomous daily hygiene (AQUA-Institut 2015d).

With regard to the ability to walk, it was observed in 2014 that after TKA $99.5 \%$ of the patients were able to walk independently upon discharge (AQUA-Institut 2015d). Of the $0.4 \%$ of patients who were unable to walk independently upon discharge, $56.6 \%$ had been able to walk independently prior to the surgery.

In addition, the data shows that $99.4 \%$ of patients were able to perform their daily hygiene routine independently upon discharge. Of the $0.5 \%$ of patients who were unable to carry out their daily hygiene routine independently upon discharge, $48.8 \%$ had been able to do so prior to surgery (AQUA-Institut 2015d).

The reported ability to walk independently and to perform a daily hygiene routine upon discharge only fluctuated slightly over the past few years (AQUA-Institut 2012a, 2013a, 2014a, b, 2010b, 2011b).

A current survey of rehabilitation hospitals in North Rhine-Westphalia found that the percentage of patients who were unable to care for themselves independently was significantly higher: Only $20.4 \%$ of the patients who had undergone TKA were able to walk on admission (> $50 \mathrm{~m}$ ), $17 \%$ were able to bend the operated knee by $>90^{\circ}$ and a further $63 \%$ of the patients by between $70^{\circ}$ to $90^{\circ}$ (Quack 2015).

The specific location into which a patient is discharged following his/her inpatient stay for primary THA can be identified based on the "Reason for discharge « documented in the External Quality Assurance for Inpatient Care assessment. Two main 


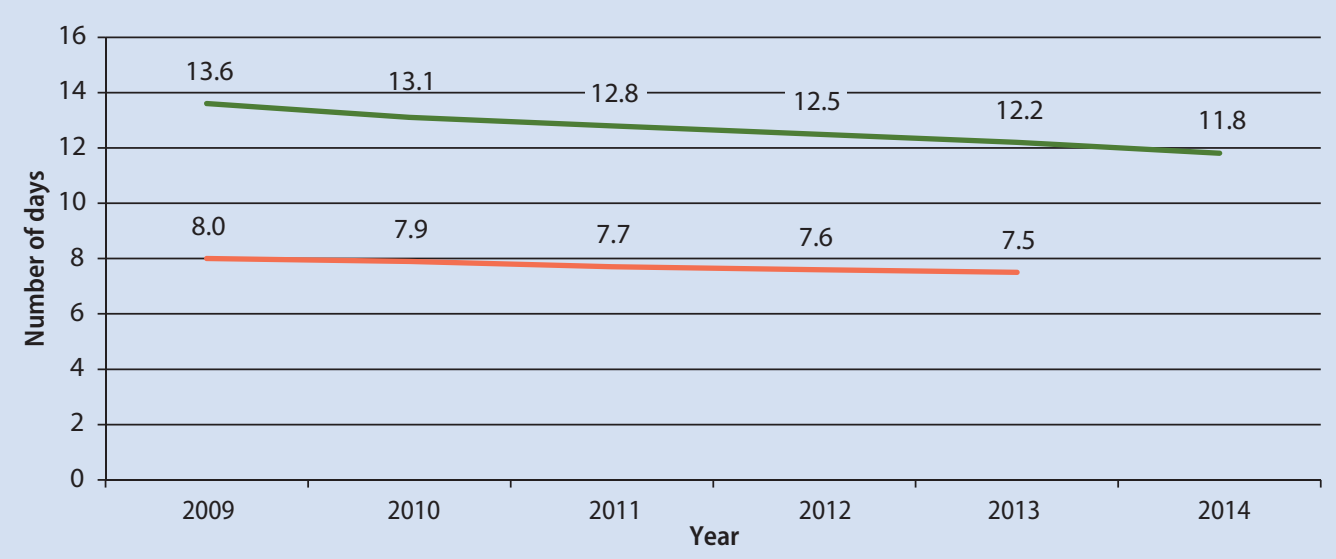

_ Primary replacement _ـ Impatient stays for all indications in Germany

- Fig. 3.4 Length of stay for THA and in general in Germany, in days (2009-2014). (Source: IGES - AQUA-Institut 2012a, 2013a, 2014a, 2014b, 2010b, 2011b and Destatis 2015a)

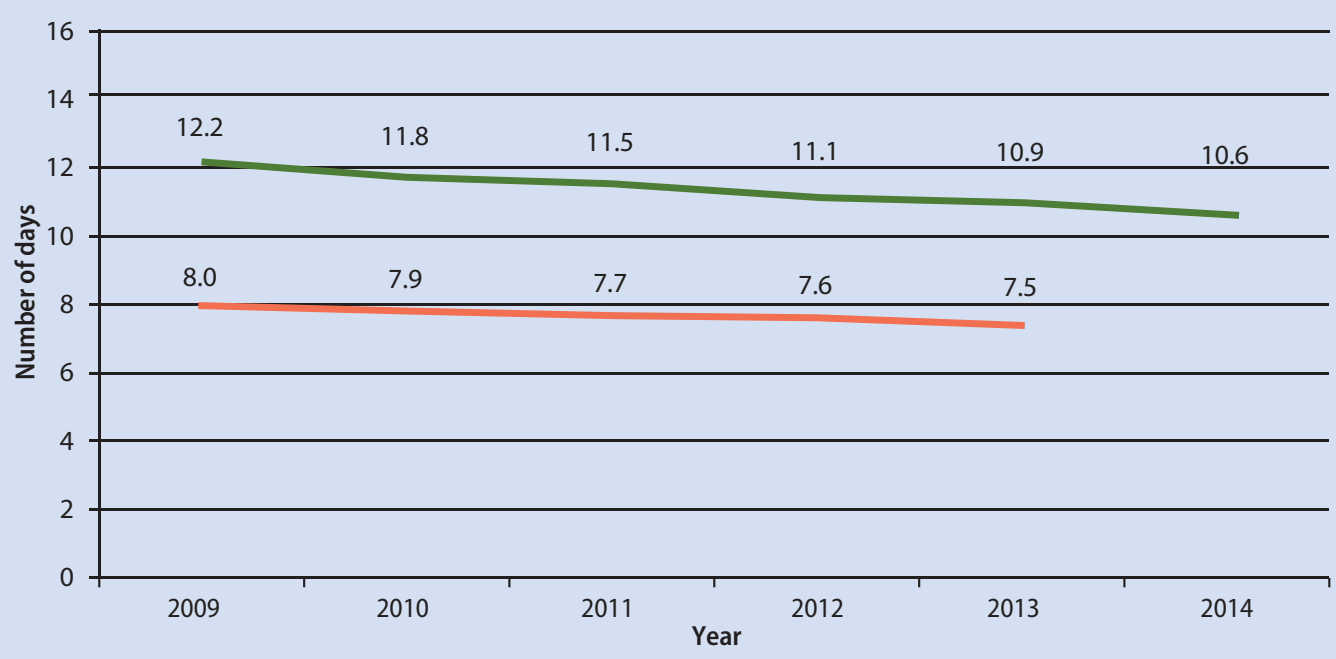

Primary replacement _ـ Impatient stays for all indications

Fig. 3.5 Length of stay for TKA and in general in Germany (2009-2014). (Source: IGES - AQUA-Institut 2012c, 2013c, 2014c, 2015d, 2010c, 2011c and Destatis 2015a)

discharge scenarios exist. In 2014, »Normal termination of treatment « was the reason provided for $47.3 \%$ of patients and $»$ Discharge into in a rehabilitation establishment for follow-up care « for $48.3 \%$ of the patients. This shows that about half the patients are transferred directly into rehabilitation follow-up care and almost the same number of pa- tients is initially discharged into their home environment. This distribution of figures had been similar in the previous years (AQUA-Institut 2012a, 2013a, 2014a, b, 2010b, 2011b).

The AQUA evaluation results are in accordance with the 2010 Barmer GEK Hospital Report survey results. Amongst the patients who received a new 
hip joint in 2008/2009 and who were interviewed in $2009,48.5 \%$ were transferred directly into a rehabilitation establishment upon discharge. $11.5 \%$ were discharged into a home environment and $39.1 \%$ initially went home and subsequently into a rehabilitation hospital (Barmer GEK 2010).

According to AQUA Institute data based on discharge after primary TKA in 2014, treatment of $50.2 \%$ of patients was terminated normally, i.e. they were discharged to return home. $45.8 \%$ of the patients were discharged directly into a rehabilitation facility. Further reasons for discharge were the normal termination of treatment with planned follow-up care $(2.2 \%)$, transfer to another hospital (1.1\%) and discharge to a care establishment (0.2\%) (AQUA-Institut 2015d).

The AQUA evaluation results are also confirmed by the 2010 Barmer GEK Hospital Report study results (Barmer GEK 2010). $48.2 \%$ of the patients who underwent TKA in 2008/2009 were transferred directly into a rehabilitation hospital upon discharge. $41.7 \%$ of the patients initially went home and were admitted into a rehabilitation hospital later. The remaining patients were discharged to return home or into another establishment.

An analysis conducted by the statutory pension insurance DRV Bund elucidates that about half of THA patients and over a third of all TKA patients were transferred straight into a rehabilitation hospital after surgery (• Fig. 3.6 and • Fig. 3.7).

In the 2010 Barmer GEK Hospital Report, patient surveys from 2004 and 2009 also provide data on the frequency of follow-up rehabilitation care. In the initial interview in $2009,88.6 \%$ of all primary hip or knee arthroplasty patients reported having undergone rehabilitation treatment. Amongst patients who had received revision surgery, the percentage was $75.6 \%$. In the initial 2004 survey, the values were markedly closer together $(88.9 \%$ vs. $85.7 \%$ respectively). This report also does not provide information on whether all the surveyed patients were capable of undergoing rehabilitation and required it, so it is not apparent as to why postoperative rehabilitation did not take place.

From these different datasets, it can be concluded that not all patients actually receive follow-up rehabilitation, and not all patients are transferred from acute hospital treatment to a rehabilitation

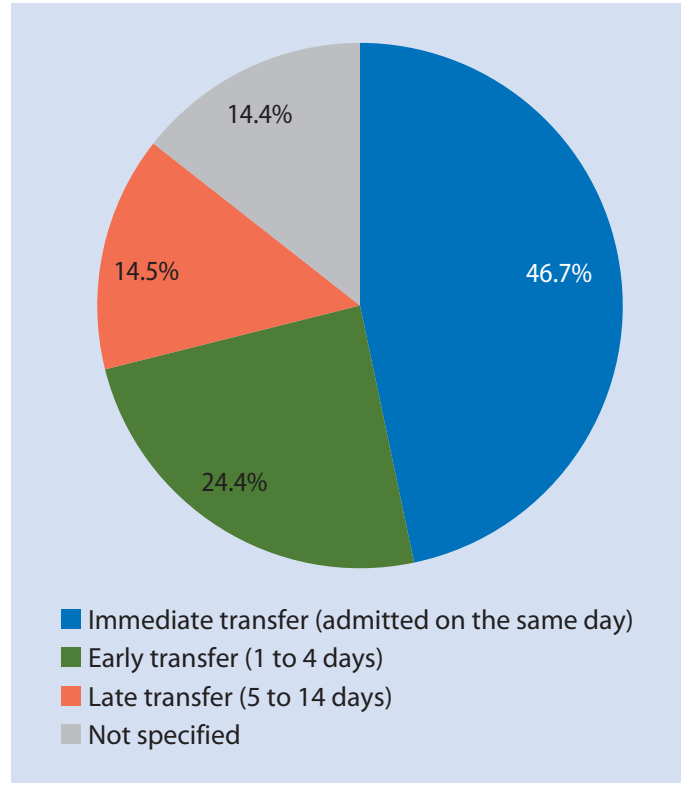

- Fig. 3.6 Time between hospital discharge and admission to a rehabilitation hospital following THA (2007). (Source: IGES - Deutsche Rentenversicherung Bund 2010)

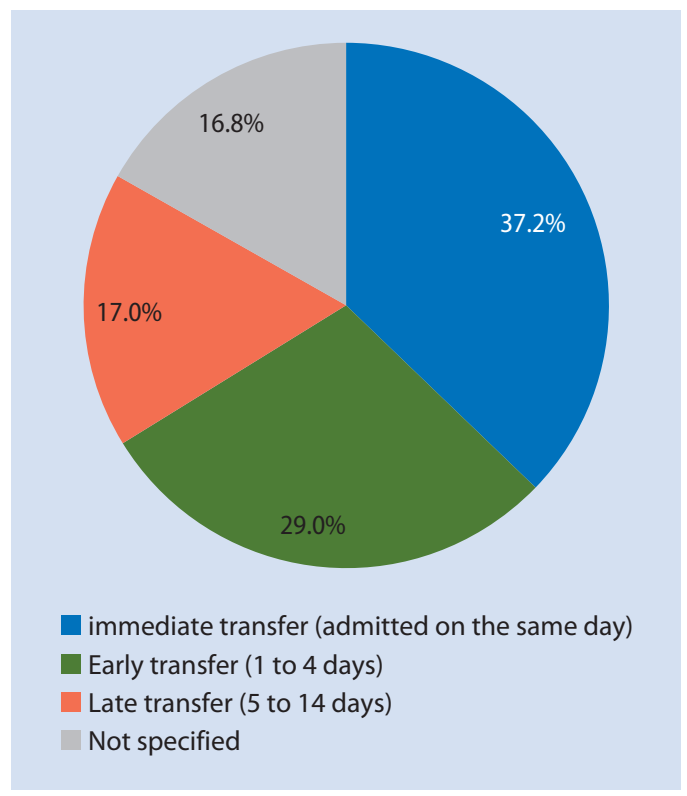

- Fig. 3.7 Time between hospital discharge and admission to a rehabilitation hospital following TKA (2007). (Source: IGES - Deutsche Rentenversicherung Bund 2010) 
Tab. 3.8 Percentage of hospitals that performed primary replacement surgery and percentage of hospitals that performed revision surgery

\begin{tabular}{|c|c|c|c|c|c|}
\hline Description & 2009 & 2010 & 2011 & 2012 & 2013 \\
\hline Number of hospitals in Germany & 2,084 & 2,064 & 2,045 & 2,017 & 1,996 \\
\hline \multicolumn{6}{|l|}{ Hip } \\
\hline $\begin{array}{l}\text { Percentage [\%] of hospitals that performed primary } \\
\text { replacements out of the total number of hospitals }\end{array}$ & 55.5 & 55.7 & 54.4 & 54.1 & 53.9 \\
\hline $\begin{array}{l}\text { Percentage [\%] of hospitals that performed revision } \\
\text { surgery out of the total number of hospitals }\end{array}$ & 51.8 & 52.4 & 51.1 & 52.0 & 51.4 \\
\hline \multicolumn{6}{|l|}{ Knee } \\
\hline $\begin{array}{l}\text { Percentage [\%] of hospitals that performed primary } \\
\text { replacements of the total number of hospitals }\end{array}$ & 49.0 & 50.2 & 50.4 & 51.2 & 51.7 \\
\hline $\begin{array}{l}\text { Percentage [\%] of hospitals that performed follow- } \\
\text { up surgery of the total number of hospitals }\end{array}$ & 44.6 & 45.6 & 46.0 & 48.0 & 48.7 \\
\hline
\end{tabular}

Source: IGES - Destatis 2015a, AQUA-Institut 2011a, 2012a, 2012b, 2013a, 2013b, 2014a, 2014b, 2010b, 2011b, AQUAInstitut 2013d, 2014d, 2010d, 2011d, 2012d

hospital »As soon as possible after achieving early mobilization « (Deutsche Rentenversicherung Bund 2009).

After the introduction of DRGs in 2003, the length of stay in acute-care hospitals reduced significantly. The »REhabilitation und DIAgnosis Related Groups « study (REDIA-Studie), a prospective, multi-center, randomized, long-term study, investigated the effects of introducing DRGs into acute care on the medical service requirements and rehabilitation costs. During the observational period from 2003 to 2009 , the average length of stay for THA patients, for instance, decreased by 3.6 days from 17.7 days to 13.3 days. Furthermore, during the period of study, it was observed that the patients « condition at the start of the rehabilitation phase deteriorated with regard to postoperative general condition and pain levels (van Eiff 2011).

\subsubsection{Revision Total Arthroplasty}

\section{- Capacity for provision of care}

The number of hospitals in Germany that perform hip joint revision surgery based on standards set by the External Quality Assurance for Inpatient Care procedures is lower than the number of hospitals that perform primary THA (• Tab. 3.8). The absolute number of these hospitals is also decreasing, in line with trends seen in the number of hospitals in general. The percentage of hospitals that perform revision surgery after TKA shows a slight upwards trend.

The reasons why not all hospitals that perform primary replacement surgery do perform revision total arthroplasty are largely unclear. Nonetheless, endoprosthetic implant and implant component replacements are significantly more demanding technically and more complicated than primary replacements (AQUA-Institut 2014d, 2012f). Perhaps not all hospitals are capable of performing this surgery.

\section{- Reasons for revision total arthroplasty}

Both primary replacements and/or the replacement of endoprosthetic hip implants and implant components are recorded for the External Quality Assurance for Inpatient Care procedures in Germany. Replacing an endoprosthesis may become necessary if the individual prosthesis components loosen due to wear and tear, amongst other things. In the External Quality Assurance for Inpatient Care procedures, the reasons for these replacements are documented in the form of preoperative radiological findings. The prevalence of each particular reason is 


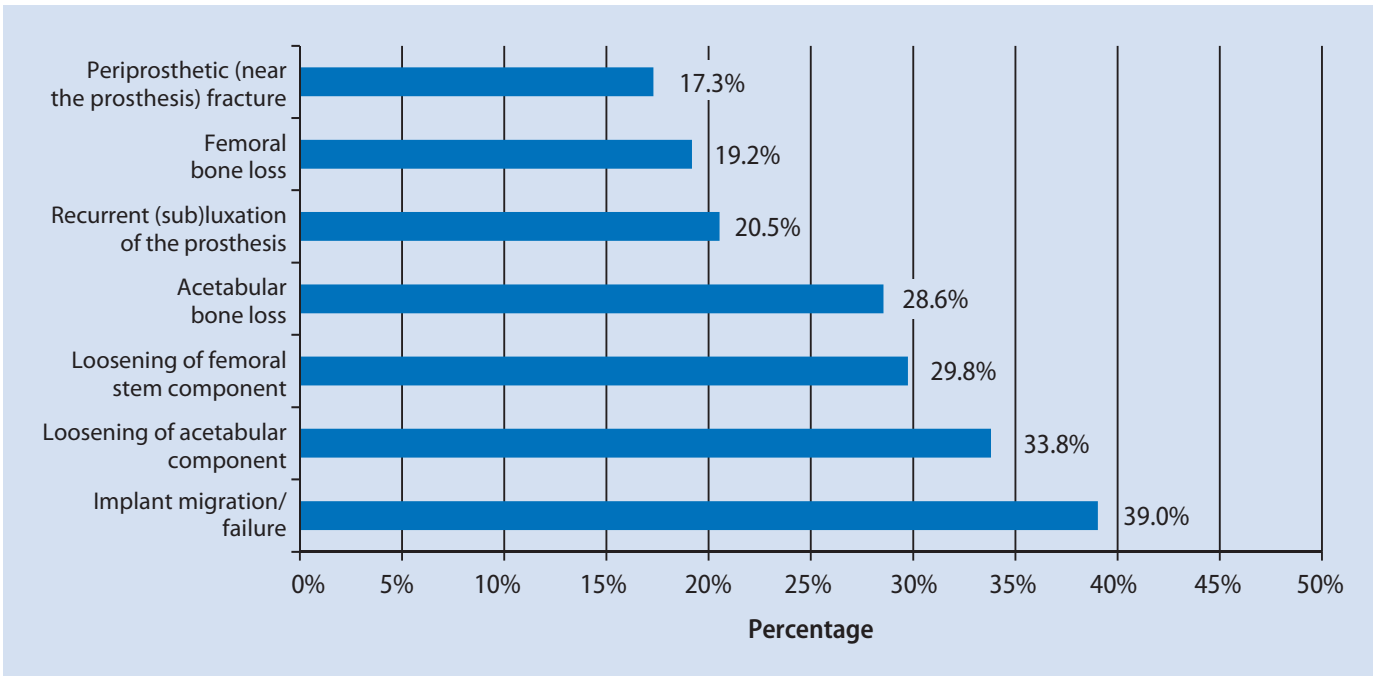

- Fig. 3.8 Preoperative, radiological findings for revision THA (2014). *Multiple answers possible. (Source: IGES - AQUAInstitut 2014b)

illustrated in Figure 3.8. Based on this, significant reasons include (recurring) (sub)luxation of the endoprosthesis, implant migration, implant failure, implant or joint wear, pain, bacterial infections and inflammation of the joint (AQUA-Institut 2014b).

From a data interpretation perspective, it must be noted that multiple responses are possible. Loss of the femoral bone, for example, may be accompanied by a loosened femoral stem component and implant migration while a periprosthetic fracture or luxation is frequently cited as the sole indication for revision hip replacement.

A systematic review conducted by Prokopetz et al. (2012) investigated the risk factors for revision total arthroplasty after primary THA. The risk factors identified, which were consistent and statistically significant across the studies evaluated, included younger patient ages at the time of primary replacement, increased comorbidity, the presence of bone necrosis (rather than osteoarthritis) and the surgeon's experience (number of joint operations carried out) and larger femoral heads. The review does not state the size of the femoral head from which point the level of risk increases. In two of the three studies examined, the maximum femoral head size of the implanted femoral component was 28 $\mathrm{mm}$ (Prokopetz et al. 2012). The review conducted by Prokopetz et al. (2012) shows that alongside wear and tear, other factors such as the surgeons' experience constitute a significant risk of revision surgery. Likewise, the revision surgery itself and the service life constitute important quality indicators for primary replacement, as well as for the overall longterm success of the treatment.

Men are at a higher risk of requiring revision total arthroplasty due to aseptic implant loosening or infection. Longer operation times constitute another risk factor for revision surgery due to infection. The results also show that smaller femoral heads $(\leq 28 \mathrm{~mm}$ ) of the femoral component constitute a risk factor for revision surgery due to dislocations (Prokopetz et al. 2012).

In the External Quality Assurance for Inpatient Care in Germany, conducted by the AQUA Institute, the replacement of knee endoprostheses and/ or prosthesis components are also evaluated. All surgeries performed on patients from the age of 20 are recorded. At least one of the indication criteria in the following overview must be present for the operation to be included in the quality assurance evaluation (AQUA-Institut 2015a). 


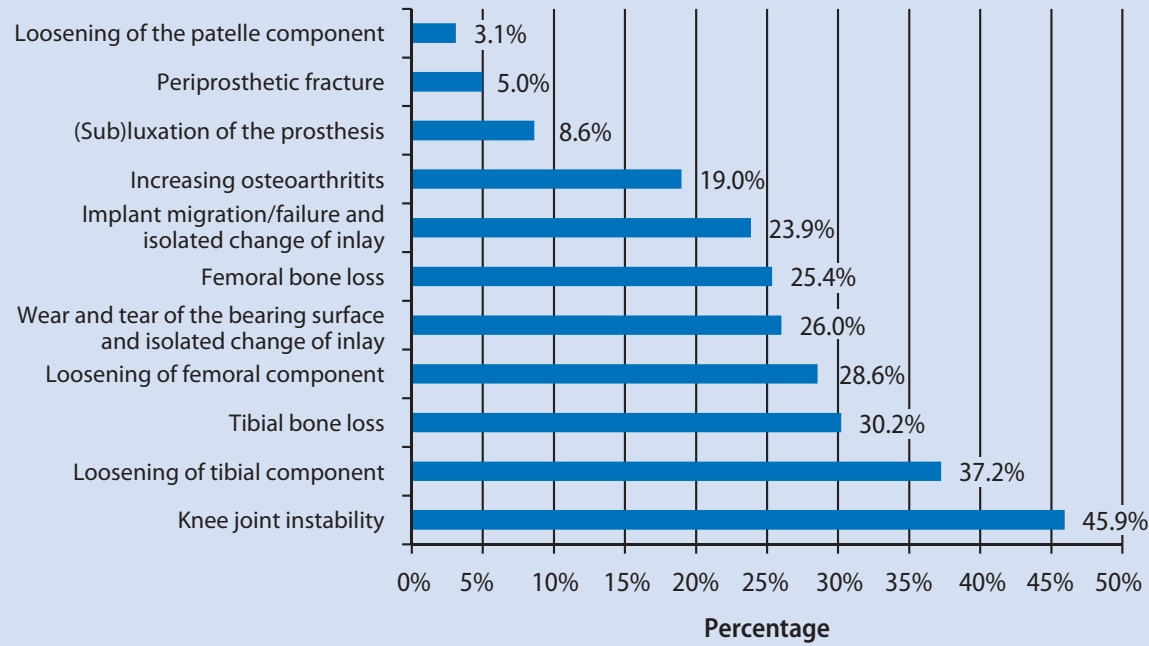

- Fig. 3.9 Radiological findings for revision TKA in the External Quality Assurance for Inpatient Care evaluation (2014). (Source: IGES - AQUA-Institut 2015a)

\section{Indication criteria for including cases in} the quality assurance evaluation conducted by the AQUA Institute

- (Sub)luxation of the prosthesis

- Implant migration, implant failure and isolated change of inlay (OPS: 5-823.19, 5-823.27, 5-823.b0, 5-823.f0)

- Wear and tear of the bearing surface and isolated change of inlay (OPS: 5-823.19, 5-823.27, 5-823.b0, 5-823.f0)

- At least one pain criterion and at least one radiological criterion

- At least one pain criterion and at least one positive pathogen detection

- Laboratory signs of inflammation and one positive pathogen detection

(Source: IGES - AQUA-Institut 2015a)

The common reasons for revision TKA in 2014, determined by the AQUA Institute's external quality assurance using objective radiological criteria, are shown in Figure 3.9.

The 2010 Barmer GEK Hospital Report evaluated revision hip and knee joint surgery data recorded until the end of 2009, based on patients who had undergone THA and TKA between 2006 and 2008. Within 90 days after discharge from hospital, $1.0 \%$ of THA patients and $0.6 \%$ of TKA patients consequently had to undergo surgery on the same side, i.e. revision surgery including revisions without replacements. Within one year following primary replacements, $2.0 \%$ of THA patients and $3.7 \%$ of patients with osteoarthritis who were being followed up underwent another operation on the same joint. In a small group of patients with atypical diagnoses, the revision rate was 6\% (Barmer GEK 2010). A survey based on routine data from the SHI Techniker Krankenkasse found that 3.5\% of patients after primary THA and $3.8 \%$ of patients after primary TKA underwent revision total arthroplasty within the first two years (Linder et al. 2012).

The correlation between the time of revision surgery and the quality of the resulting outcome was investigated in a further study (Hardeman et al. 2012). Early revision total arthroplasty taking place less than two years after primary replacement had higher failure rates than revision total arthroplasty carried out later. Better results were observed in older patients ( $>65$ years) and in partial revision surgery. Patients with low KSS scores (Knee Society Score) before revision total arthroplasty also had 


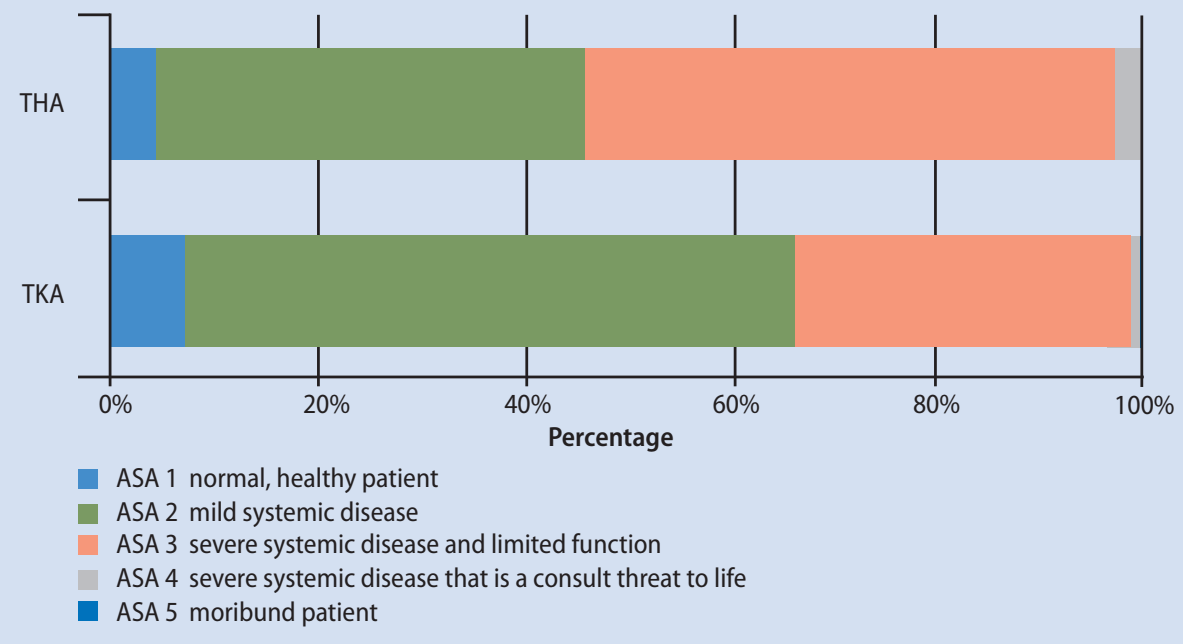

Fig. 3.10 ASA classification of revision THA and TKA recorded for the External Quality Assurance for Inpatient Care evaluation (2014). ASA = American Society of Anesthesiology. (Source: IGES - AQUA 2015c, e)

lower scores after the revision. However, the improvement in score in this group was significantly higher than for patients who had had higher values at the start of the study (Hardeman et al. 2012).

\section{- Perioperative risk}

The 2014 quality assurance of inpatient care analyses recorded ASA classifications, which are aimed at giving a point of reference in the assessment of perioperative risk. Here, the analyses indicated that the majority of patients who underwent revision THA were allocated to ASA class 3 (patients with severe systemic disease and functional limitations) (50.5\%). Patients who underwent revision TKA were proportionately more frequently grouped into class 2 (mild systemic disease) (52.7 \%) (• Fig. 3.10). Compared to primary replacement (hip and knee), patients undergoing hip or knee revision surgery often have a higher ASA score (AQUA-Institut 2015c). Differences in ASA scores between primary and revision surgery patients are particularly due to the higher average age of hip replacement patients and hence also associated with a higher age-related comorbidity.

\section{- Surgical procedures}

Compared to primary replacements, revision total arthroplasty is described as technically more demanding and more complicated (Claes et al. 2012;
Wirtz 2011). The surgeon performing the procedure has to take into account primary replacement surgery, the procedure and materials used. The current status of the patient, in particular with regard to the periarticular status (bone structure, soft tissue) must also be taken into account. If an infection is suspected, additional laboratory tests must be conducted. In contrast to primary replacements, the entire joint may not need replacing but potentially only the defective parts. Both cemented and uncemented fixation of the new endoprosthesis are possible (AQUA-Institut 2012f).

According to information from the External Quality Assurance for Inpatient Care assessments, the average duration of both revision THA and TKA has been about 2 hours for several years, which is considerably longer than the time taken for primary replacements (75 or 85 minutes) (AQUA-Institut 2010a, 2011a, 2012b, 2013b, 2014b, 2015d).

\section{- Length of stay}

Patients undergoing revision total arthroplasty usually have a considerably longer length of hospital stay than for primary replacements.

Just as is the case for primary TKA, the length of stay in hospital after revision TKA is longer (by approximately 8 days) than the general average length of stay in German hospitals. After revision surgery, 


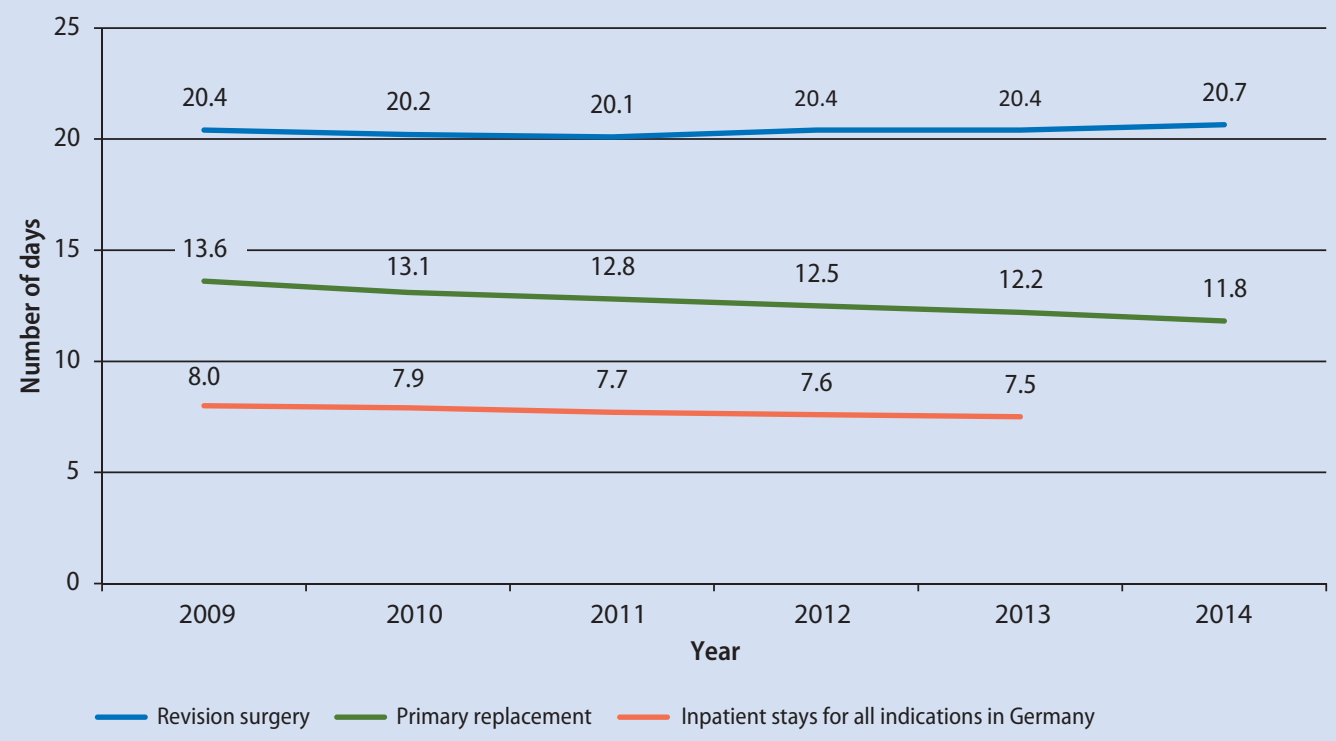

Fig. 3.11 Length of stay of patients undergoing revision surgery, primary THA, and the average length of stay in Germany, in days. Note: At the time of writing, the average length of stay in Germany for 2014 was not yet available. (Source: IGES AQUA-Institut 2010a, 2011a, 2012b, 2013b, 2014b and Destatis 2015a)

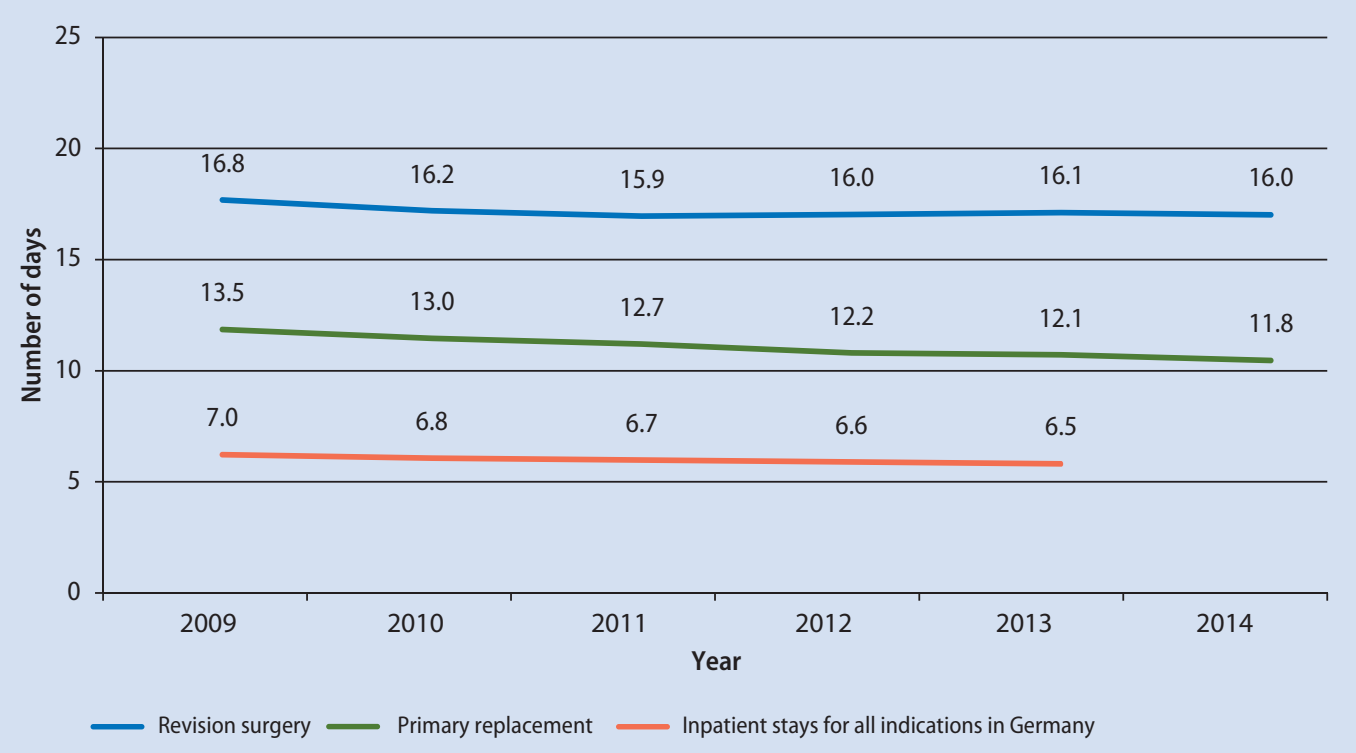

- Fig. 3.12 Mean length of stay in days for revision surgery after TKA, 2009 to 2014. Note: At the time of writing, the average length of stay in Germany for 2014 was not yet available. (Source: IGES - AQUA-Institut 2013d, 2014d, 2015e, 2010d, 2011d, 2012d and Destatis 2015c) 
patients remained in hospital for 3 to 4 days longer than after primary replacement surgery (• Fig. 3.11 and - Fig. 3.12).

\section{- Discharge from hospital}

In Germany, patient independence upon discharge after revision total arthroplasty differed from patient independence after primary total arthroplasty.

With regard to THA, more patients were unable to walk independently or perform daily hygiene independently upon discharge after revision THA than after the primary replacement (6.3\% vs. $0.4 \%$ and $7.1 \%$ vs. $0.5 \%$ respectively) (- Fig. 3.13 and Section 3.3.1).

As with primary arthroplasty, the results showed only minor variations over the previous years (AQUA-Institut 2010a, 2011a, 2012b, 2013b, 2014b, 2015c).

$97.6 \%$ of patients who had undergone revision TKA were able to walk independently upon discharge (99.5\% after primary arthroplasty) (AQUA-Institut 2015e). $97.6 \%$ of the patients were able to perform their daily hygiene themselves upon discharge (primary arthroplasty: 99.4\%) (• Fig. 3.14).

\section{Independent walking upon discharge}

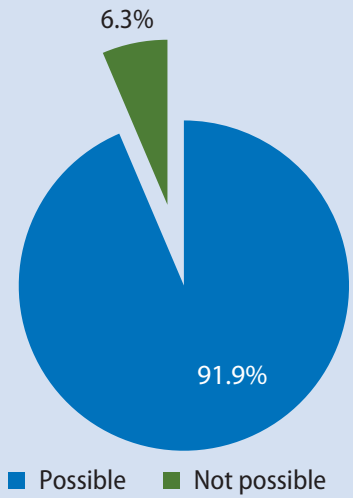

\section{Autonomous daily hygiene upon discharge}

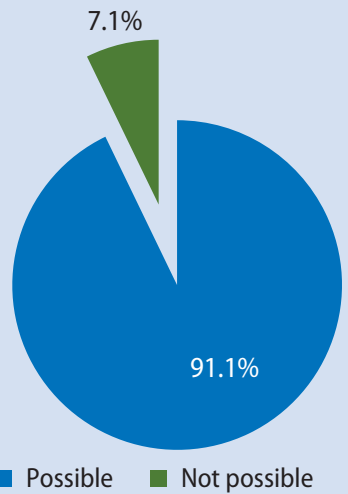

- Fig. 3.13 Ability to walk independently and carry out autonomous daily hygiene after revision THA at the time of discharge in 2014. (Source: IGES - AQUA-Institut 2015c)

Independent walking upon discharge

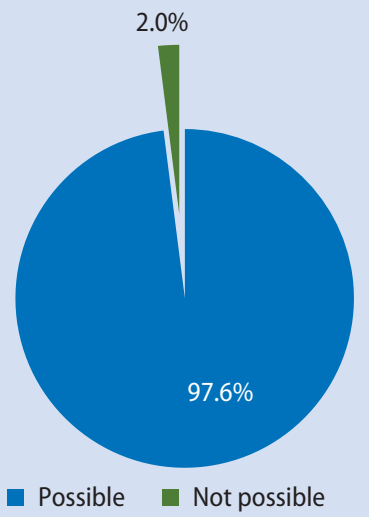

Autonomous daily hygiene upon discharge

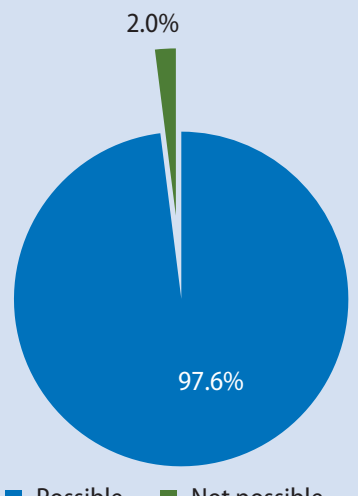

Possible Not possible

- Fig. 3.14 Ability to walk independently and to carry out autonomous daily hygiene after revision TKA at the time of discharge in 2014. (Source: IGES - AQUA-Institut 2015e) 
Tab. 3.9 Reasons for discharge following primary and revision total arthroplasty (2014)

\begin{tabular}{|c|c|c|c|c|}
\hline $\begin{array}{l}\text { Reasons for discharge in } 2014 \text { (acc.to } § 301 \\
\text { Volume V German Social Security Code) }\end{array}$ & Primary THA & Revision THA & Primary TKA & Revision TKA \\
\hline Discharge into a rehabilitation establishment (\%) & 48.3 & 32.1 & 45.8 & 32.9 \\
\hline Treatment ended normally (\%) & 47.3 & 52.6 & 50.2 & 59.0 \\
\hline Transfer to another hospital (\%) & 1.4 & 5.6 & 1.1 & 2.6 \\
\hline Discharge into nursing care (\%) & 0.3 & 3.7 & 0.2 & 0.9 \\
\hline Death (\%) & 0.2 & 1.8 & 0.1 & 0.4 \\
\hline
\end{tabular}

The External Quality Assurance for Inpatient Care assessment shows that as with primary replacement, only a small number of patients are transferred straight into a rehabilitation facility after revision surgery (•Tab. 3.9).

\subsubsection{Accompanying Measures during Inpatient Stay}

\section{- Pain management}

Regardless of the surgical access route, endoprosthetic surgery for osteoarthritis of the hip (THA) and osteoarthritis of the knee (TKA) is associated with a high intensity of pain (Laubenthal and Neugebauer 2009). Effective pain management contributes to improved convalescence, rapid mobilization and a reduced rate of complications such as deep vein thrombosis (DVT) (Simanski 2008). Pain management comprises pre-, intra- and postoperative phases and also plays an important role for the patients « in long-term ambulatory care (Laubenthal and Neugebauer 2009).

Particularly after TKA, individually tailored and continuous pain management is considered crucial in the success of treatment. Various studies show that continuous postoperative pain management is better relative to single injections or to the administration of medication as required. Moreover, it has been demonstrated that continuous analgesia by means of peripheral catheter procedures reduces the use of postoperative morphine and contributes to quicker rehabilitation compared to single injec- tions. In addition, evidence shows that peripheral catheter procedures can lead to early mobilization and better functionality compared to the general administration of systemic opioids (Cappelleri et al. 2011).

The S3 guideline »Treatment of acute perioperative and posttraumatic pain ${ }^{1}$ recommends the use of non-opioid analgesics after both THA and TKA for pain management after discharge from hospital (Laubenthal and Neugebauer 2009). Randomized studies have demonstrated the effectiveness of conventional, non-steroidal antiphlogistics and non-opioid analgesics, such as paracetamol for postoperative pain control (Lohom et al. 2002; Peduto et al. 1998; Silvanto et al. 2002). For high intensity pain these can be combined with strong opioids in multimodal analgesic therapy (Simanski 2008).

\section{- Thromboprophylaxis}

Besides appropriate pain management and mobilization, thromboprophylaxis plays an important role in THA and TKA procedures. Hip and knee joint replacements are amongst the primary causes of venous thromboembolism (VTE) (European Society of Cardiology 2014). VTE includes deep vein thrombosis (DVT) and pulmonary embolism (PE), which are the most serious complications of DVT. The PE mortality rate within the first few weeks following THA is between $0.09 \%$ and $0.19 \%$ (Fender

1 The implementation of the S3 guideline on the »Treatment of acute perioperative and posttraumatic pain« is currently under review. 
et al. 1997; Howie et al. 2005; Khan et al. 2007; Shepherd and Mills 2006).

Thrombosis is a vascular disease that occurs when a blood vessel is narrowed or occluded by a blood clot. Causes include damage to the vascular walls through surgery (Perka 2011). In order to avoid such complications, blood coagulability is reduced through medication (anticoagulation) (AWMF 2015). Anticoagulants are used to inhibit the growth of the thrombus and constitute a prerequisite for physiological fibrinolysis which dissolves the thrombus. The period of risk period associated with VTE begins with surgery. Several days or weeks can elapse before a thrombus develops and as a result most cases of symptomatic vein thrombosis occur after the inpatient stay. As a result, thromboembolism prophylaxis is also necessary after discharge (AWMF 2015).

Although in principle VTE is associated with all types of surgery, orthopedic patients are at a higher risk owing to the activation of coagulation due to tissue and bone injuries, vein damage, immobilization and heat generation from the use of bone cement (Perka 2011). Further distinctive factors include advanced age (above 60 years), weight (BMI $>30$ ), tumor diseases and previous venous thromboembolism in the patient or the patient's family history (AWMF 2015, Cionac Florescu et al. 2013; Falck-Ytter et al. 2012).

Without thromboprophylaxis, approximately $40 \%-60 \%$ of all patients who undergo elective THA and TKA develop VTE (Perka 2011). With thromboprophylaxis, this is reduced to $1.09 \%$ in patients who undergo knee replacement surgery and $0.53 \%$ of patients who undergo hip replacement surgery (Januel et al. 2012).

\section{- Pharmacological VTE prophylaxis}

The rate of VTE complications can be reduced significantly through medication (AWMF 2015) (European Society of Cardiology 2014; Falck-Ytter et al. 2012). Pharmacological prophylaxis can also be accompanied by physical and mobilization measures to further reduce the risk of VTE. The same approach should be taken for VTE prophylaxis for both inpatient and ambulatory care. Certain guidelines recommend pharmacological prophylaxis for hip joint surgery over a period of 28 to 35 days and for at least 10 to 14 days after knee joint surgery (AWMF 2015; Falck-Ytter et al. 2012). For TKA, the current American College of Chest Physicians (ACCP) guidelines recommend extending pharmacological prophylaxis for a period of up to 35 days after the inpatient stay (Falck-Ytter et al. 2012). If the VTE risk is increased, especially due to additional concomitant diseases, VTE prophylaxis should be continued for as long as the disease persists (AWMF 2015).

A recent prospective study by Jorgensen et al. indicates that thromboprophylaxis for the duration of inpatient stay is sufficient for patients who are treated according to a "fast track « THA and TKA treatment concept, and that there are no additional benefits exist in continuing the treatment during ambulatory care (Jorgensen et al. 2013). In this study, approximately 4,700 patients with a length of stay of $\leq 5$ days received VTE prophylaxis. During the 90 day follow-up period, thromboembolic events occurred in $0.84 \%$ of the patients and VTE was found in $0.41 \%$. These complication rates correspond to those observed in other studies in which VTE prophylaxis was conducted over a longer period. However, due the study design, it cannot be ultimately concluded that conducting VTE prophylaxis solely during the period of inpatient stay is sufficient. The study by Jorgensen et al. did not compare its findings with an internal control group but with data from different studies in which the patient populations might have differed with regard to relevant risk factors (e.g. comorbidity, immobilization, length of stay).

Currently recommended, effective VTE pharmacoprophylaxis after joint replacement includes factor Xa inhibitors, (low-molecular-weight) heparins (LMWH), thrombin inhibitors, vitamin $\mathrm{K}$ antagonists (VKA) and other anticoagulants (AWMF 2015; European Society of Cardiology 2014).

Acetylsalicylic acid should not be used as a monotherapy due its low prophylactic effect against VTE compared to the other medications mentioned above (AWMF 2015; Falck-Ytter et al. 2012). The Association of the Scientific Medical Societies in Germany (AWMF) does not recommend the use of VKA such as warfarin and phenprocoumon, after taking into consideration the effectiveness and the risk of bleeding compared to the heparins (Encke et 
al. 2015). The AWMF refers to a study conducted by Samana et al., amongst others, which demonstrated that there was no difference between VTE prophylaxis with warfarin or LMWH in patients with hip surgery with regard to DVT rates, but that the patients treated with warfarin showed a much higher prevalence of bleeding complications (5.5\% versus $1.4 \%$ ) (Samana et al. 2002). In contrast, the ACCP and European Society of Cardiology (ESC) guidelines advocate the use of VKA for VTE prophylaxis (European Society of Cardiology 2014; Falck-Ytter et al. 2012).

Contraindications for thromboprophylaxis are: the known risk of bleeding, hemorrhagic and ischemic strokes within the previous six months and gastrointestinal bleeding within the previous month (European Society of Cardiology 2014). If contraindications exist, intermittent pneumatic compression (e.g. foot, calf and thigh) should instead be used for patients who have had THA and physical measures (e.g. medical compression stockings) for patients after TKA (AWMF 2015).

\section{- - Bleeding risk in patients on anticoagulant therapy}

The primary risk of anticoagulant therapy for VTE prophylaxis is bleeding, which accounts for $2 \%$ to $3 \%$ over a period of 3 months (Scherz et al. 2013). Specific patient characteristics that are associated with an increased bleeding risk during anticoagulant therapy are renal failure, a history of bleeding and a simultaneous intake of platelet aggregation inhibitors (Decousus et al. 2011; Falck-Ytter et al. 2012). The level of risk doubles in older patients ( $\geq 65$ years) compared to younger patients (Spencer et al. 2008).

Different scoring methods have been developed to assess an individual patient's risk of bleeding (Beyth et al. 1998; Kearon 2003; Kuijer et al. 1999; Ruíz-Giménez et al. 2008). These scores stratify the patients according to their bleeding risk. However, these risk scores have not been sufficiently tested in patients in orthopedic surgery (Falck-Ytter et al. 2012), and do not differentiate between low and high bleeding risks precisely enough, particularly in older patients ( $\geq 65$ years) (Scherz et al. 2013). Hence, there is a need to develop and validate tools to stratify risks in patient populations after THA and TKA.

\section{- Physiotherapeutic measures and mobility}

In general, physiotherapeutic and physical therapies such as balneotherapy, massage, gait training and cooling should be carried out after joint surgery. According to the S3 guideline »Prophylaxis of venous thromboembolism (VTE) « further physical measures for the preventing VTE include medical compression stockings, e.g. thigh-length and kneelength stockings that increase venous blood velocity and consequently prevent thrombus formation. Such measures are particularly prudent when a contraindication for pharmacological VTE prophylaxis exists, e.g. due to an increased bleeding risk (AWMF 2015).

Physiotherapy aims to assist mobilization and in the prevention of functional impairments, as well as in pain relief, and therefore an integral part of comprehensive pain management regimes (Laubenthal and Neugebauer 2009). A recent review showed that particularly early mobilization (defined as "getting out of bed " and "walking" as soon as possible after hip or knee replacement surgery) can result in shortening the length of stay by approximately 2 days (Guerra et al. 2015; Tayrose et al. 2013). Moreover, improvements were noted with regard to free movement, muscle power and health-related quality of life. Undesired events caused by early mobilization, such as hemodynamic instability or the increased risk of falling, did not occur significantly more frequently when compared to control groups without early mobilization (Guerra et al. 2015). Other studies were able to demonstrate lower risks of DTV, PE, chest infections and urinary retention during early mobilization (Renkawitz et al. 2010).

\subsubsection{Complications}

Intra- and postoperative surgical complications during inpatient stays are recorded for the External Quality Assurance for Inpatient Care assessments in Germany. The case rates for primary total arthroplasty in 2014 are summarized in • Tab. 3.10.

The documented rate of operations that involved at least one complication during the inpatient stay lies in the single-digit percentage range. Over the last few years, this rate has been declining, as has the rate of all cases, except for fractures. How- 
Tab. 3.10 Intra-/postoperative surgical complications requiring treatment after primary and revision total arthroplasty during hospital stays in Germany in 2014

\begin{tabular}{|c|c|c|c|c|}
\hline $\begin{array}{l}\text { Intra-/postoperative surgical complications } \\
\text { requiring treatment }\end{array}$ & Primary THA & Revision hip & Primary TKA & Revision knee \\
\hline $\begin{array}{l}\text { Number of operations with at least one com- } \\
\text { plication (\%) }\end{array}$ & 2.76 & 9.00 & 1.91 & 4.29 \\
\hline Malposition of the implant (\%) & 0.05 & 0.19 & 0.03 & 0.12 \\
\hline Dislocation of the implant (\%) & 0.10 & 0.40 & 0.03 & 0.06 \\
\hline Luxation of the endoprosthesis (\%) & 0.27 & 1.94 & - & 0.09 \\
\hline Misalignment of the patella (\%) & & & 0.02 & 0.1 \\
\hline Wound hematoma/postoperative bleeding (\%) & 0.86 & 2.95 & 0.86 & 2.17 \\
\hline Vascular lesion (\%) & 0.03 & 0.16 & 0.02 & 0.07 \\
\hline Nerve damage (\%) & 0.25 & 0.56 & 0.1 & 0.09 \\
\hline Fracture (\%) & 0.82 & 1.73 & 0.15 & 0.39 \\
\hline Other (\%) & 0.54 & 2.09 & 0.8 & 1.69 \\
\hline
\end{tabular}

ever, a change in the counting method since 2013 (number of operations rather than of patients) only permits a limited comparison with the case rates in previous years.

The percentage of patients with at least one general postoperative complication that required treatment following joint replacement (primary and revision surgery) is in the single digit range, as with the rates for the other cases (- Tab. 3.11).

Compared to 2009, a decline in the rate of postoperative wound infections can be observed, although the overall case rates (other wound infections) stagnated or rose during the same period (•Tab. 3.12).

In addition, for primary arthroplasty, it is important to note the rate of registered, revision surgery required resulting from complications related to hip endoprostheses during the inpatient stay. This also showed a decrease from 2009 (1.7\%) to 2014 (1.4\%). The rate of revision surgery required due to complications with the knee endoprostheses ranged between $1.4 \%$ of patients in 2009 and $0.87 \%$ of patients in 2012. In 2013 and 2014, revision surgery due to complications was at $1.3 \%$ and/or $1.15 \%$ for hip and knee surgery respectively.
- Tab. 3.13 and 0 Tab. 3.14 show that the rate of complications in revision total arthroplasty is several times higher than the rate of complications in primary replacements. The same applies to the rate of registered, revision surgery required due to complications. For revision total arthroplasty, these varied between $5.6 \%$ and $7.5 \%$ between 2009 and 2014. In contrast to primary replacements, a noticeable declining trend in case rates is not apparent. It should be noted that the rate of complications mentioned so far refer to the period during which the patient is treated in an acute-care hospital.

Up to a third of the complications following hip joint replacements occur after an inpatient stay, as shown by an analysis conducted by the AOK Research Institute (Wissenschaftliches Institut der AOK, WIdO) (Jeschke and Günster 2014). The analysis used AOK routine data while conducting "Quality Assurance with Routine Data« procedures (Section 3.3.4)

The evaluation included 154,470 patients from 930 hospitals who had undergone primary hip joint replacements (THA and partial replacements) between 2007 and 2009 whose treatment diagnosis 
- Tab. 3.11 General postoperative complications requiring treatment following primary and revision total arthroplasty during hospital stays in Germany in 2014

\begin{tabular}{|c|c|c|c|c|}
\hline $\begin{array}{l}\text { General postoperative complications } \\
\text { requiring treatment }\end{array}$ & $\begin{array}{l}\text { Primary hip } \\
\text { replacement }\end{array}$ & Revision hip & $\begin{array}{l}\text { Primary knee } \\
\text { replacement }\end{array}$ & $\begin{array}{l}\text { Revision } \\
\text { knee }\end{array}$ \\
\hline $\begin{array}{l}\text { Number of patients with at least one } \\
\text { complication (\%) }\end{array}$ & 2.92 & 7.98 & 3.02 & 4.91 \\
\hline Pneumonia (\%) & 0.16 & 0.86 & 0.17 & 0.38 \\
\hline Cardiovascular complications (\%) & 0.67 & 2.44 & 0.62 & 1.22 \\
\hline Deep vein thrombosis in leg/pelvis (\%) & 0.09 & 0.16 & 0.40 & 0.26 \\
\hline Pulmonary embolism (\%) & 0.08 & 0.28 & 0.17 & 0.24 \\
\hline Other (\%) & 2.11 & 5.40 & 1.89 & 3.31 \\
\hline
\end{tabular}

Source: IGES - AQUA-Institut 2015b, 2015c, 2015d, 2015e

- Tab. 3.12 Postoperative wound infection after primary and revision total arthroplasty during inpatient stays in Germany in 2014

\begin{tabular}{|l|l|l|l|}
\hline Postoperative wound infection & $\begin{array}{l}\text { Primary hip } \\
\text { replacement }\end{array}$ & Revision hip & $\begin{array}{l}\text { Primary knee } \\
\text { replacement }\end{array}$ \\
\hline Surgery with wound infections (\%) & 0.42 & 4.18 & 0.26 \\
knee
\end{tabular}

Source: IGES - AQUA-Institut 2015b, 2015c, 2015d, 2015e

- Tab. 3.13 Rate of complications after acute-inpatient treatment following hip joint replacement

\begin{tabular}{|l|l|l|l|l|}
\hline Quality indicator & $\begin{array}{l}\text { Total number } \\
\text { of cases }(\mathrm{n})\end{array}$ & $\begin{array}{l}\text { Follow-up obser- } \\
\text { vation period (\%) }\end{array}$ & $\begin{array}{l}\text { Inpatient phase pri- } \\
\text { mary replacement (\%) }\end{array}$ & $\begin{array}{l}\text { Overall } \\
\text { period (\%) }\end{array}$ \\
\hline Revision surgery within 365 days & 149,637 & 1.88 & 1.65 & 3.53 \\
\hline Surgical complications within 90 days & 152,567 & 1.96 & 5.29 & 7.25 \\
\hline $\begin{array}{l}\text { Thrombosis/pulmonary embolism } \\
\text { within 90 days }\end{array}$ & 152,354 & 0.43 & 0.69 & 1.12 \\
\hline Femoral fracture within 90 days & 152,885 & 0.25 & 1.74 & 1.99 \\
\hline Mortality within 90 days & 154,220 & 0.48 & 0.43 & 0.91 \\
\hline Complication index* & 154,240 & 3.36 & 7.73 & 11.09 \\
\hline
\end{tabular}

* Sum of individual quality indicators, cases in which a patient had several complications were counted as a single event.

Source: IGES - Jeschke and Günster 2014 
Tab. 3.14 Postoperative complications of AOK patients after TKA

\begin{tabular}{|l|c|c|}
\hline Description & Patients & Percentage [\%] \\
\hline Total & 40,483 & 100 \\
\hline Pneumonia & 149 & 0.4 \\
\hline Pulmonary embolism & 215 & 0.5 \\
\hline Thrombotic events & 828 & 2.0 \\
\hline Bleeding complications & 5,267 & 13.0 \\
\hline Ventilation for over $24 \mathrm{~h}$ & 69 & 0.2 \\
\hline Postoperative infection & 143 & 0.4 \\
\hline Other postoperative complications & 514 \\
\hline Complications through orthopedic endoprostheses, implants or transplants & 689 \\
\hline Luxation, sprain and strain of the knee joint and knee joint ligaments & 67 & 1.3 \\
\hline Source: IGES - WiDO 2007 & 1.7 \\
\hline
\end{tabular}

was documented as »osteoarthritis of the hip « $(97 \%$ of patients). Patients who had already undergone a hip joint replacement two years prior to the index surgery were excluded, as well as hospitals with fewer than 30 cases in the above-mentioned period (•Tab. 3.13).

With regard to primary replacements, the study shows that complications caused by the surgery can especially develop in the period of up to 90 days following discharge from hospital. The "Surgical complications « quality indicator was defined by the ICD-10 diagnosis codes "Luxation " (ICD-10: S73), "Complications of internal orthopedic prosthetic devices" (ICD-10: T84.0/5/8/9) and "Complications of procedures (ICD-10: T81.2/3/5/8/9). The evaluation primarily investigated the connection between complications occurring during inpatient stays and during the follow-up period of observation. The publication makes the following general statement: »With regard to hospital-related complications, barely any links can be observed between the events during the initial inpatient stay and during the follow-up period for any of the indicators investigated [...] « (Jeschke and Günster 2014).

Similar analyses are available for knee endoprostheses. The Federal Association of the AOK's final 2007 report on the Quality Assurance of Hos- pital Care using Routine Data (QSR) analyzed 2003 routine data of postoperative complications of AOK insurees who had undergone knee replacements (bicondylar surface replacement prosthesis or hinged endoprosthesis) (WiDO 2007). In total, data from 40,483 patients who had undergone knee joint replacements in 2003 were analyzed $(73.8 \%$ women, average age of 70.1 years). Patients of 30 years of age or younger were excluded. The most frequently documented complications were general surgical risks, such as bleeding or a thrombotic event (•Tab. 3.14).

During the inpatient stay, revision TKA with replacement or removal was performed in $0.3 \%$ of the patients (WiDO 2007).

An analysis based on pre-defined reasons for readmission to hospital showed that in the first year after TKA, $1.8 \%$ of patients were readmitted for revision with replacement or removal of the prosthesis. Revisions without replacement or removal were performed on an inpatient basis in $0.6 \%$ of patients within the period of one year (WiDO 2007). 


\subsection{Rehabilitation}

According to $₫ 26$ of the German Social Security Code Volume IX, the overall goals of medical rehabilitation services are:

1. To prevent, overcome, minimize, stabilize and inhibit the deterioration of a disability, including chronic disease.

2. To avoid, overcome and minimize restrictions in the ability to work, reduce nursing care requirements, prevent deterioration of the disability and thwart a premature need for continuous social security benefits and/or reduce the amount of ongoing social security benefits.

Medical rehabilitation comprises treatment by the physician, drugs and wound dressings, therapeutic products, orthopedic devices and other medical technical aids and if necessary, endurance tests. The major medical rehabilitation payers are statutory health insurances (SHI), the German Statutory Pension Insurance (Deutsche Rentenversicherung (DRV)) and the German Statutory Social Accident Insurance (Deutsche Gesetzliche Unfallversicherung (DGUV)). According to the German Social Security Code Book policy »Rehabilitation before Nursing Care«, statutory health insurances are obliged to fund rehabilitation treatment for patients who are no longer of working age. The DRV funds treatment for patients of working age according to the »Rehabilitation Before Pension « policy (Kladny 2013).

Rehabilitation measures that are initiated without prior hospital treatment are termed »Heilverfahren $(\mathrm{HV})$ « (curative procedure) in German. Rehabilitation after surgery is termed "Anschlussrehabilitation" or "Anschlussheilbehandlung (AHB) « (subsequent rehabilitation). Socio-medical prerequisites for subsequent rehabilitation $(\mathrm{AHB})$ are that the diagnosis is included in the AHB indication group list, that there is an existing need of rehabilitation, that the patient is able to undergo rehabilitation and a has positive rehabilitation prognosis. "Status post endoprosthetic surgery of the hip joint, knee joint, shoulder joint and the ankle joint « is considered to be a diagnosis eligible for subsequent rehabilitation (AHB). Further prerequisites for subsequent rehabilitation $(\mathrm{AHB})$ are that rehabilitation is to be conducted "Subsequent to postoperative care « and that "Persistent postoperative functional restrictions « exist (Deutsche Rentenversicherung 2005).

The German Statutory Pension Insurance considers patients to be in need of rehabilitation if the ability to work is severely jeopardized or already impaired. Statutory health insurances consider patients to be in need of rehabilitation if everyday functions are impaired for a longer period of time than normal. If there is solely residual muscle weakness and restriction of movement, ambulatory therapeutic products and functional training are deemed sufficient (Maier-Börries and Jäckel 2013). An indication for postoperative rehabilitation should therefore be made if patients have restrictions in performing activities of daily living and participating in daily life, which require medically led and supervised interdisciplinary multimodal treatment.

A patient's ability to undergo rehabilitation encompasses both the physical and psychological ability to use all of the therapeutic services offered as well as a willingness to do so. A patient undergoing rehabilitation treatment must

- have undergone early mobilization and be able to eat without assistance, wash themselves and to move about in the ward;

- be strong enough to endure effective rehabilitation treatment;

- be motivated and have the mental capacity and necessary physical strength to actively participate in rehabilitation treatment (DRV-Indikationsliste $\mathrm{AHB}$ ).

Overall basic prerequisites for inpatient rehabilitation treatment after hip and knee replacement surgery usually include:

- non-irritated wound without any indication of local infection,

- being predominantly independent with regard to the most important activities of daily living (Barthel ADL index score of at least 65),

- having sufficient and safe mobility, at least for short walking distances in the ward (with the help of walking aids),

- having already attained minimum satisfactory functionality of the operated joint: 
- hip: extension/flexion $0 / 0 / 80^{\circ}$

- knee: extension/flexion 0/5/80-90

- having sufficient personal motivation to undergo rehabilitation and

- being in a sufficient cognitive state (no severe dementia).

The aim of subsequent rehabilitation (AHB) is to prepare the patients for the demands of their everyday and working lives. An important focus is the regain of lost functions and/or learning to compensate for them as much as possible. Rehabilitation prognosis is an assessment of the likelihood of a patient reaching set rehabilitation goals. Reaching of these goals must be highly likely, and should take into consideration both the type as well as the duration of the treatments required in order to enable the patient to participate in daily life.

Ambulatory rehabilitation services have received special funding with the range of services having been expanded over the past few years (Deutsche Rentenversicherung Bund 2009) which are based on certain legal requirements (cf. $\$ 19$, section 2, Volume IX of the German Social Security Code). Prerequisites for participation in ambulatory rehabilitation are that patients are physically and emotionally capable and have a degree of mobility that is higher than the degree required for inpatient rehabilitation. Patients must be able to reach the facility by means of public transport within a reasonable amount of time. The following aspects support the case for inpatient rehabilitation (Heisel and Jerosch 2007):

- walking distance under $100 \mathrm{~m}$,

- use of public transport and use of a private vehicle not possible,

- danger of falling due to insecure gait,

- unable to climb stairs,

- increased need of nursing care,

- provision of care at home not guaranteed,

- comorbidities in need of treatment,

- driving distance to an ambulatory rehabilitation center of longer than 30 minutes.

Applications for subsequent rehabilitation (AHB) are made by the treating physician on behalf of the patient. Consequently, the applicant is the person undergoing rehabilitation. The physician is respon- sible for assessing the necessary prerequisites and for making recommendations for the need for subsequent rehabilitation (AHB) to the relevant social insurance institution.

Existing data with regard to (medical) rehabilitation is generally considered to be very limited, fragmented and in need of improvement (Augurzky et al. 2011; SVR Gesundheit 2014). The following chapters aim to portray the circumstances for patients who have undergone total arthroplasty.

\subsubsection{Therapy Recommendations and Standards}

In general, hardly any guidelines exist with recommendations for specific rehabilitation therapy for individual diseases (SVR Gesundheit 2014). However, extensive textbooks (Heisel and Jerosch 2007; Imhoff et al. 2015; Stein and Greitemann 2015) and specific scientific publications (Heisel 2012; Kladny 2007; Rupp and Wydra 2012) exist which describe the basics in detail.

The German Statutory Pension Insurance (DRV) has developed standards for subsequent rehabilitation (AHB) therapy following THA and TKA. These standards constitute part of the DRV's quality assurance. They differ from the general guidelines in that they do not include any therapy algorithms. They aim to put forward »Evidence-based care provision of therapeutic rehabilitation services«. The standards are predominantly based on scientific guidelines, literature reviews, expert surveys as well as on an analysis of rehabilitation services that have actually been covered in Germany by the pension insurance (Deutsche Rentenversicherung Bund 2010). The standards apply to both THA and TKA indication fields. Evidence-based treatment modules (ETM) were derived from this. These individual modules include a list of services in accordance with the standardized classification of therapeutic services (KTL) with a minimum of specific ETM (Deutsche Rentenversicherung Bund 2011). Fields of major significance include movement therapy, training in activities of daily living, as well as educating patients in matters related to total arthroplasty and health (•Tab. 3.15). 
Tab. 3.15 Evidence-based rehabilitation therapy standards for THA and TKA developed by the German Statutory Pension Insurance

\begin{tabular}{|l|l|l|}
\hline ETM & Description & $\begin{array}{l}\text { Minimum percentage of patients to be treated } \\
\text { accordingly (\%) }\end{array}$ \\
\hline 01 & Movement therapy & 90 \\
\hline 02 & Activities of daily living training & 90 \\
\hline 03 & Physical therapy & 50 \\
\hline 04 & THA/TKA patient education & 80 \\
\hline 05 & Health education & 80 \\
\hline 06 & Nutritional education & 20 \\
\hline 07 & Psychological counseling and therapy & 10 \\
\hline 08 & Relaxation training & 10 \\
\hline 09 & Social and social security law counseling & 30 \\
\hline 10 & Job integration support & 20 \\
\hline 11 & Follow-up care and social integration & 50 \\
\hline ETM = Evidence-based therapy modules & \\
\hline Source: IGES - Deutsche Rentenversicherung Bund (2011) & \\
\hline
\end{tabular}

\subsubsection{Provision of Care}

In 2014, almost 2 million patients underwent inpatient rehabilitation. No explicit data is available for the indications and case numbers for hip and knee joint replacements. In 2014, there were 399 rehabilitation hospitals with specialist orthopedic departments in Germany which treated approximately 650,000 patients in total (Destatis 2014).

For some indications, particular emphasis is placed on the importance of having access to rehabilitation services close to the patient's domicile, as this allows for incorporating family and social environments into the treatment. However, rehabilitation does not necessarily take place close to a patient's home. The German Statutory Pension Insurance figures for 2014 demonstrate that, within the country, a patient's domicile and the rehabilitation hospital are not always in the same region. For example, many patients living in Berlin, Hamburg or Bremen undergo inpatient rehabilitation treatment in other federal states, while, on the other hand for example, more patients undergo rehabilitation treatment in Hessen, Mecklenburg-Western Pomer- ania and Schleswig-Holstein than are residents of those federal states (GBE-Bund 2015).

According to the Integrated Care Policy ( $\$ 140$, Volume V German Social Security Code), contracts are concluded between statutory health insurance funds and service providers of acute and rehabilitation care. The contracts aim to better interlink acute inpatient treatment and the subsequent hospital or ambulatory rehabilitation measures. A study on improving care demonstrated that integrated care concepts, which ensure a seamless connection between the acute phase and inpatient rehabilitation for hip and knee joint replacement patients, had positive effects on patient satisfaction and outcome quality (Bethge et al. 2011).

\subsubsection{Utilization of Services}

The Federal Statistical Office publishes the number of full-time inpatients in preventive medicine facilities and rehabilitation establishments with over 100 beds, classified according to the main diagnoses groups (Destatis 2015b). In 2014, a total of 1.66 mil- 


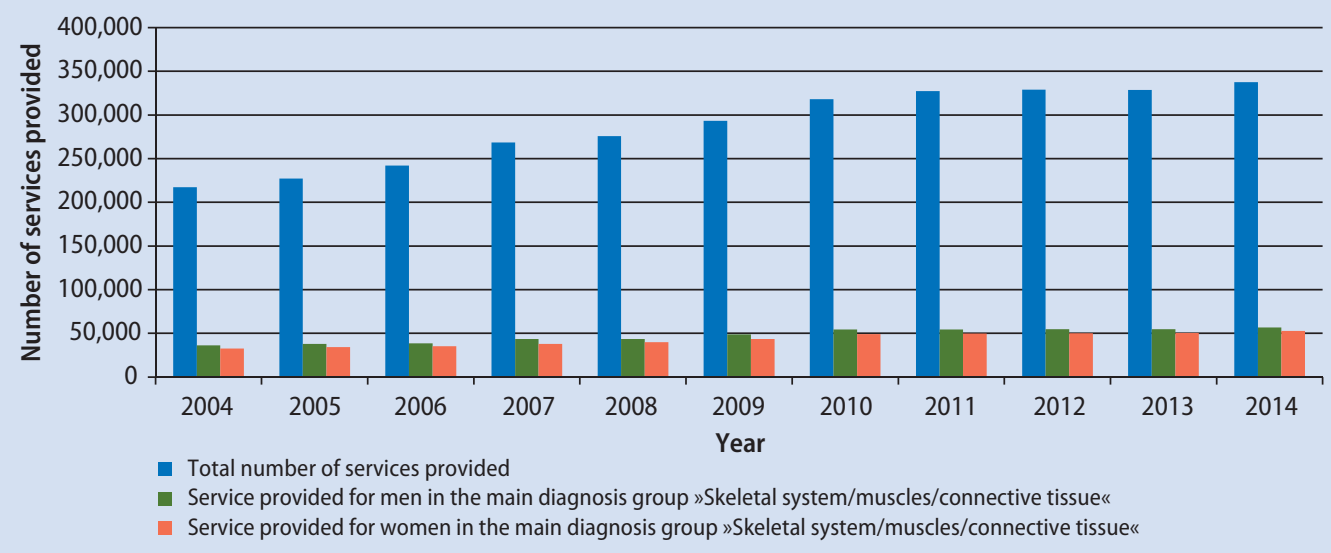

Fig. 3.15 Services provided in subsequent rehabilitation treatment (AHB) in the DRV (2004 to 2014) (Source: IGES - Deutsche Rentenversicherung Bund 2014b)

lion patients were treated, of which 606,000 were treated in orthopedic departments. 518,000 patients had diseases of the musculoskeletal system, a further 102,000 suffered from injuries. The most common main diagnosis in 2014 was osteoarthritis of the hip (coxarthrosis), followed by osteoarthritis of the knee (gonarthrosis). Approximately 104,500 patients with an indication of osteoarthritis of the hip (ICD-10 M17) were treated in these facilities. The highest patient numbers were recorded for the age group between 70 and 75 years $(21,099)$ and between 75 and 80 years $(20,808)$. With further increasing age, patient numbers decreased significantly. In total, significantly more women than men with osteoarthritis of the hip (approx. 63,000 vs approx. 41,000 respectively) underwent rehabilitation treatment. This ratio was even more pronounced for osteoarthritis of the knee $(66,000$ vs. 38,000$)$ (Destatis 2015b). These figures take into account all payers, but no distinction is made between curative procedures for osteoarthritis and subsequent rehabilitation (AHB) after replacement surgery.

DRV statistics show that in 2014 over 1 million medical rehabilitation services were provided for people in employment, of which 350,655 (36\%) were related to "Skeletal system/muscles/connective tissue« disorders. Follow-up services for rehabilitation constituted about one third of all medical rehabilitation services $(337,618)$. One in three of the procedures are performed for musculoskeletal indications (Deutsche Rentenversicherung Bund 2014b). Figure 3.15 illustrates the developments since 2004 as well as the number of services performed for indications in the main diagnosis group for "Skeletal system/muscles/connective tissue « disorders according to gender. Besides hip and knee replacements, the 56,603 procedures recorded for men and 52,652 for women in 2014 also include further procedures on the spine and other extremities.

Ambulatory rehabilitation services account for $13 \%$ of the entire range of medical rehabilitation services funded by the DRV, of which around two thirds of the indications are in the musculoskeletal domain. In the main diagnosis group »Skeletal system/muscles/connective tissue«, the percentage of ambulatory services out of the entire volume of medical rehabilitation services is under $25 \%$. This accounts for about 76,000 measures (Deutsche Rentenversicherung Bund 2014a).

According to the Federal Statistical Office, in 2014 patients within the main diagnosis group »Musculoskeletal system and connective tissue«, had an average length of stay of 22.1 days in (inpatient) preventive medicine and rehabilitation facilities with over 100 beds. The length of stay was 21.1 days for cases within the more specific main diagnosis group »Polyosteoarthritis and osteoarthritis« (ICD-10 M0506 and M15-19) (Statistisches Bundesamt 2013). 


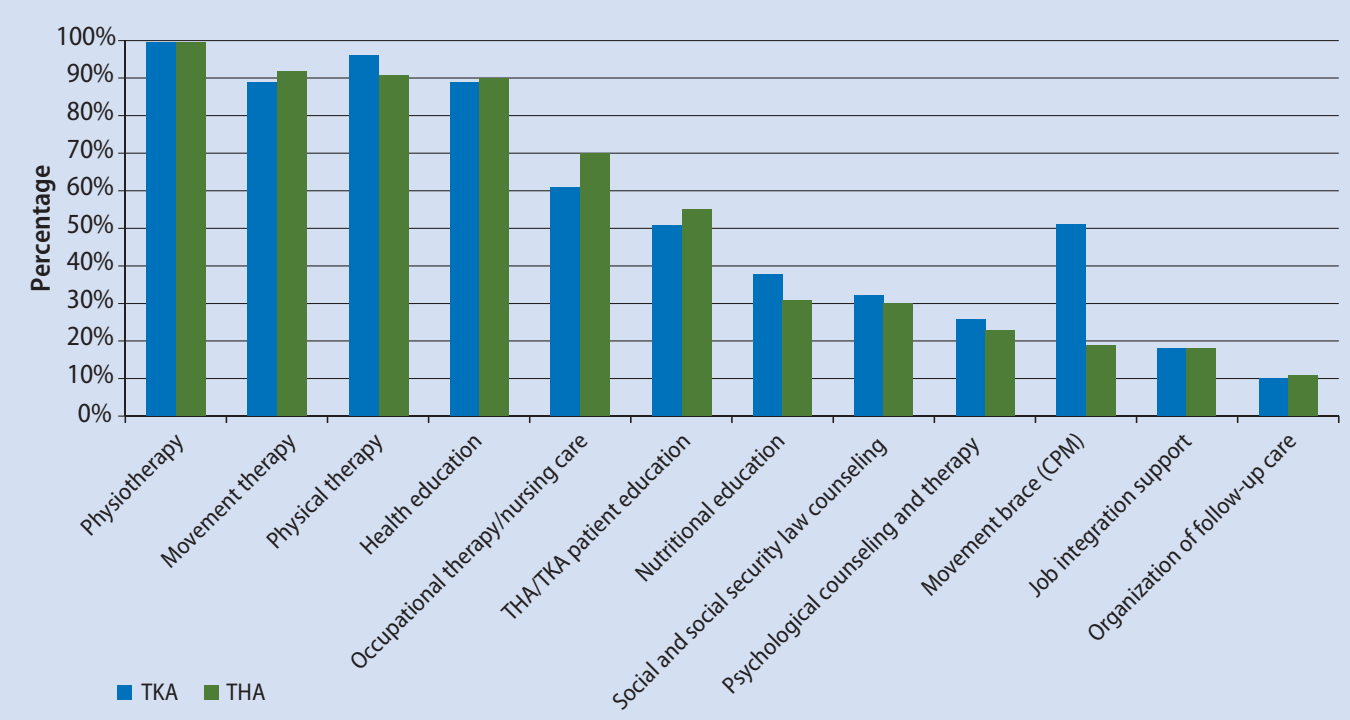

Fig. 3.16 KTL analysis: Percentage of patients undergoing rehabilitation with at least one therapy unit/ rehabilitation. (Source: IGES - Deutsche Rentenversicherung Bund 2010). Note: KTL = classification of therapeutic services (Klassifikation therapeutischer Leistungen); the data presented is derived from the commonly used German Statutory Pension Insurance classification system for therapeutic services. The system uncodes all the services rendered with the help of four-figure codes. The data is collected routinely every year and serves the purpose of documentation and quality control within the German Statutory Pension Insurance.

\subsubsection{Implementation of Therapeutic Measures}

The »Therapy standards for medical rehabilitation following THA and TKA « developed by the German Statutory Pension Insurance provides an overview of therapeutic measures performed during subsequent rehabilitation (AHB) (Section 3.4.1) (Deutsche Rentenversicherung Bund 2011). The standards were developed based on an analysis of all rehabilitation measures funded by DRV Bund which were completed between 1 January 2007 and the cut-off date of November 10, 2007 (Deutsche Rentenversicherung Bund 2010).

This analysis included patients in subsequent rehabilitation (AHB) who received therapy and who had a primary or secondary diagnosis of "osteoarthritis of the hip (ICD-10 M16) or »osteoarthritis of the knee" (ICD-10 M17) recorded in their discharge summary and who had had a joint implant (Z96.6 or Z98.8). Under these criteria, 66,842 KTL datasets from 3,652 patients after hip replacement and 41,459 KTL datasets from 2,186 patients after knee replacement were recorded (Deutsche Rentenversicherung Bund 2010).

The KTL data analysis contains information on the percentages of patients who received treatment with the evidence-based therapy modules in question and the average number of therapy units that were performed in one week (Gülich et al. 2010). The results are summarized in Figure 3.16 and Figure 3.17.

According to this table, the majority of patients received physiotherapy (99.5\%), physical therapy $(96.0 \%)$, movement therapy $(89.0 \%)$ and health education $(89.0 \%)$. Over half the patients received occupational therapy/nursing care (61.0\%), THA/ TKA education (51.0 \%) and therapy with a movement brace (CPM) $(51.0 \%)$. It is important to note that the DRV therapy standards were revised in 2011 and in part include some reworded evidence-based therapy module titles and different KTL code allocations. However, the titles of some modules remain the same and the core contents 


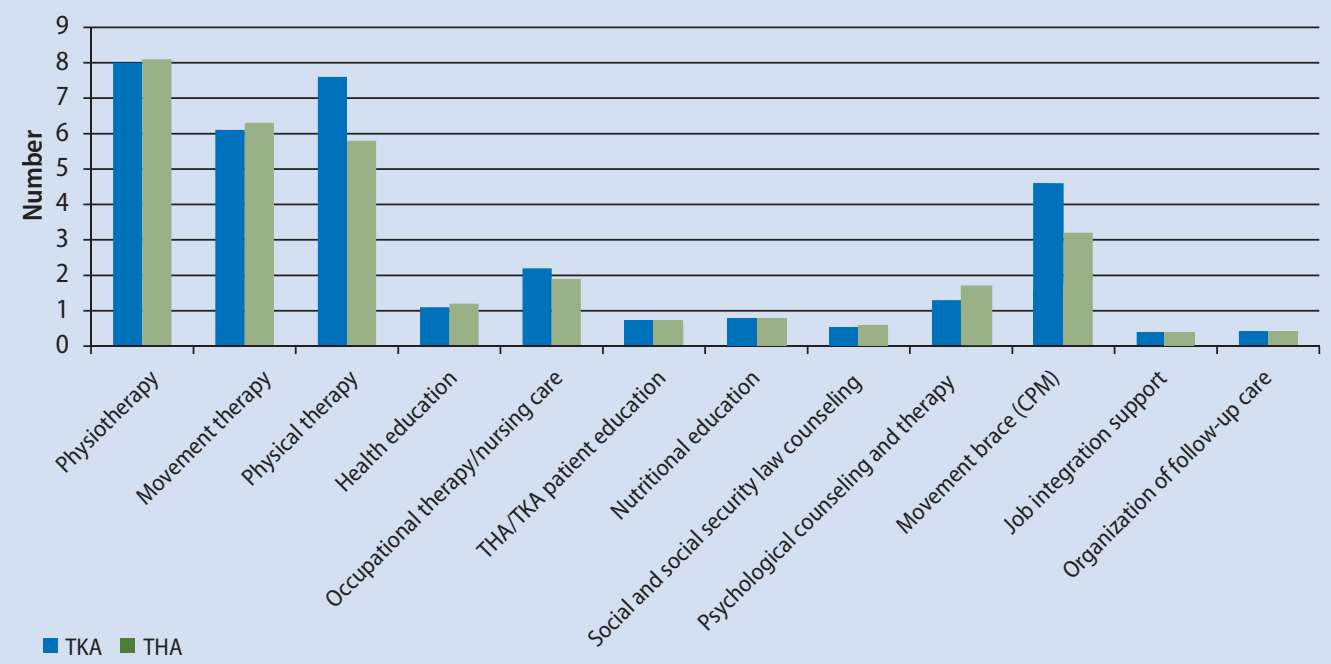

- Fig. 3.17 KTL analysis: Therapy units per week (mean values). (Source: IGES - Deutsche Rentenversicherung Bund 2010). Note: $\mathrm{KTL}$ = classification of therapeutic services (Klassifikation therapeutischer Leistungen); the data presented is derived from the commonly used German Statutory Pension Insurance classification system for therapeutic services. The system uncodes all the services rendered with the help of four-figure codes. The data is collected routinely every year and serves the purpose of documentation and quality control within the German Statutory Pension Insurance.

are comparable (cf. Deutsche Rentenversicherung Bund 2011, 2010). This means that the current provision of care, if provided according to the revised therapy standards, may differ slightly from the results presented.

It should be noted that the analyses only include working people. Accordingly, the patients « ages are comparatively low (THA: 54.1; TKA: 55.7) and cannot be considered representative of all patients undergoing rehabilitation after endoprosthetic surgery (Gülich et al. 2010).

Statutory health insurances are responsible for funding subsequent rehabilitation (AHB) of a majority of patients who are not working. However, to date, only little data on rehabilitation for SHI insurees has been published.

The Barmer GEK reports that in 2009 almost $90 \%$ of approximately 2,200 insurees who had undergone THA or TKA underwent inpatient rehabilitation. Their average age was 65 years, two thirds were over the age of 60 (Barmer GEK 2010).

The AOK Rheinland conducted a pilot project with the intention of establishing rehabilitation timelines and investigated 120 THA and 110 TKA patients. The average ages were 75 and 74 years respectively. The final quality outcome of rehabilitation outcome quality was measured based on the Staffelstein-score which takes into account both objective clinical findings and subjective aspects. »Pain", "Activities of daily living" and »Range of movement « are each weighted one third. A total score of 120 points can be achieved. The evaluation was conducted with reference to an achievable rehabilitation potential. It is suitable for both THA and TKA. The Staffelstein-score improved from 64 to 92 in the group of investigated THA patients and from 57 to 87 in the group of TKA patients. On average, the greatest progress in rehabilitation determined by this score was observed in the first 2 weeks of therapy. The rehabilitation goal for both groups was set at a score of 86 , which was achieved by $76 \%$ of THA patients and by $57 \%$ of TKA patients. The average length of stay was 19.1 and 19.8 days respectively. However, in both groups almost $10 \%$ of the patients needed significantly more than 21 days (Tuncel et al. 2015b).

An investigation conducted by the Techniker Krankenkasse as part of the »TK EVA« rehabilita- 
tion project investigated over 8,600 THA and 8,100 TKA patients in 9 rehabilitation hospitals in Rhineland-Palatinate between 2007 and 2009. The average patient age was just under 75 years. By means of a modified Staffelstein-score, the measured THA outcomes improved from $53 \%$ to $78 \%$ and the TKA outcomes from $50 \%$ to $76 \%$ (Baulig et al. 2015).

\subsubsection{Effectiveness of Subsequent Rehabilitation}

Rehabilitation is generally regarded as a multidimensional intervention and is consequently difficult to evaluate. Literature reviews have described that numerous small-scale controlled studies illustrate the positive effects of subsequent rehabilitation treatment (AHB) after total hip and knee replacement (Aliyev 2010; Baulig et al. 2015; Kladny et al. 2002, 2001; Middeldorf and Caaer 2010; Müller et al. 2015; Tuncel et al. 2015a, 2015b). Clear indications of improved pain reduction, improved joint mobility, increased mobility and independence, reduced falls, self-management as well as improvements in performing activities of daily living and participation in daily life have been observed.

A systematic literature review on the effectiveness of different rehabilitation therapies in patients who have undergone hip and knee joint replacements have shown that the studies conducted are vastly heterogeneous, and do not contain enough significant data. Up to now, it has been demonstrated that individual therapy measures, such as sports and movement therapy as well as physiotherapy, are effective. However, the data did not allow for conclusions about the required frequency and duration of the measures (Müller et al. 2009). In 2014, the Advisory Council on the Assessment of Developments in the Healthcare System (Sachverständigenrat zur Begutachtung der Entwicklung im Gesundheitswesen (SVR)) established that »the lack of an evidence base common to many cases does not automatically prove that rehabilitation is ineffective«. Even though there is predominantly no proof of efficacy under controlled conditions, it can indeed be assumed that benefits exist. However, it is often questionable as to whether they have an added benefit over alternative treatments (SVR Gesundheit 2014).

\subsubsection{Post-Rehabilitation Care}

Post-rehabilitation care aims to guarantee the longterm outcome and presents an ongoing challenge. Most patients require further treatment after their rehabilitation treatment is completed. To this end, the German Statutory Pension Insurance has initiated a post-rehabilitation care system called »IRENA« (Intensivierte REhabilitations NAchsorge) which, however, has not yet been adopted by other payers. The system permits the patient to continue with movement therapy measures after completion of the DRV-funded rehabilitation. These measures usually take place in groups in rehabilitation facilities close to the patient's domicile. Alternatively, the practice-based treating physician prescribes 3 to 8 weeks of physiotherapy or device-based physiotherapy. However, not all patients need this therapeutic prescription in which case continuing with the training program learned during rehabilitation for a period of about 6 weeks sufficiently compensates for any remaining deficits. Patients can also be integrated into functional training which, for example, is organized by the German league against rheumatism (Rheumaliga).

\subsubsection{Challenges}

After the introduction of DRGs in 2003, the length of acute-care hospital stays reduced significantly. The "REhabilitation und DIAgnosis Related Groups« study (REDIA-Studie) is a prospective, multi-center, randomized long-term study on the effects of DRG introduction into acute care on medical service requirements and the costs of rehabilitation (von Eiff et al. 2011). 10 years later, admission to rehabilitation hospitals after hip or knee replacement is, on average, one week earlier. Due to this premature start of rehabilitation, a significant deterioration in the patients « condition at the start of the rehabilitation was observed. This, in turn, led significantly higher costs for the rehabilitation hospitals, i.e. for more staff to assist with the therapy, changing dressings and wound treatment as well as for more pain medication, antibiotics, thromboprophylaxis and laboratory tests. Patient resilience was affected owing to the reduced overall condition 
after surgery. The Staffelstein-score decreased from 78 to 70 . The number of complications also increased steadily. Therefore, between 2003 and 2009, the number of wound healing complications increased from 1.6 to $6.5 \%$, the number of hematomas from 4 to $10.8 \%$ and mobility impairments due to complications from 1.6 to $12.3 \%$. A consequent increase in the number of patient transferals back into acute care constituted a significant cost factor for the rehabilitation institutions involved, as the transport costs are usually included in the rehabilitation case fees.

While these figures undoubtedly demonstrate a higher financial burden on the rehabilitation institutions, no increase of the remuneration rates for subsequent rehabilitation treatment (AHB) can be seen in practice, not even for the nursing rates paid by the statutory health insurance funds.

Process changes could potentially lead to improvements: The immediate start of so-called »fasttrack rehabilitation " in the acute-care hospital could become an interesting option. A recent literature review found that this can reduce the length of hospital stays. In addition, there were indications that early intervention can improve the patient's physical state at the start of rehabilitation treatment (Quack et al. 2015).

\subsubsection{Outlook}

The demographic change with its increasingly aging population and simultaneous improved care has led to a marked rise in the number of patients who undergo elective joint replacement surgery and in endoprosthetic treatment of femoral neck fractures (Dreinhofer and Schwarzkopf 2010). Evidently, this has a significant impact on acute-care hospitals and particularly also on the rehabilitation hospitals: An increasing number of multimorbid patients with significant mobility restrictions and who are in need of nursing care need to be looked after.

This demands a structural change: The development of geriatric traumatology centers can be understood as a response to the increasing number of fragility fractures and is characterized by the interdisciplinary treatment through surgical departments and geriatric institutions. However, given the expected patient numbers in orthopedics and trauma surgery, covering this demand through geriatric departments will be very challenging. In addition, not all elderly patients benefit from geriatric treatment because they do not require it (Kladny 2015). More often, specialist rehabilitation by a multidisciplinary team with competency in geriatric medical care will be required. Specialist rehabilitation treatment will have to adapt to the specific requirements of a patient group which is growing increasingly older (Dreinhofer and Schwarzkopf 2010).

This urgently requires structural and financial adaptations. At present, there is only one so-called rehabilitation phase in orthopedic treatment, which, as described earlier, has prerequisites such as the ability to undergo rehabilitation and is largely based on patients who are mobile and can look after themselves. Meanwhile, however, this is undoubtedly no longer the case. A multi-phase care system with several levels of care, as has already been introduced in neurology, also seems worthwhile for orthopedics. The patient is assigned to a specific rehabilitation phase depending on the intensity of the required assistance and nursing care. With increasing independence, the rehabilitation the phase may be changed to the next phase. Naturally, the required resources for phases that require a high intensity of nursing care are significantly higher and are consequently accompanied by higher nursing care fee rates.

From a scientific perspective, the data situation for assessing the effectiveness and cost-effectiveness for rehabilitation measures, including their duration and intensity, is limited for subsequent rehabilitation (AHB) following replacement surgery as well as for most other procedures. Moreover, no clear criteria for allocating patients to ambulatory or inpatient rehabilitation exist. In 2014, the Advisory Council on the Assessment of Developments in the Healthcare System found: »There is a lack of high-quality, multiarmed, prospective studies which could be conducted in a rehabilitation setting despite some methodological challenges. In order to realize such studies, more rehabilitation research funding is needed so that appropriate high-quality study designs can be applied to large patient cohorts. To this end, rehabilitation research should be organized across the payer institutions in future» (SVR Gesundheit 2014). 


\subsection{Quality Aspects of Care}

Quality of care can be considered from different perspectives. From the angle of attaining treatment outcomes which are relevant to the patient, factors such as avoiding complications and improving quality of life are in the foreground. From a statutory health insuree perspective, maintaining high average treatment outcomes throughout Germany, avoiding unnecessary primary replacements and premature revision surgery are important for making efficient use of financial resources. On the other hand, the providers of core medical services (replacements/ revision surgery) and rehabilitation establishments are interested in avoiding complications in patients and attaining optimal results with limited funds. In doing so, they aim to fulfill their medical responsibility, successfully acquire patients in competition with other establishments and, beyond this, fulfil statutory quality assurance standards. The following section will discuss factors that could have an influence on the quality of care.

\subsubsection{Materials}

The materials used in replacement surgery have been subject to continuous step-by-step innovation for a long time. All materials used in endoprosthetics are subject to mechanical strain, especially the articular joint surfaces, i.e. the bearing, high-friction surfaces. Over time, friction will inevitably lead to wear and tear of the material, through which particles can also be released into the surrounding tissue. This can lead to tissue reactions and bone loss which, in turn, lead to loosening and failure of the joint implant. Materials are advanced with the help of tribology research, as has been the case, for instance, with more wear-resistant materials (Mittelmeier et al. 2012).

Joint replacement registries can contribute to the early detection of undesired features or anomalies in certain product types and devices, even though validation through direct comparison is not possible and despite the fact that international registries have neither consistent nor uniform early warning concepts (Liebs et al. 2014).
The meanwhile established German joint replacement registry "Endoprothesenregister Deutschland (EPRD)«(Section 4.3) aims to inform manufacturers "through an early warning system that provides early feedback on potential problems, innovation risks and outcome shortfalls" as well as longer-term results for the implants used (Hassenpflug and Liebs 2014). For example, for hip and knee prostheses, the Australian National Joint Replacement Registry separately details specific, concrete products with higher than anticipated rates of revision (AOA 2014). As different registries use different systems, detailed knowledge of the registry's methodology is necessary for evaluating and comparing the results.

\subsubsection{Surgery and Perioperative Management}

There are no conclusive study results which permit definite comparisons and demonstrate a specific procedure to be fundamentally superior. For hip joint replacements, less invasive access routes with techniques that are sparing with the soft tissue (no detachment of the muscle insertions) are considered advantageous. There are some studies which suggest that using such techniques subsequently result in less pain, shorter lengths of stay and fewer blood transfusions. However, a higher learning curve must be taken into account on introducing less invasive access techniques and their overall significance is ultimately still unclear (Ibrahim et al. 2013). To date, for knee joint replacements, it has not been shown that less invasive access techniques with reduced muscular trauma and less impact on the tissues surrounding the joint are advantageous compared to conventional access techniques (Ibrahim et al. 2013). Precise implant alignment plays a major role in knee replacement. A wrong alignment and incorrect rotation can result in an abnormally high degree of implant abrasion, early loosening and patellofemoral problems (Ibrahim et al. 2013).

A retrospective analysis of over 1,100 cases of primary hip replacements in a German university hospital suggests that a longer duration of surgery significantly increases the probability of postoperative complications, particularly if the surgery takes 
longer than 90 minutes (6.4-fold increased risk of complication). Therefore, a shorter duration of surgery is more favorable for the treatment outcome (Zenk et al. 2014).

In addition, Prokopetz et al. (2012) report a link between longer surgery duration and revision surgery and the occurrence of infections. In Germany, performing a TKA takes an average of 74.5 minutes. In contrast, average revision surgery, as defined by External Quality Assurance for Inpatient Care standards, takes over 2 hours and has higher complication rates during the inpatient stay compared with inpatient stays for primary replacement.

Hip revision can be performed in one-stage or two-stage (i.e. in two steps over time) procedures. According to the report on External Quality Assurance for Inpatient Care in Germany, $9.4 \%$ of all revision surgery in 2014 was reported to have been performed in a two-stage procedure (AQUA-Institut 2015b).

In cases of aseptic loosening, one-stage surgery is generally accepted, whereas revision surgery for infected endoprostheses (septic endoprosthesis) is usually performed in a two-stage procedure. At any rate, early and radical wound debridement with removal of the infected implant is considered important in the treatment of septic endoprostheses. The two-stage procedure permits identifying the pathogen and potential resistance between removing the endoprosthesis and the actual revision. A disadvantage here is a higher morbidity and lower quality of life during the time when the patient is without an endoprosthesis (Gravius et al. 2011).

Preoperative patient information ranks highly amongst the non-surgical quality assurance measures. This not only involves providing information about risks, advantages, the procedure and follow-up care for the respective surgery, which alone can lead to reduced pain and less anxiety for the patient. Matching the surgeon's and the patient's expectations for the treatment outcome is of greater importance as these often diverge and, additionally, there is a link between patient satisfaction and fulfilled expectations.

The anesthetic method is individually selected for the patient and takes into account the perioperative risk, the surgical procedure and the expected (postoperative) pain and mobility, amongst other things. In studies and meta-analyses, regional anesthesia for hip replacements is considered superior to general anesthesia with regard to the duration of surgery, blood loss, the need for transfusions, the risk of thromboembolic events, postoperative nausea and vomiting. A positive effect on functional outcomes 3, 6 and 12 months after surgery is unclear (Atchabahian et al. 2015). The intraoperative injection of local anesthetics into the area surrounding the joint can have a positive effect on the postoperative pain (Andersen and Kehlet 2014; Kerr and Kohan 2008).

Antibiotic prophylaxis, which is also performed in the majority of cases in Germany, is deemed necessary and reduces the risk of postoperative wound infections, particularly when administered as a single shot, regardless of whether this is done locally (in the cement) or systemically (Gollwitzer et al. 2011). Multimodal (interdisciplinary) care concepts (such as »fast track" or "enhanced recovery«) encompass the inpatient treatment period from admission to discharge. The concepts aim to shorten the time required for functional recovery and increase patient satisfaction by reaching functional goals more rapidly during inpatient treatment and consequently shortening the length of stay. Moreover, they aim at reducing the overall patient mortality and morbidity. Additionally, avoiding complications while accelerating convalescence can contribute to improved cost efficiency (Husted 2012). The multimodal care concepts implement clinical elements such as pain management, thromboembolism prophylaxis and mobilization. They also integrate individual patient characteristics and aspects of their home life into structured interdisciplinary treatment pathways with clearly defined and documented outcome parameters (therapy goals) (Husted 2012).

In a meta-analysis ( $\mathrm{n}=22$ studies), Barbieri et al. (2009) investigated the effect of structured treatment pathways for hip and knee joint replacements. For the observed treatment pathways the rate of inpatient complications was significantly lower and the length of stay shorter compared to the normal care pathway (Barbieri et al. 2009).

A retrospective cohort study conducted in the Netherlands demonstrated a clear reduction in the length of stay for hip joint replacements after the 
- Tab. 3.16 Surgeons and anesthetists' assessments and prognosis of the degree of influence of individual factors on length of stay reduction for hip and knee joint replacement

\begin{tabular}{|c|c|c|c|c|}
\hline \multirow[t]{2}{*}{ Area } & \multicolumn{4}{|c|}{ Evaluation for the period } \\
\hline & 2010-2012 & Prognosis (2013-2015) & 2010-2012 & Prognosis (2013-2015) \\
\hline \multicolumn{5}{|l|}{ Hip } \\
\hline & \multicolumn{2}{|l|}{ Surgeon } & \multicolumn{2}{|l|}{ Anesthetist } \\
\hline Anesthetic method & Low & Low & Medium & Low \\
\hline Treatment pathways & High & High & High & High \\
\hline Fixed discharge criteria & Medium & Medium & Medium & Medium \\
\hline Reduction of complications & Medium & Medium & Medium & Medium \\
\hline Surgical technique & Medium & Medium & High & Medium \\
\hline Economic factors & High & Medium & Medium & High \\
\hline Patient education & Medium & High & Low & Low \\
\hline Patient selection & Low & Low & Low & Medium \\
\hline Pain management & High & High & High & High \\
\hline \multicolumn{5}{|l|}{ Knee } \\
\hline & \multicolumn{2}{|l|}{ Surgeon } & \multicolumn{2}{|l|}{ Anesthetist } \\
\hline Anesthetic method & Medium & Medium & Medium & Low \\
\hline Treatment pathways & High & High & High & High \\
\hline Fixed discharge criteria & High & High & Medium & Medium \\
\hline Reduction of complications & Medium & Medium & Medium & Medium \\
\hline Surgical technique & Medium & Medium & High & Medium \\
\hline Economic factors & Medium & Medium & Medium & High \\
\hline Patient education & Medium & Medium & Low & Low \\
\hline Patient selection & Low & Low & Low & Medium \\
\hline Pain management & High & High & High & High \\
\hline
\end{tabular}

implementation of an enhanced recovery treatment pathway compared to before or after the implementation phase (den Hartog et al. 2015).

A registry study showed that in Norway, a fast track treatment concept was also associated with low rates of complication and revision and high patient satisfaction after primary and revision hip and knee surgery, even in the 1 year follow-up (Winther et al. 2015).
In 2014, Jaschinski et al. published a nationwide survey of hospital physicians in Germany, asking which factors the physicians considered relevant for reducing the length of stay (in the past and in future). The assessments of surgeons performing hip and knee replacements and those of the anesthetists are presented in - Tab. 3.16, grouped into three degrees of impact (high, medium, low) for each potential influencing factor. 
This shows that especially treatment pathways and pain management are considered to be factors that significantly influence the reduction of the length of stay. Patient selection (i.e. the careful selection of patients for surgery) and the anesthetic method chosen, on the other hand, are considered to have the lowest level of influence according those surveyed (Jaschinski et al. 2014).

\subsubsection{Surgeon}

The surgeon plays a major role. $\mathrm{He} / \mathrm{she}$ is responsible for planning treatment and performing the surgery, through which he/she substantially influences all aspects specific to the procedure which are reflected in the treatment outcome.

In their systematic review, Prokopetz et al. demonstrated that surgeons who have conducted low numbers of operations constitute a risk factor for revision total arthroplasty after primary THA. Conversely, this signifies a lower risk of revision total arthroplasty when the surgeon has more experience. The surgeon's (practical) experience therefore seems to be of significant importance. Regardless of the precise anchoring technique for hip replacements (hybrid, cemented, cementless), the most experienced surgeons only took an average of 53.2 $( \pm 17.4)$ minutes, surgeons with medium-level experience took on average 74.5 ( \pm 25.5$)$ minutes and surgeons with the least experience took an average of $80.8( \pm 21.9)$ minutes.

The rate of postoperative complications was highest for the least experienced surgeons with $5.0 \%$, as opposed to $3.0 \%$ for the more experienced and $2.7 \%$ for the most experienced surgeons. The analysis shows that for surgeons with the least experience, the risk of complications is always fundamentally higher, regardless of the actual duration of the surgery (Zenk et al. 2014).

Overviews of studies on surgeons performing knee and hip replacements demonstrate a predominantly positive correlation between the case numbers of performed operations performed by a surgeon and the outcome with regard to complications or revision (Haas et al. 2013). Experienced (specialist) surgeons who have performed a higher number of operations have a positive effect on the treatment outcome.

\subsubsection{Hospital}

Given the major role surgeons play and the importance of their degree of experience for treatment outcomes gives rise to the question of whether a minimum number of replacement surgery cases should be made a requirement in hospitals as well. Studies demonstrate a link between a surgeon's number of performed cases and postoperative mortality, and suggest that the mortality associated with hip replacements is related to the number of patients treated in the hospital (Haas et al. 2013).

In Germany, a minimum number of cases per hospital has been set as a requirement for total knee arthroplasty ( $\triangleright$ Chapter 4 ), but not yet for hip replacements.

Regardless of minimum case number regulations, the hospital structures are of significant importance for setting discharge criteria. Discharge criteria can contribute to shorter length of stays when used in multidisciplinary settings but they have only been established in $40 \%$ of hospitals in Germany ( $\triangleright$ Chapter 4).

Meanwhile, many hospitals have been certified, with which they aim to validate and improve their quality assurance measures and to inform their patients about their good quality of care. Particularly the EndoCert system described in $>$ Chapter 4 is particularly worth mentioning here.

\subsubsection{Patient}

Fulfilled patient expectations with regard to the surgery have a significant impact on treatment outcome satisfaction. Therefore, it is important that the surgeon and the patient discuss expectations prior to surgery. Patient and surgeon surveys suggest that patients with total hip replacements have particularly higher expectations of being able to do sports after the operation than their surgeons. In general, patients with more physical restrictions and those with lower incomes tend to be more optimistic than their surgeons with regard to the treatment outcomes (Jourdan et al. 2012).

A study involving more than 1,300 patients who underwent primary total hip replacement across a total of twelve European countries demonstrated 
that patients with higher expectations prior to surgery are more likely to have improvements after the operation (measured by means of functionality scores). Especially joint function and/or joint stiffness as well as pain perception correlated positively with the expectations (Judge et al. 2011). • Tab. 3.17 shows the different expectations of the patients surveyed in the study in the order of frequency of response.

Further patient-related factors that can influence treatment outcomes can evidently be found in the patient prerequisites (Günther et al. 2015). In the past, for instance, a patient's body mass index (BMI) was often discussed, i.e. how far being overweight has an impact on the treatment outcome. A review, which included a quantitative analysis, concluded that obese THA patients more frequently have dislocations, aseptic loosening, infections and venous thromboembolism (Haverkamp et al. 2011). A higher body mass index (BMI) in knee joint replacement patients can cause higher rates of postoperative complications and a lower prosthesis service life. Additionally, this has a negative impact on the (subjective) patient satisfaction (Lüring et al. 2013). Therefore, obesity seems to tend to have a negative effect on the treatment outcome with regard to complications. In individual studies, obesity was also observed to have a negative effect on hip revisions (Lübbeke et al. 2007).

Other investigations, which included several thousand THA patients from different studies, show that even with a high BMI, there were significant improvements in patient-reported treatment outcomes and from this point of view, a high BMI should not be an obstacle for total arthroplasty (Judge et al. 2014).

Concomitant diseases are discussed as frequently as patient-related influencing factors. They are considered to be cofactors for the THA implant survival period and have a direct impact on the rate of complications. Especially diabetes mellitus and other diseases that negatively influence the patient's immune response increase the rate of postoperative infections (Günther et al. 2015; Zhu et al. 2015). This is confirmed by calculations conducted by the Barmer GEK based on surveys and routine data. They identified that a higher patient age and the presence of concomitant diseases constitute negative factors for successful surgery (Barmer GEK 2010).
Tab. 3.17 Range of patient expectations related to THA

\begin{tabular}{|l|l|}
\hline $\begin{array}{l}\text { Subject and related patient } \\
\text { expectation }\end{array}$ & $\begin{array}{l}\text { percentage [\%] } \\
(\mathbf{n}=1,035)\end{array}$ \\
\hline Long walking distance & 46.0 \\
\hline Housework & 26.7 \\
\hline Activities of daily living & 25.7 \\
\hline Sport and leisure activities & 25.1 \\
\hline Feeling less pain & 23.6 \\
\hline Being pain-free & 23.0 \\
\hline Gardening & 19.1 \\
\hline Shopping & 10.9 \\
\hline Work & 8.2 \\
\hline Leading an independent life & 8.0 \\
\hline Returning to normal activities as & 7.3 \\
\hline far as possible & 1.9 \\
\hline Driving & 0.5 \\
\hline Holidays & 5.4 \\
\hline Looking after others & 3.5 \\
\hline Sleeping & 3.4 \\
\hline Sexual activity & 1.0 \\
\hline No expectations & \\
\hline Source: IGES - Judge et al. 2011 & \\
\hline
\end{tabular}

It is unclear whether exercise has a positive or negative impact on the (medium to long-term) treatment outcome. Patient surveys indicate that THA patients who do sports have a higher overall satisfaction with the surgery (Simmel et al. 2008). Regardless of the types of exercise "permitted « by international guidelines, literature recommends advising patients individually on the possibilities and risks of specific sport activities after THA, also with regard to specific rehabilitation measures that can help prepare the patient for a specific sport activity (Jacobs et al. 2009). Early revision total arthroplasty for younger patients is discussed, as they exercise a comparably higher strain on the endoprosthesis (Claes et al. 2012, Wirtz 2011). 
Smokers are advised to refrain from smoking for at least 4 weeks before and after the surgery, as this has shown advantages for hip and knee joint surgery complication risks (Gollwitzer et al. 2011). Beyond this, alcohol abuse is considered a patient-related risk factor, i.e. a behavior that is entirely within the patient's responsibility, for aseptic loosening (AQUA-Institut 2012e). The prescribed postoperative medication, e.g. for pain management, should be taken consistently so that the patient is as symptom-free as possible (Section 3.3.3).

Furthermore, there seems to be a link between high ASA scores and the frequency of postoperative complications. Being over the age of 70 , male and having a concomitant disease also lead to a higher complication profile for knee joint replacements (Lüring et al. 2013).

There also seems to be a connection between the preoperative stage of the disease and postoperative patient satisfaction with knee replacements in that patients who suffer from only mild osteoarthritis are less satisfied (excluding mechanical reasons). Additionally, existing osteoporosis could be a negative factor for treatment outcome. Other factors that have a negative influence, at least in the short term, could be the patient's life circumstances (being single, separated, widowed, unemployed, pensioned) or suffering from depression (Schäfer et al. 2010). Ultimately, however, these connections have not been validated, as individual studies have reported the opposite and the complex interconnections have not yet been fully elucidated (Lüring et al. 2013).

Providing good preoperative patient information not only enables discussion of expectations, advantages and risks of the surgery, but also informs the patient about the demands of postoperative rehabilitation and the necessity of his or her active participation in the recovery process. The patient's compliance and motivation are of major importance, particularly for complex rehabilitation measures (AQUA-Institut 2012f).

\subsubsection{Post-Discharge Treatment Outcomes}

In general, about 6 to 7 weeks following (primary) hip or knee joint replacement patients should largely be able to move the affected leg free of pain and bear full weight on it. Walking without any support at all is usually possible after 10 to 12 weeks. However, annual medical follow-ups should be conducted to examine the patient's gait, any residual symptoms as well as to assess the need for medical technical aids, amongst other things (Heisel 2008). Whether sporting activities outside of medical rehabilitation (e.g. fitness workouts, cycling, swimming) can be undertaken after a total replacement, particularly after THA, mostly depends on individual patient characteristics such as age, concomitant diseases, bone quality and condition of the muscles. Psychological factors, including risk awareness and ambition, should also be taken into account when making any recommendations. As a rule, patients are recommended to abstain from undertaking medically unsupervised (leisure) sports activities for 3 to 6 months (Schmitt-Sody et al. 2011). In addition, a recent meta-analysis found evidence that the behavioral and movement restrictions which are, in part, still frequently prescribed for the first few weeks or months following hip replacements (e.g. supine lying position, using walking aids, avoiding bending the hip joint by over 90 degrees) do not lead to lower rates of luxation. On the contrary, patients who were given more lenient behavioral restriction recommendations (»not sitting with crossed legs«) or none at all resumed activities earlier and showed a greater level of satisfaction (van der Weegen et al. 2015).

The 2010 Barmer GEK Hospital Report investigated the quality of life of selected insured patients and their level of outcome satisfaction following THA or TKA treatment by means of a written, retrospective and multidimensional survey.

The results show that the quality of life for THA patients who were operated in 2003 was comparable to that of patients who had surgery later in 2008/2009 (determined at an average of 9.2 and 9.3 months after the index surgery respectively). This demonstrates that the quality of surgery remained consistent over a period of several years. The report uses scores based on the so-called Nottingham 
Tab. 3.18 Patient satisfaction results after hip surgery, survey on behalf of Barmer GEK

\begin{tabular}{|c|c|c|c|c|}
\hline & \multicolumn{2}{|l|}{ Hip } & \multicolumn{2}{|l|}{ Knee } \\
\hline & Initial survey 2004 & Initial survey 2009 & Initial survey 2004 & Initial survey 2009 \\
\hline $\begin{array}{l}\text { Satisfaction with the } \\
\text { artificial hip joint: }\end{array}$ & $n=556$ & $\mathrm{n}=1,106$ & $n=334$ & $n=1,016$ \\
\hline - (entirely) satisfied & $58.3 \%$ & $63.4 \%$ & $44.9 \%$ & $43.2 \%$ \\
\hline - partially satisfied & $33.3 \%$ & $28.7 \%$ & $38.0 \%$ & $38.5 \%$ \\
\hline - not satisfied & $8.5 \%$ & $8.0 \%$ & $17.1 \%$ & $18.3 \%$ \\
\hline $\begin{array}{l}\text { Willing to undergo } \\
\text { another total arthro- } \\
\text { plasty if required: }\end{array}$ & $n=559$ & $n=1,109$ & $\mathrm{n}=335$ & $\mathrm{n}=1,020$ \\
\hline - fully & $76.9 \%$ & $75.4 \%$ & $62.7 \%$ & $60.7 \%$ \\
\hline - with limitations & $18.2 \%$ & $20.9 \%$ & $29.6 \%$ & $27.6 \%$ \\
\hline- no & $4.8 \%$ & $3.7 \%$ & $7.8 \%$ & $11.7 \%$ \\
\hline $\begin{array}{l}\text { Willing to recommend } \\
\text { total arthroplasty: }\end{array}$ & $n=552$ & $\mathrm{n}=1,102$ & $n=332$ & $\mathrm{n}=1,020$ \\
\hline - fully & $80.3 \%$ & $81.1 \%$ & $68.7 \%$ & $65.5 \%$ \\
\hline - with limitations & $15.9 \%$ & $15.5 \%$ & $20.8 \%$ & $21.8 \%$ \\
\hline- no & $3.8 \%$ & $3.4 \%$ & $10.5 \%$ & $12.7 \%$ \\
\hline
\end{tabular}

Health Profile (NHP), a tool for collecting subjective patient reports (patient-reported outcome measures, PROM) for the domains energy, pain, emotional reaction, sleep, social isolation and physical mobility. The highest scores and hence the most marked limitations, were assessed for the domains energy, pain, sleep and physical mobility (highest score, i.e. worst result: 20.4 out of a maximum of 100 for sleep in the initial 2004 survey) (Barmer GEK 2010).

Three aspects were surveyed for outcome satisfaction: satisfaction with the artificial hip joint, willingness to undergo another total arthroplasty if required, and willingness to recommend total arthroplasty. The results of the initial 2004 and 2009 surveys are presented in $\bullet$ Tab. 3.18. According to these results, the majority of patients who had undergone surgery in 2003 and in 2008/2009 were satisfied with the joint replacement and were willing to undergo another total arthroplasty or to recom- mend the procedure. However, a small number of the interviewees had undergone revision surgery and not primary surgery.

Additionally, response results from patients who had been interviewed for the first time in 2004 and who were again interviewed in $2009(\mathrm{n}=424, \mathrm{n}$ $=425, \mathrm{n}=421$ ) differed only slightly to the previous results, showing that the overall level of symptoms remained distinctly low, even 5 years after primary surgery (Lequesne index). Results for patient satisfaction were also comparable to the first survey (Barmer GEK 2010).

A similar analysis is available for TKA patients. In initial surveys conducted in 2004 and in 2009, health-related quality of life and satisfaction of the selected patients were recorded approximately 9 months after surgery (Barmer GEK 2010). To this effect, the Nottingham Health Profile was used, enabling the patients to self-rate their subjective health in six domains: energy, pain, emotional reaction, 
Tab. 3.19 Mean values and standard deviations as percentages of satisfied/dissatisfied patients after TKA

\begin{tabular}{|l|l|l|}
\hline & Satisfaction (\%) & Dissatisfaction (\%) \\
\hline $1990-1999$ & $81.2( \pm 9.5)$ & $16.9( \pm 10.5)$ \\
\hline $2000-2012$ & $85.0( \pm 7.9)$ & $8.5( \pm 5.6)$ \\
\hline Europe (13 publications) & $83.8( \pm 8.0)$ & $8.9( \pm 6.6)$ \\
\hline North America (10 publications) & $85.2( \pm 6.9)$ & $12.5( \pm 4.2)$ \\
\hline Source: IGES - Schulze and Scharf 2013 & & \\
\hline
\end{tabular}

sleep, social isolation and physical mobility. The highest scores, and hence the greatest limitations were rated for pain, sleep, physical mobility and energy. The health-related quality of life scores in 2004 and 2009 remained almost unchanged. The overall highest score ( 31.8 out of a maximum of 100 points) was observed for pain in the initial 2004 survey. Six and a half years after the index surgery, minor to moderate declines were observed in all domains compared to the survey conducted 9 months after surgery. Noticeable deteriorations were observed in the domains of energy (+5.9) and physical mobility $(+4.0)$, which are not, however, statistically significant. The scores for pain remained at a higher level and relatively stable.

The results also show that almost half of the patients with artificial knee joints were entirely satisfied and that the majority of patients were prepared to undergo another total arthroplasty and were willing to recommend the procedure to others. These levels of satisfaction, however, tended to be lower than those for THA.

The results of the follow-up survey in 2009 are also available. The responses of the patients who were followed-up in 2009 and had been interviewed for the first time in 2004 differed only slightly from the earlier results $(n=261$ for satisfaction with the artificial knee joint, $n=260$ for willingness to undergo another total arthroplasty, $\mathrm{n}=206$ for willingness to recommend total arthroplasty). Consequently, the reduction of symptoms and the satisfaction 5 years after surgery were comparable to the values obtained 9 months after surgery (Barmer GEK).

A systematic review based on existing studies investigated postoperative patient satisfaction after TKA for periods from 1990 to 1999 and from 2001 to 2012. - Tab. 3.19 shows the most significant results and illustrates the patients « overall higher level of satisfaction and lower level of dissatisfaction following surgery compared to the previous decade. The main influencing factors with regard to postoperative satisfaction were body mass index, postoperative joint function, expectations, pain, mental function and employment status (Schulze and Scharf 2013). In addition, preoperative expectations, particularly with regard to functional improvement, influenced treatment outcomes and consequently patient satisfaction (Judge et al. 2011). Improved outcome quality is linked to providing patients with realistic information, patients " attitudes towards the procedure as well as the careful selection of patients. (Halawi et al. 2015).

Additionally, the success of joint replacement surgery can be measured based on whether a patient reintegrates into working life. An analysis of routine data from the German Statutory Pension Insurance shows that $85 \%$ of patients aged between 18 to 60 years, who had undergone hip joint replacements and subsequent rehabilitation (AHB), were able to resume work within 2 years after rehabilitation treatment. Particular risk factors for failing to return to working life were older age and having a manual occupation. The analysis also shows that after rehabilitation approximately $37 \%$ of the patients observed earned a lower salary and hence had lower social security contributions. Moreover, the authors demonstrated that $17 \%$ of the patients observed changed jobs after hip joint replacement (Krischak et al. 2013). 
Tab. 3.20 Surgery with documented, fulfilled indication criteria, primary arthroplasty and revision total arthroplasty. Nationwide results based on operations performed in Germany (2014)

\begin{tabular}{|l|l|l|}
\hline Quality indicator & Result 2014 & Trend \\
\hline Primary hip replacement with fulfilled indication criteria & $95.84 \%$ & $\nearrow$ \\
\hline Revision hip replacement with fulfilled indication criteria & $93.10 \%$ & $\rightarrow$ \\
\hline Primary knee replacement with fulfilled indication criteria & $96.86 \%$ & $\nearrow$ \\
\hline Revision knee replacement with fulfilled indication criteria & $92.31 \%$ & $\rightarrow$ \\
\hline
\end{tabular}

Note: The arrows in the »Trend « column describe »whether progress in quality of care in 2014 compared to 2013 is positive (upward pointing arrow), negative (downward pointing arrow) or unchanged (horizontal arrow) .

Source: IGES - AQUA-Institut 2015b, c, d, e

\subsubsection{Indications}

A German federal group of experts defines the indicator used for external quality assurance for inpatient care purposes, for both primary THA and TKA. This is standard procedure for defining quality indicators in general. The defined quality goal is that "an appropriate indication be used frequently", which is why the indicator selection is based on equivalent features found in literature and in international guidelines. For primary hip replacements, data is recorded in patients with at least one pain criterion or at least one movement restriction criterion as well as one specific documented value for the degree of severity of osteoarthritis. For primary knee replacements, data is recorded in patients who have at least one pain criterion and a specific documented value for the degree of severity of osteoarthritis. The number of operations that meet these documented criteria are assessed in relation to the total number of recorded operations (AQUA-Institut 2015b, d).

According to in a national survey on primary hip and knee replacements, the overall results have been within the target range and have been improving continuously for several years. The increase in documentation of appropriate indications for the national survey shows that surgery with documented, previously undefined indication criteria was performed in individual cases only $(2014:<5 \%)$. A limiting factor, however, is that the fundamental criteria such as the degree of pain or the time of the surgery, do not yet exist in standardized or evidence-based forms (Claes et al. 2012, Wirtz 2011, Günther et al. 2013). In addition, cases with defined standardized indications such as trauma cases, amongst others, are not represented in the external quality assurance ( $\triangleright$ Chapter 6 ).

For revision total arthroplasty, the rate of appropriate indications documented is lower than for primary surgery and shows a consistent trend. The indicator is defined differently than in primary surgery. The quality goal for hip and knee arthroplasty here is "a frequently used appropriate indication based on clinical symptoms, radiological criteria or signs of inflammation «. Operations in patients with the defined criteria are assessed in relation to the total number of recorded operations (• Tab. 3.20; AQUA-Institut 2015c, e).

\subsubsection{Regional Differences}

Studies suggest that there are regional differences in quality of care. Figure 3.18 shows the rates for each federal state of unfulfilled indication criteria developed by the AQUA Institute based on THA patients. For comparison purposes, the average rates in Germany are also presented. This shows that in Lower-Saxony, the number of unfulfilled (or not recorded) indication criteria is almost twice as high as the German average of $4.8 \%$ or $3.4 \%$ for THA and TKA respectively. Besides Lower-Saxony, Bavaria, Saxony-Anhalt and Rhineland-Palatinate 


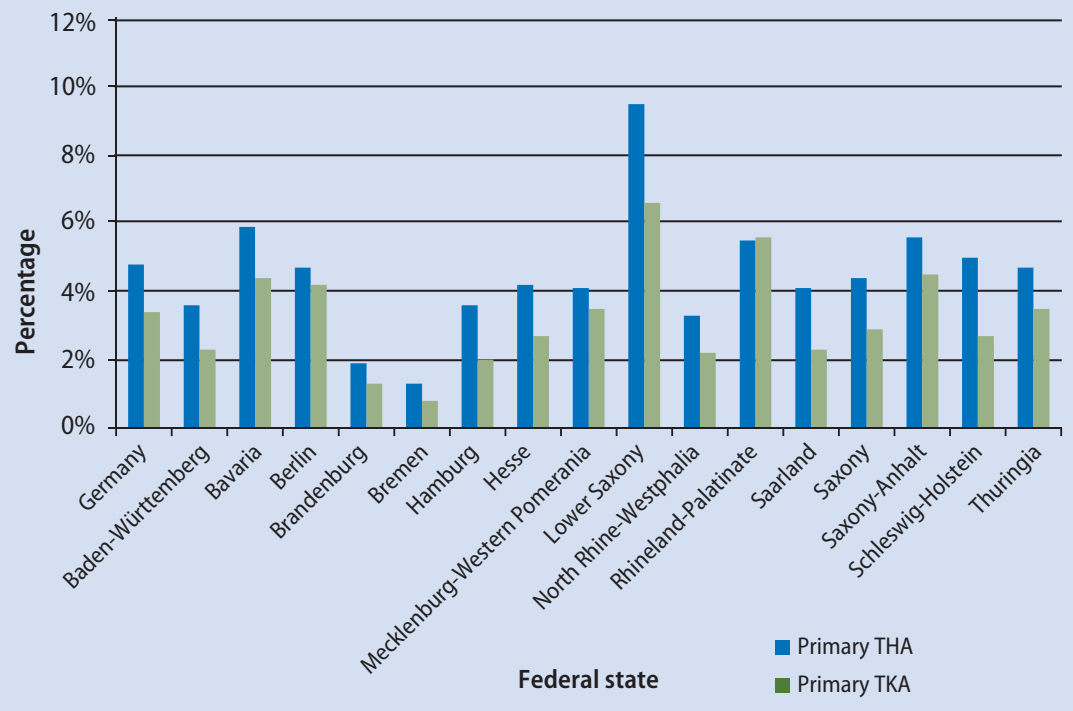

- Fig. 3.18 Percentage of unfulfilled indication criteria used for external quality assurance for inpatient care for primary THA and TKA in German federal states (2013). (Source: IGES - AQUA-Institut 2014a, 2014c)

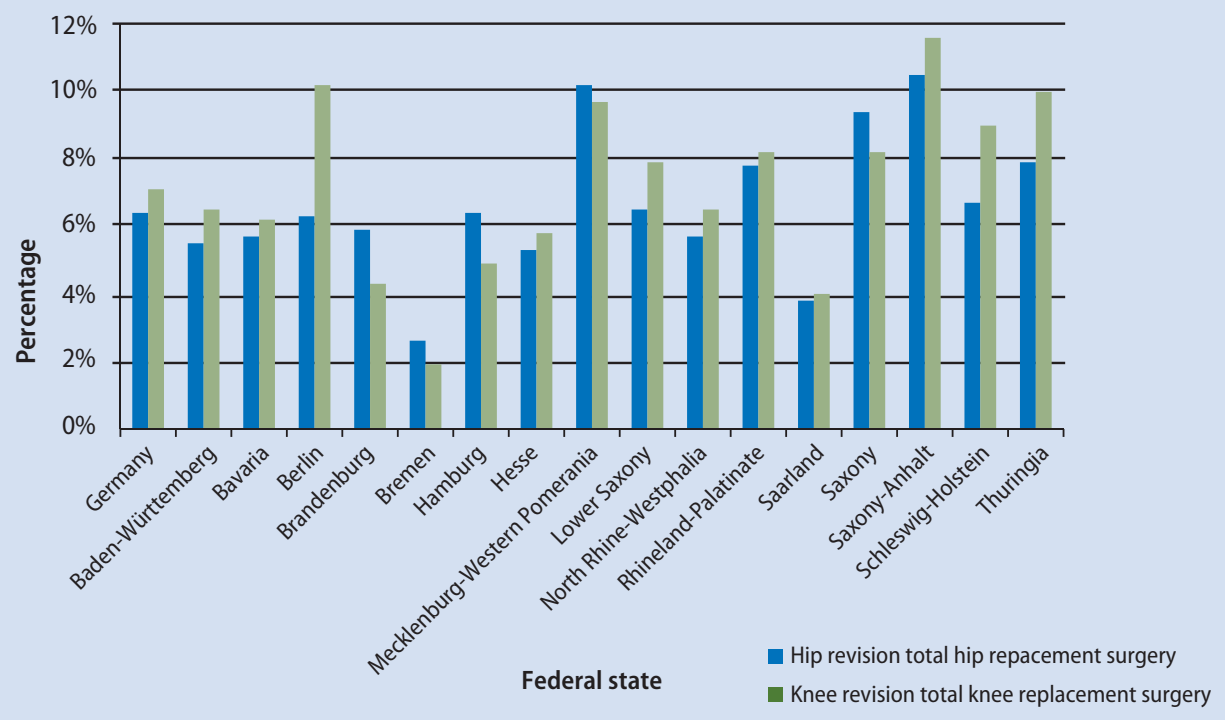

- Fig. 3.19 Percentage of unfulfilled indication criteria used for external quality assurance of inpatient care for revision THA and TKA in German federal states. (Source: IGES - AQUA-Institut 2014b, 2014d) 
are above the national average with regard to the rate of unfulfilled of indication criteria for both hip and knee replacement surgery. These rates have shown relatively constant trends in most of the federal states. The results for entire Germany, Baden-Württemberg, Bavaria and Schleswig-Holstein improved relative to the previous year (AQUAInstitut 2013a).

The same analysis with regard to revision total arthroplasty shows a different regional distribution (- Fig. 3.19). Saxony-Anhalt, Mecklenburg-Western Pomerania, Saxony, Thuringia, Rhineland-Palatinate, Schleswig-Holstein as well as Lower-Saxony are above the nationwide average of $6.4 \%$ and $7.1 \%$ with regard to unfulfilled indication criteria for the hip and knee respectively.

The general trend of these rates has remained relatively constant in most federal states. The results for entire Germany, Baden-Württemberg, Bavaria and Schleswig-Holstein improved relative to the previous year (AQUA-Institut 2014a).

While the trends for individual federal states do not show any significant changes compared to the previous year, a decrease by 0.7 percentage points was documented in the average for Germany (AQUA-Institut 2014b).

Open Access This chapter is published under the Creative Commons Attribution NonCommercial 4.0 International license (http://creativecommons.org/licenses/by-nc/4.0/deed.de) which grants you the right to use, copy, edit, share and reproduce this chapter in any medium and format, provided that you duly mention the original author(s) and the source, include a link to the Creative Commons license and indicate whether you have made any changes.

The Creative Commons license referred to also applies to any illustrations and other third party material unless the legend or the reference to the source states otherwise. If any such third party material is not licensed under the above-mentioned Creative Commons license, any copying, editing or public reproduction is only permitted with the prior approval of the copyright holder or on the basis of the relevant legal regulations.

\section{References}

Aliyev RM (2010): Alloarthroplastischer Hüftgelenkersatz mit dem Staffelstein-Score: Ergebnisevaluation der stationären Rehabilitation. Der Orthopäde 39(12), 1163-1170. DOI: 10.1007/s00132-010-1651-z.

Andersen LO \& Kehlet H (2014): Analgesic efficacy of local infiltration analgesia in hip and knee arthroplasty: a systematic review. British journal of anaesthesia 113(3), 360-374. DOI: 10.1093/bja/aeu155. http://www.ncbi.nlm. nih.gov/pubmed/24939863.

AOA (2014): Hip and Knee Arthroplasty. Annual Report 2014. Australian Orthopaedic Association National Joint Replacement Registry. ISSN: 1445-3657.

AQUA-Institut (2010a): Bundesauswertung zum Erfassungsjahr 2009: 17/3 - Hüft-Endoprothesenwechsel und -komponentenwechsel: Qualitätsindikatoren. Göttingen: AQUA Institut für angewandte Qualitätsförderung und Forschung im Gesundheitswesen $\mathrm{GmbH}$ (Hrsg.).

AQUA-Institut (2010b): Bundesauswertung zum Verfahrensjahr 2009: 17/2 - Hüft-Endoprothesen-Erstimplantation: Qualitätsindikatoren. Göttingen: AQUA Institut für angewandte Qualitätsförderung und Forschung im Gesundheitswesen $\mathrm{GmbH}$ (Hrsg.).
AQUA-Institut (2010c): Bundesauswertung zum Verfahrensjahr 2009: 17/5 - Knie-Totalendoprothesen-Erstimplantation: Qualitätsindikatoren. Göttingen: AQUA Institut für angewandte Qualitätsförderung und Forschung im Gesundheitswesen GmbH (Hrsg.).

AQUA-Institut (2010d): Bundesauswertung zum Verfahrensjahr 2009: 17/7 - Knie-Endoprothesenwechsel und -komponentenwechsel: Qualitätsindikatoren. Göttingen: AQUA Institut für angewandte Qualitätsförderung und Forschung im Gesundheitswesen $\mathrm{GmbH}$ (Hrsg.).

AQUA-Institut (2011a): Bundesauswertung zum Erfassungsjahr 2010: 17/3 - Hüft-Endoprothesenwechsel und -komponentenwechsel: Qualitätsindikatoren. Göttingen: AQUA Institut für angewandte Qualitätsförderung und Forschung im Gesundheitswesen $\mathrm{GmbH}$ (Hrsg.).

AQUA-Institut (2011b): Bundesauswertung zum Verfahrensjahr 2010: 17/2 - Hüft-Endoprothesen-Erstimplantation: Qualitätsindikatoren. Göttingen: AQUA Institut für angewandte Qualitätsförderung und Forschung im Gesundheitswesen $\mathrm{GmbH}$ (Hrsg.).

AQUA-Institut (2011c): Bundesauswertung zum Verfahrensjahr 2010: 17/5 - Knie-Totalendoprothesen-Erstimplantation: Qualitätsindikatoren. Göttingen: AQUA Institut für 
angewandte Qualitätsförderung und Forschung im Gesundheitswesen GmbH (Hrsg.).

AQUA-Institut (2011d): Bundesauswertung zum Verfahrensjahr 2010: 17/7 - Knie-Endoprothesenwechsel und -komponentenwechsel: Qualitätsindikatoren. Göttingen: AQUA Institut für angewandte Qualitätsförderung und Forschung im Gesundheitswesen $\mathrm{GmbH}$ (Hrsg.).

AQUA-Institut (2012a): Bundesauswertung zum Erfassungsjahr 2011: 17/2 - Hüft-Endoprothesen-Erstimplantation: Qualitätsindikatoren. Göttingen: AQUA Institut für angewandte Qualitätsförderung und Forschung im Gesundheitswesen $\mathrm{GmbH}$ (Hrsg.).

AQUA-Institut (2012b): Bundesauswertung zum Erfassungsjahr 2011: 17/3 - Hüft-Endoprothesenwechsel und -komponentenwechsel: Qualitätsindikatoren. Göttingen: AQUA Institut für angewandte Qualitätsförderung und Forschung im Gesundheitswesen $\mathrm{GmbH}$ (Hrsg.).

AQUA-Institut (2012c): Bundesauswertung zum Erfassungsjahr 2011: 17/5 - Knie-Totalendoprothesen-Erstimplantation: Qualitätsindikatoren. Göttingen: AQUA Institut für angewandte Qualitätsförderung und Forschung im Gesundheitswesen GmbH (Hrsg.).

AQUA-Institut (2012d): Bundesauswertung zum Verfahrensjahr 2011: 17/7 - Knie-Endoprothesenwechsel und -komponentenwechsel: Qualitätsindikatoren. Göttingen: AQUA Institut für angewandte Qualitätsförderung und Forschung im Gesundheitswesen $\mathrm{GmbH}$ (Hrsg.).

AQUA-Institut (2012e): Hüftendoprothesenversorgung. Abschlussbericht. Göttingen: AQUA - Institut für angewandte Qualitätsförderung und Forschung im Gesundheitswesen $\mathrm{GmbH}$.

AQUA-Institut (2012f): Knieendoprothesenversorgung. Abschlussbericht. Göttingen: AQUA - Institut für angewandte Qualitätsförderung und Forschung im Gesundheitswesen $\mathrm{GmbH}$.

AQUA-Institut (2013a): Bundesauswertung zum Erfassungsjahr 2012: 17/2 - Hüft-Endoprothesen-Erstimplantation: Qualitätsindikatoren. Göttingen: AQUA Institut für angewandte Qualitätsförderung und Forschung im Gesundheitswesen $\mathrm{GmbH}$ (Hrsg.).

AQUA-Institut (2013b): Bundesauswertung zum Erfassungsjahr 2012: 17/3 - Hüft-Endoprothesenwechsel und -komponentenwechsel: Qualitätsindikatoren. Göttingen: AQUA Institut für angewandte Qualitätsförderung und Forschung im Gesundheitswesen $\mathrm{GmbH}$ (Hrsg.).

AQUA-Institut (2013c): Bundesauswertung zum Erfassungsjahr 2012: 17/5 - Knie-Totalendoprothesen-Erstimplantation: Qualitätsindikatoren. Göttingen: AQUA Institut für angewandte Qualitätsförderung und Forschung im Gesundheitswesen GmbH (Hrsg.).

AQUA-Institut (2013d): Bundesauswertung zum Erfassungsjahr 2012: 17/7 - Knie-Endoprothesenwechsel und -komponentenwechsel: Qualitätsindikatoren. Göttingen: AQUA Institut für angewandte Qualitätsförderung und Forschung im Gesundheitswesen $\mathrm{GmbH}$ (Hrsg.).

AQUA-Institut (2014a): Bundesauswertung zum Erfassungsjahr 2013: 17/2 - Hüft-Endoprothesen-Erstimplantation:
Qualitätsindikatoren. Göttingen: AQUA Institut für angewandte Qualitätsförderung und Forschung im Gesundheitswesen $\mathrm{GmbH}$ (Hrsg.).

AQUA-Institut (2014b): Bundesauswertung zum Erfassungsjahr 2013: 17/3 - Hüft-Endoprothesenwechsel und -komponentenwechsel: Qualitätsindikatoren. Göttingen: AQUA Institut für angewandte Qualitätsförderung und Forschung im Gesundheitswesen $\mathrm{GmbH}$ (Hrsg.).

AQUA-Institut (2014c): Bundesauswertung zum Erfassungsjahr 2013: 17/5 - Knie-Totalendoprothesen-Erstimplantation: Qualitätsindikatoren. Göttingen: AQUA Institut für angewandte Qualitätsförderung und Forschung im Gesundheitswesen GmbH (Hrsg.).

AQUA-Institut (2014d): Bundesauswertung zum Erfassungsjahr 2013: 17/7 - Knie-Endoprothesenwechsel und -komponentenwechsel: Qualitätsindikatoren. Göttingen: AQUA Institut für angewandte Qualitätsförderung und Forschung im Gesundheitswesen $\mathrm{GmbH}$ (Hrsg.).

AQUA-Institut (2015a): Beschreibung der Qualitätsindikatoren für das Erfassungsjahr 2014: Knie-Endoprothesenwechsel und -komponentenwechsel: Indikatoren 2014. Göttingen: AQUA Institut für angewandte Qualitätsförderung und Forschung im Gesundheitswesen GmbH (Hrsg.).

AQUA-Institut (2015b): Bundesauswertung zum Erfassungsjahr 2014: 17/2 - Hüft-Endoprothesen-Erstimplantation: Qualitätsindikatoren. Göttingen: AQUA Institut für angewandte Qualitätsförderung und Forschung im Gesundheitswesen $\mathrm{GmbH}$ (Hrsg.).

AQUA-Institut (2015c): Bundesauswertung zum Erfassungsjahr 2014: 17/3 - Hüft-Endoprothesenwechsel und -komponentenwechsel: Qualitätsindikatoren. Göttingen: AQUA Institut für angewandte Qualitätsförderung und Forschung im Gesundheitswesen $\mathrm{GmbH}$ (Hrsg.).

AQUA-Institut (2015d): Bundesauswertung zum Erfassungsjahr 2014: 17/5 - Knie-Totalendoprothesen-Erstimplantation: Qualitätsindikatoren. Göttingen: AQUA Institut für angewandte Qualitätsförderung und Forschung im Gesundheitswesen GmbH (Hrsg.).

AQUA-Institut (2015e): Bundesauswertung zum Erfassungsjahr 2014: 17/7 - Knie-Endoprothesenwechsel und -komponentenwechsel: Qualitätsindikatoren. Göttingen: AQUA Institut für angewandte Qualitätsförderung und Forschung im Gesundheitswesen $\mathrm{GmbH}$ (Hrsg.).

Atchabahian A, Schwartz G, Hall CB, Lajam CM \& Andreae MH (2015): Regional analgesia for improvement of long-term functional outcome after elective large joint replacement. Cochrane Database Syst Rev 8, Cd010278. DOI: 10.1002/14651858.CD010278.pub2.

Augurzky B, Reichert AR \& Scheuer M (2011): Faktenbuch Medinische Rehabilitation 2011. Heft 66. Essen: Rheinisch-Westfälisches Institut für Wirtschaftsförderung. ISBN: 978-3-86788-285-9.

AWMF (2009a): Endoprothese bei Gonarthrose. AWMF-Leitlinien-Register [AWMF guideline register] No. 012/008. Validity expired. Guideline currently under review. Arbeitsgruppe Leitlinien der Dt. Gesellschaft für Unfallchirurgie (DGU) [guideline working group of the DGU]. 
AWMF (2009b): Koxarthrose. AWMF-Leitlinien-Register [AWMF guideline register] No. 033/001. Deutsche Gesellschaft für Orthopädie und Orthopädische Chirurgie e. V. [German orthopedics and orthopedic surgery association]

AWMF (2015): S3-Leitlinie - Prophylaxe der venösen Thromboembolie (VTE). AWMF-Leitlinien-Register [AWMF guideline register] No. 003/001. 2. komplett überarbeitete Auflage, Stand: 15.10.2015. [as of 15 October 2015] Marburg: Arbeitsgemeinschaft der Wissenschaftlichen Medizinischen Fachgesellschaften e. V. [Association of the Scientific Medical Societies in Germany]

Barbieri A, Vanhaecht K, Van Herck P, Sermeus W, Faggiano F, Marchisio S \& Panella M (2009): Effects of clinical pathways in the joint replacement: a meta-analysis. BMC medicine 7, 32. DOI: 10.1186/1741-7015-7-32.

BARMER GEK Report Krankenhaus 2010. Schwerpunktthema: Trends in der Endoprothetik des Hüft- und Kniegelenks. Schriftenreihe zur Gesundheitsanalyse, Band 3. St. Augustin: Asgard-Verlag. ISBN: 978-537-44103-4.

Baulig C, Grams M, Röhrig B, Linck-Eleftheriadis S \& Krummenauer F (2015): Clinical outcome and cost effectiveness of inpatient rehabilitation after total hip and knee arthroplasty. A multi-centre cohort benchmarking study between nine rehabilitation departments in Rhineland-Palatinate (Western Germany). European Journal of Physical and Rehabilitation Medicine. http://www.ncbi. nlm.nih. gov/pubmed/26006080 [accessed: 28 January 2016].

Bethge M, Bartel S, Streibelt M, Lassahn C \& Thren K (2011): [Improved outcome quality following total knee and hip arthroplasty in an integrated care setting: results of a controlled study]. Die Rehabilitation 50(2), 86-93. DOI: 10.1055/s-0030-1265144.

Beyth RJ, Quinn LM \& Landefeld CS (1998): Prospective evaluation of an index for predicting the risk of major bleeding in outpatients treated with warfarin. The American journal of medicine 105(2), 91-99. ISSN: 0002-9343.

Braun B (2013): Knie- und Hüft-(Total-) Endoprothesen 2008 bis 2012 - hkk Gesundheitsreport. Bremen: hkk Erste Gesundheit. https://www.hkk.de/fileadmin/doc/ broschueren_flyer/sonstiges/20131129_hkk_Gesundheitsreport_KnieHueft-Tep.pdf. [accessed: 03 November 2015].

Cappelleri G, Ghisi D, Fanelli A, Albertin A, Somalvico F \& Aldegheri G (2011): Does continuous sciatic nerve block improve postoperative analgesia and early rehabilitation after total knee arthroplasty? A prospective, randomized, double-blinded study. regional anesthesia and pain medicine 36(5), 489-492. DOI: 10.1097/AAP.0b013e3182286a2b.

Charlson ME, Pompei P, Ales KL \& MacKenzie CR (1987): A new method of classifying prognostic comorbidity in longitudinal studies: development and validation. Journal of Chronic Diseases. 1987; 40(5): 373-83.

Cionac Florescu S, Anastase DM, Munteanu AM, Stoica IC \& Antonescu D (2013): Venous Thromboembolism Following Major Orthopedic Surgery. Maedica - A Journal of Clinical Medicine 8(2), 189-194.
Conner-Spady BL, Sanmartin C, Johnston GH, McGurran JJ, Kehler M, Noseworthy TW (2011): The importance of patient expectations as a determinant of satisfaction with waiting times for hip and knee replacement surgery.

Claes L, Kirschner S, Perka C \& Rudert M (2012): AE-Manual der Endoprothetik - Hüfte und Hüftrevision. Heidelberg: Springer. ISBN: 978-3-642-14645-9.

Decousus H, Tapson VF, Bergmann JF, Chong BH, Froehlich JB, Kakkar AK, Merli GJ, Monreal M, Nakamura M, Pavanello R, Pini M, Piovella F, Spencer FA, Spyropoulos AC, Turpie AG, Zotz RB, Fitzgerald G, Anderson FA \& Investigators I (2011): Factors at admission associated with bleeding risk in medical patients: findings from the IMPROVE investigators. Chest 139(1), 69-79. DOI: 10.1378/chest.09-3081.

den Hartoq YM, Mathijssen NM \& Vehmeijer SB (2013): Reduced length of hospital stay after the introduction of a rapid recovery protocol for primary THA procedures. Acta Orthop. 84(5), 444-447. DOI: 10.3109/17453674.2013.838657.

Destatis (2013): Fallpauschalenbezogene Krankenhausstatistik (DRG-Statistik) Diagnosen, Prozeduren, Fallpauschalen und Case Mix der vollstationären Patientinnen und Patienten in Krankenhäusern. https://www.destatis.de/ DE/Publikationen/Thematisch/Gesundheit/Krankenhaeuser/FallpauschalenKrankenhaus2120640137004. pdf?__blob=publicationFile.

Destatis (2014): Gesundheit - Grunddaten der Vorsorge- oder Rehabilitationseinrichtungen 2013. https://www.destatis. de/DE/Publikationen/Thematisch/Gesundheit/VorsorgeRehabilitation/GrunddatenVorsorgeReha.html.

Destatis (2015a): Die 50 häufigsten Operationen der vollstationären Patientinnen und Patienten in Krankenhäusern (Rang, Anzahl, Anteil in Prozent). Gliederungsmerkmale: Jahre, Deutschland, Geschlecht, Art der Operation. http:// www.gbe-bund.de/oowa921-install/servlet/oowa/aw92/ dboowasys921.xwdevkit/xwd_init?gbe.isgbetol/xs_ start_neu/\&p_aid=3\&p_aid=73077937\&nummer= $666 \&$ p_sprache $=D \& p \_i n d s p=-\& p \_$aid $=38818394$ [accessed: 02 November 2015].

Destatis (2015b): Durchschnittliche Verweildauer. https:// www.destatis.de/DE/ZahlenFakten/GesellschaftStaat/ Gesundheit/Glossar/Verweildauer.html [accessed: 4 July 2015].

Destatis (2015c): Krankheitskosten. Wiesbaden: Statistisches Bundesamt. https://www.destatis.de/DE/ZahlenFakten/ GesellschaftStaat/Gesundheit/Krankheitskosten/Krankheitskosten.html\#Tabellen [accessed: 11 November 2015].

Deutsche Rentenversicherung (2005): Medizinische Voraussetzungen der $\mathrm{ABH}$. http://www.deutsche-rentenversicherung.de/cae/servlet/contentblob/208282/publicationFile/2266/ahb_indikationskatalog.pdf [accessed: 08 December 2015].

Deutsche Rentenversicherung Bund (2009): Rahmenkonzept zur medizinischen Rehabilitation in der gesetzlichen Rentenversicherung. Berlin.

Deutsche Rentenversicherung Bund (2010): Therapiestandards für die Rehabilitation nach Hüft- oder Knietotal- 
endoprothese. Methodenbericht: Ergebnisse der Projektphasen der Entwicklung der Pilotversion Reha- Therapiestandards Hüft- und Knie-TEP. Freiburg, Berlin.

Deutsche Rentenversicherung Bund (2011): Reha-Therapiestandards Hüft- und Knie-TEP. Leitlinie für die medizinische Rehabilitation der Rentenversicherung. Berlin.

Deutsche Rentenversicherung Bund (2014a): Reha-Bericht Update 2014. Die medizinische und berufliche Rehabilitation der Rentenversicherung im Licht der Statistik. Berlin. ISSN: 2193-5718.

Deutsche Rentenversicherung Bund (2014b): Rentenversicherung in Zeitreihen. DRV-Schriften Band 22.

Dreinhoefer KE \& Schwarzkopf SR (2010): Outcomes bei Alterstrauma. Der Unfallchirurg 113(6), 462-468. DOI: 10.1007/s00113-010-1746-3.

Drosos Gl, Triantafilidou T, Ververidis A, Agelopoulou C, Vogiatzaki T \& Kazakos K (2015): Persistent post-surgical pain and neuropathic pain after total knee replacement. World Journal of Orthopedics 6(7), 528-536. DOI: 10.5312/wjo.v6.i7.528.

Effenberger H, Zumstein MD \& Rehart SS, A. (2008): Benchmarking in der Hüftendoprothetik. Orthopädische Praxis 44(5), 2013-2225.

European Society of Cardiology (Hrsg) (2014): 2014 ESC Guidelines on the diagnosis and management of acute pulmonary embolism. European Heart Journal, 30333080. DOI: 10.1093/eurheartj/ehu283.

Falck-Ytter Y, Francis CW, Johanson NA, Curley C, Dahl OE, Schulman S, Ortel TL, Pauker SG, Colwell CW, Jr. \& American College of Chest P (2012): Prevention of VTE in orthopedic surgery patients: Antithrombotic Therapy and Prevention of Thrombosis, 9th ed: American College of Chest Physicians Evidence-Based Clinical Practice Guidelines. Chest 141(2 Suppl), e278S-325S. DOI: 10.1378/ chest.11-2404.

Fender D, Harper WM, Thompson JR \& Gregg PJ (1997): Mortality and fatal pulmonary embolism after primary total hip replacement. Results from a regional hip register. The Journal of bone and joint surgery 79(6), 896-899. ISSN: 0301-620X.

Finkenstädt V \& Niehaus F (2013): Rationierung und Versorgungsunterschiede in Gesundheitssystemen. Ein internationaler Überblick. Köln: Wissenschaftliches Institut der PKV. ISBN: 978-3-9813569-4-6.

Friedrich J \& Belvers A (2009): Patientenwege ins Krankenhaus: Räumliche Mobilität bei Elektiv- und Notfallleistungen am Beispiel von Hüftendoprothesen. In: Klauber J, Robra, B.P., Schellschmidt, H.: Krankenhaus-Report 2008/2009. 155-181.

GBE-Bund (2015): Abgeschlossene Leistungen zur medizinischen Rehabilitation und sonstige Leistungen zur Teilhabe in der Gesetzlichen Rentenversicherung (Anzahl). Gliederungsmerkmale: Jahre, Region (Wohnort/Ort der Leistung); Geschlecht, Maßnahmeart. Tabelle für das Jahr 2013. Gesundheitsberichterstattung des Bundes. https:// www.gbebund.de/oowa921 install/servlet/oowa/aw92/ WS0100/_XWD_FORMPROC?TARGET=\&PAGE $=$ _XWD_2
10\&OPINDEX=1\&HANDLER=XS_ROTATE_ADVANCED\&DATACUBE $=$ XWD_238\&D.000=PAGE\& ... 1/ [accessed: 23 June 2015].

Gollwitzer H, Gerdesmeyer L, Gradinger R \& von EisenhartRothe R (2011): [Evidence-based update in hip arthroplasty]. Orthopade 40(6), 535-542. DOI: $10.1007 /$ s00132011-1763-0.

Gravius S, Randau T \& Wirtz DC (2011): [What can be done when hip prostheses fail? New trends in revision endoprosthetics]. Der Orthopäde 40(12), 1084-1094. DOI: 10.1007/s00132-011-1844-0.

Guerra ML, Singh PJ \& Taylor NF (2015): Early mobilization of patients who have had a hip or knee joint replacement reduces length of stay in hospital: a systematic review. Clinical Rehabilitation 29(9), 844-854. DOI: 10.1177/ 0269215514558641.

Gülich M, Mittag O, Müller E, Uhlmann A, Bruggemann S \& Jackel WH (2010): Ergebnisse einer Analyse der therapeutischen Leistungsdaten (KTL-Daten) von 5838 Rehabilitandinnen und Rehabilitanden nach Hüft- bzw. Knieendoprothesenimplantation. Rehabilitation (Stuttg) 49(1), 13-21. DOI: 10.1055/s-0029-1246155 PM:20178057.

Günther KP, Jeszenszky C, Schäfer T, Hannemann F, Niethard F (2013): Hüft- und Kniegelenkersatz in Deutschland Mythen und Fakten zur Operationshäufigkeit. Das Krankenhaus Heft 9/2013, Copyright W. Kohlhammer GmbH Stuttgart.

Günther K-P, Haase E, Lange T, Kopkow C, Schmitt J, Jeszenszky C, Balck F, Lützner J, Hartmann A \& Lippmann M (2015): Persönlichkeitsprofil und Komorbidität: Gibt es den »schwierigen Patienten« in der primären Hüftendoprothetik? Der Orthopäde 44(7), 555-565. DOI: 10.1007/ s00132-015-3097-9.

Haas H, Grifka J, Günther KP, Heller KD, Niethard FU, Windhagen H, Ebner M \& Mittelmeier W (2013): EndoCert. Zertifizierung von Endoprothetischen Versorgungszentren in Deutschland. Stuttgart: Georg Thieme Verlag KG. ISBN: 978-3-13-174081-6.

Halawi MJ. (2015): Outcome Measures in Total Joint Arthroplasty: Current Status, Challenges, and Future Directions. Orthopedics. 2015 Aug;38(8):e685-9. doi: 10.3928/01477447-20150804-55

Hardeman F, Londers J, Favril A, Witvrouw E, Bellemans J \& Victor J (2012): Predisposing factors which are relevant for the clinical outcome after revision total knee arthroplasty. Knee Surgery, Sports Traumatology, Arthroscopy 20(6), 1049-1056. DOI: 10.1007/s00167-011-1624-8.

Hassenpflug J \& Liebs TR (2014): Register als Werkzeug für mehr Endoprothesensicherheit: Erfahrungen aus anderen Ländern und dem Aufbau des Endoprothesenregisters Deutschland. Bundesgesundheitsblatt - Gesundheitsforschung - Gesundheitsschutz 57(12), 1376-1383. DOI: 10.1007/s00103-014-2057-6.

Haverkamp D, Klinkenbijl MN, Somford MP, Albers GH \& van der Vis HM (2011): Obesity in total hip arthroplasty - does it really matter? A meta-analysis. Acta Orthop 82(4), 417-422. DOI: 10.3109/17453674.2011.588859. 
Heisel J \& Jerosch J (2007): Rehabilitation nach Hüft- und Knieendoprothese. Köln: Deutscher Ärzte-Verlag. ISBN: 978-3769105322.

Heisel J (2008): Rehabilitation following total hip and knee replacement. Der Orthopäde 37(12), 1217-1232. DOI: 10.1007/s00132-008-1379-1.

Heisel J (2012): Rehabilitation nach minimal-invasiver Hüftendoprothesenimplantation. Der Orthopäde 41(5), 407-412. DOI: 10.1007/s00132-011-1896-1.

Howie C, Hughes H \& Watts AC (2005): Venous thromboembolism associated with hip and knee replacement over a ten-year period: a population-based study. The Journal of bone and joint surgery 87(12), 1675-1680. DOI: 10.1302/0301-620X.87B12.16298.

Husted H (2012): Fast-track hip and knee arthroplasty: clinical and organizational aspects. Acta Orthop Suppl. 83(346), 1-39. DOI: 10.3109/17453674.2012.700593.

Ibrahim MS, Khan MA, Nizam I \& Haddad FS (2013): Perioperative interventions producing better functional outcomes and enhanced recovery following total hip and knee arthroplasty: an evidence-based review. BMC Med 11, 37. DOI: 10.1186/1741-7015-11-37.

InEK (2015): Datenbankabfrage. G-DRG V2011 Daten 2010 gem. § 21 KHEntgG - G-DRG Browser. 147A: Revision oder Ersatz des Hüftgelenkes ohne komplizierende Diagnose, ohne Arthrodese, ohne äußerst schwere CC, Alter > 15 Jahre, mit komplizierendem Eingriff oder mit Implantation/Wechsel einer Radiuskopfprothese und 147B: Revision oder Ersatz des Hüftgelenkes ohne komplizierende Diagnose, ohne Arthrodese, ohne äußerst schwere CC, Alter > 15 Jahre, ohne komplizierenden Eingriff.

Jacobs CA, Christensen CP \& Berend ME (2009): Sport Activity After Total Hip Arthroplasty: Changes in Surgical Technique, Implant Design, and Rehabilitation. Journal of Sport Rehabilitation 18(1), 47-59.

Jämsen E, Nevalainen P, Eskelinen A, Huotari K, Kalliovalkama J \& Moilanen T (2012): Obesity, diabetes, and preoperative hyperglycemia as predictors of periprosthetic joint infection: a single-center analysis of 7181 primary hip and knee replacements for osteoarthritis. The Journal of Bone \& Joint Surgery. 2012; 94(14):e101. doi: 10.2106/ JBJS.J.01935.

Januel J-M, Chen G, Ruffieux C, Quan H, Douketis JD, Crowther MA, Collin C, Ghali WA \& Burnand B (2012): Symptomatic In-Hospital Deep Vein Thrombosis and Pulmonary Embolism Following Hip and Knee Arthroplasty Among Patients Receiving Recommended Prophylaxis: A Systematic Review. Journal of the American Medical Association 307(3), 294-303.

Jaschinski G, Pieper D, Eikermann M, Steinhausen S, Linke C, Heitmann T, Pani M \& Neugebauer E (2014): Aktueller Status der Hüft- und Knieendoprothetik in Deutschland - Ergebnisse einer bundesweiten Umfrage. Zeitschrift für Orthopädie und Unfallchirurgie (455-461). DOI: 10.1055/ s-0034-1383023.

Jeschke E \& Günster C (2014): Zum Zusammenhang von Behandlungshäufigkeit und -ergebnis in der Hüftendo- prothetik. In: Wissenschaftliches Institut der AOK: Krankenhaus Report 2014.

Jorgensen CC, Jacobsen MK, Soeballe K, Hansen TB, Husted H, Kjaersgaard-Andersen P, Hansen LT, Laursen MB \& Kehlet H (2013): Thromboprophylaxis only during hospitalisation in fast-track hip and knee arthroplasty, a prospective cohort study. BMJ Open 3(12), e003965. DOI: 10.1136/ bmjopen-2013-003965.

Jourdan C, Poiraudeau S, Descamps S, Nizard R, Hamadouche M, Anract P, Boisgard S, Galvin M \& Ravaud P (2012): Comparison of Patient and Surgeon Expectations of Total Hip Arthroplasty. PLoS ONE 7(1), 1-9. DOI: 10.1371/journal. pone.0030195.

Judge A, Cooper C, Arden NK, Williams S, Hobbs N, Dixon D, Günther K-P, Freinhoefer K \& Dieppe PA (2011): Pre-operative expectation predicts 12-month post-operative outcome among patients undergoing primary total hip replacement in European orthopaedic centres. Osteoarthritis and Cartilage 19(6), 659-667. DOI: 10.1016/j. joca.2011.03.009.

Kearon C (2003): Natural history of venous thromboembolism. Circulation 107(23 Suppl 1), I22-30. DOI: 10.1161/01. CIR.0000078464.82671.78.

Kerr DR \& Kohan L (2008): Local infiltration analgesia: a technique for the control of acute postoperative pain following knee and hip surgery: a case study of 325 patients. Acta Orthopaedica Scandinavica 79(2), 174-183. DOI: 10.1080/17453670710014950.

Khan A, Kiryluk S \& Fordyce MJ (2007): Fatal pulmonary embolism, death rates and standardised mortality ratios after primary total hip replacement in a joint replacement centre. Hip International 17(2), 59-63.

Kladny B (2015): Stationäre und ambulante Rehabilitation in Deutschland: Aktueller Stand und weitere Entwicklung. Der Unfallchirurg 118(2), 103-111. DOI: 10.1007/ s00113014-2613-4.

Krischak G, Kaluscha R, Kraus M, Tepohl L \& Nusser M (2013): Rückkehr in das Erwerbsleben nach Hüfttotalendoprothese. Unfallchirurg 116(8), 755-759. DOI: 10.1007/ s00113-013-2424-z.

Kuijer PM, Hutten BA, Prins MH \& Buller HR (1999): Prediction of the risk of bleeding during anticoagulant treatment for venous thromboembolism. Archives of internal medicine 159(5), 457-460. ISSN: 0003-9926.

Lau TW, Fang C \& Leung F (2016): Assessment of postoperative short-term and long-term mortality risk in Chinese geriatric patients for hip fracture using Charlson comorbidity score. Hong Kong Medical Journal. 2016; 22(1):1622. doi: 10.12809/hkmj 154451.

Laubenthal H \& Neugebauer E (2009): S3-Leitlinie »Behandlung akuter perioperativer und posttraumatischer Schmerzen« (AWMF-Register Nr. 041/001). 20 April 2009 - Validity expired. Bochum: Deutsche Interdiszi plinäre Vereinigung für Schmerztherapie e.V.

Liebs TR, Melsheimer O \& Hassenpflug J (2014): Frühzeitige Detektion systematischer Schadensfälle durch Endopro- 
thesenregister. Orthopäde 43(6), 549-554. DOI: 10.1007/ s00132-014-2293-3.

Lohom G, Walsh M, Higgins G \& Shorten G (2002): Effect of perioperative administration of dexketoprofen on opioid requirements and inflammatory response following elective hip arthroplasty. British Journal of Anasthesia 88(4), 520-526.

Lübbeke A, Katz JN, Perneger TV \& Hoffmeyer P (2007): Primary and revision hip arthroplasty: 5 -year outcomes and influence of age and comorbidity. The Journal of rheumatology 34(2), 394-400. ISSN: 0315-162X.

Maier-Börries O \& Jäckel WH (2013): Rehabilitation nach Implantation künstlicher Hüft- und Kniegelenke. Die Rehabilitation 52(03), 202-212. DOI: 10.1055/s-00331343142.

Middeldorf S \& Caaer R (2010): Verlauf- und Ergebnisevaluation stationärer Rehabilitationsmassnahmen nach alloarthroplastishem Knie- und Hüftgelenksersatz mit dem Staffelstein-Score. Orthopädische Praxis (36), 230-238.

Mittelmeier W, Josten C, Siebert HR, Niethard FU, Marzi I \& Klü B D (2012): Forschung in Orthopädie und Unfallchirugie - Bestandsaufnahme und Ausblick - Weißbuch Forschung in Orthopädie und Unfallchirugie der Deutschen Gesellschaft für Orthopädie und Unfallchirurgie. Aachen: Shaker Verlag GmbH. ISBN: 978-384401775-5.

Müller E, Mittag O, Gülich M, Uhlmann A \& Jäckel WH (2009): Systematische Literaturanalyse zu Therapien in der Rehabilitation nach Hüft- und Kniegelenks-Total- Endoprothesen: Methoden, Ergebnisse und Herausforderungen. Die Rehabilitation 48(2), 62-72. DOI: 10.1055/s0029-1202295.

Müller M, Toussaint R \& Kohlmann T (2015): Hüft- und Knietotalendoprothesenversorgung - Ergebnisse ambulanter orthopädischer Rehabilitation. Der Orthopäde 44(3), 203-211. DOI: 10.1007/s00132-014-3000-0.

Peduto VA, Ballabio M \& Stefanini S (1998): Efficacy of propacetamol in the treatment of postoperative pain. Morphine-sparing effect in orthopedic surgery. Italian Collaborative Group on Propacetamol. Acta Anaesthesiologica Scandinavica 42(3), 293-298.

Perka C (2011): Preoperative versus postoperative initiation of thromboprophylaxis following major orthopedic surgery: safety and efficacy of postoperative administration supported by recent trials of new oral anticoagulants. Thrombosis journal 9, 17. DOI: 10.1186/1477-9560-9-17.

Prokopetz JJ, Losina E, Bliss RL, Wright J, Baron JA \& Katz JN (2012): Risk factors for revision of primary total hip arthroplasty: a systematic review. BMC Musculoskeletal Disorders 13(251), 1-13. DOI: 10.1186/1471-247413-251.

Quack V, Ippendorf AV, Betsch M, Schenker H, Nebelung S, Rath B, Tingart M \& Lüring C (2015): Multidisziplinäre Rehabilitation und multimodale Fast-Track-Rehabilitation in der Knieendoprothetik: Schneller, besser, günstiger? Eine Umfrage und systematische Literaturrecherche. Die Rehabilitation 54(4), 245-251. DOI:

10.1055/s-0035-1555887.
Renkawitz T, Rieder T, Handel M, Koller M, Drescher J, Bonnlaender G \& Grifka J (2010): Comparison of two accelerated clinical pathwaysafter total knee replacement how fast can we really go? Clinical Rehabilitation 24(3), 230239. DOI: 10.1177/0269215509353267.

RKI (2015): Gesundheit in Deutschland. https://www.rki.de/ DE/Content/Gesundheitsmonitoring/Gesundheitsberichterstattung/Ges/nDtld/gesundheit_in_deutschland_2015.pdf?_blob=publicationFile [accessed 01 July 2016].

Ruíz-Giménez N, Suárez C, González R, Nieto JA, Todolí JA, Samperiz AL \& Monreal M (2008): Predictive variables for major bleeding events in patients presenting with documented acute venous thromboembolism. Findings from the RIETE Registry. Thrombosis and Haemostasis 100(1), 26-31. DOI: 10.1160/TH08030193.

Rupp S \& Wydra G (2012): Anschlussheilbehandlung nach Knietotalendoprothesenimplantation: Konservative Orthopadie und Sportwissenschaft. Der Orthopäde 41(2), 126-135. DOI: 10.1007/s00132-011-1863-x.

Samama CM, Vray M, Barré J, Fiessinger J-N, Rosencher N, Lecompte T, Potron G, Basile J, Hull R \& Desmichels D (2002): Extended Venous Thromboembolism Prophylaxis After Total Hip Replacement: A Comparison of Low Molecular-Weight Heparin With Oral Anticoagulant. Archives of Internal Medicine 162(19), 2191-2196. DOI: 10.1001/archinte.162.19.2191.

Schäfer T, Krummenauer F, Mettelsiefen J, Kirschner S \& Günther KP (2010): Social, educational, and occupational predictors of total hip replacement outcome. Osteoarthritis and Cartilage 18(8), 1036-1042. DOI: 10.1016/j. joca.2010.05.003.

Schäfer T, Pritzkuleit R, Jeszenszky C, Malzahn J, Maier W, Gunther KP \& Niethard F (2013): Trends and geographical variation of primary hip and knee joint replacement in Germany. Osteoarthritis and Cartilage 21(2), 279-288. DOI: 10.1016/j.joca.2012.11.006.

Scherz N, Mean M, Limacher A, Righini M, Jaeger K, Beer HJ, Frauchiger B, Osterwalder J, Kucher N, Matter CM, Banyai M, Angelillo-Scherrer A, Lammle B, Husmann M, Egloff M, Aschwanden M, Bounameaux H, Cornuz J, Rodondi N \& Aujesky D (2013): Prospective, multicenter validation of prediction scores for major bleeding in elderly patients with venous thromboembolism. Journal of thrombosis and haemostasis 11(3), 435-443. DOI: 10.1111/jth.12111.

Schmitt-Sody M, Pilger V \& Gerdesmeyer L (2011): [Rehabilitation and sport following total hip replacement]. Der Orthopäde 40(6), 513-519. DOI: 10.1007/s001320111761-2.

Schulze A \& Scharf HP (2013): Zufriedenheit nach Knietotalendoprothesenimplantation: Vergleich 1990-1999 mit 2000-2012. Der Orthopäde 42(10), 858-865. DOI: 10.1007/s00132-013-2117-x.

Shepherd A \& Mills C (2006): Fatal pulmonary embolism following hip and knee replacement. A study of 2153 cases using routine mechanical prophylaxis and selective chemoprophylaxis. Hip Internatinal 16(1), 53-56. 
Singh JA, Jensen M, Harmsen S \& Lewallen D (2013): Are gender, comorbidity and obesity risk factors for postoperative periprosthetic fractures following primary total hip replacement. The Journal of Arthroplasty. 2013; 28(1):126-31. doi: 10.1016/j.arth.2012.03.010.

Silvanto M, Lappi M \& Rosenberg PH (2002): Comparison of the opioidsparing efficacy of diclofenac and ketoprofen for 3 days after knee arthroplasty. Acta Anaesthesiologica Scandinavica 46(3), 322-328.

Simanski CJP (2008): Schmerztherapie an den unteren Extremitäten. Der Orthopäde 37(10), 959-969. DOI: 10.1007/ s00132-008-1337-y.

Simmel S, Hörterer H \& Horstmann T (2008): Sport nach Hüft-Totalendoprothese - Expertenmeinung versus Patientenrealität. Deutsche Zeitschrift für Sportmedizin 59(11), 268-272.

Spencer FA, Gore JM, Lessard D, Emery C, Pacifico L, Reed G, Gurwitz JH \& Goldberg RJ (2008): Venous thromboembolism in the elderly. A community-based perspective. Thrombosis and haemostasis 100(5), 780-788. ISSN: 0340-6245.

Stargardt T (2008): Health service costs in Europe: cost and reimbursement of primary hip replacement in nine countries. Health economics $17(1$ Suppl), S9-20. DOI: 10.1002/hec.1328.

Statistisches Bundesamt (Hrsg.) (2013): Gesundheit. Diagnosedaten der Patienten und Patientinnen in Vorsorgeoder Rehabilitationseinrichtungen. Fachserie 12 Reihe 6.2.2.

SVR Gesundheit (2014): Bedarfsgerechte Versorgung - Perspektiven für ländliche Regionen und ausgewählte Leistungsbereiche: Gutachten 2014. Sachverständigenrat zur Begutachtung der Entwicklung im Gesundheitswesen (Hrsg.).

Tayrose G, Newman D, Slover J, Jaffe F, Hunter T \& Bosco Jr (2013): Rapid mobilization decreases lengthofstay in joint replacement patients. Bulletin of the Hospital for Joint Diseases 71(3), 222-226.

The Commonwealth Fund (2010): The Commonwealth Fund 2010 International Health Policy Survey in Eleven Countries. http://www.commonwealthfund.org/ /media/files/ publications/chartbook/2010/pdf_2010_ihp_survey_ chartpack_full_12022010.pdf [accessed: 05 October 2015].

Tuncel T, Simon S \& Peters KM (2015): Flexibilisierte Rehabilitationsdauer nach alloplastischem Hüft- und Kniegelenkersatz. Der Orthopäde 44(6), 465-473. DOI: 10.1007/ s00132015-3089-9.

Tuncel T, Krämer A \& Peters KM (2015): Scoregesteuerte Dauer der Anschlussheilbehandlung nach alloplastischem Hüftund Kniegelenkersatz. Zeitschrift für Orthopädie und Unfallchirurgie 153(1), 30-37. DOI:

10.1055/s-0034-1383257.

von Eiff W, Schüring S, Greitemann B \& Karoff M (2011): REDIA - Auswirkungen der DRG-Einführung auf die Rehabilitation. Die Rehabilitation 50(4), 214-221. DOI: 10.1055/s0031-1275720. van der Weegen W, Kornuijit A \& Das D (2015): Do lifestyle restrictions and precautions prevent dislocation after total hip arthroplasty? A systematic review and metaanalysis of the literature. [Systematic Review] Clinical Rehabilitation, 1-11. DOI: 10.1177/0269215515579421.

WiDO (2007): Qualitätssicherung der stationären Versorgung mit Routinedaten (QSR): Abschlussbericht. Bonn: Wissenschaftliches Institut der AOK (Hrsg.). ISBN: 978-392209342-8.

Winther SB, Foss OA, Wik TS, Davis SP, Engdal M, Jessen V \& Husby OS (2015): 1-year follow-up of 920 hip and knee arthroplasty patients after implementing fast-track. Acta Orthop. 86(1), 78-85. DOI: 10.3109/17453674.2014.957089.

Wirtz DC (2011): AE-Manual der Endoprothetik - Knie. Heidelberg: Springer. ISBN: 978-3-642-12888-2.

Zenk K, Finze S, Kluess D, Bader R, Malzahn J \& Mittelmeier W (2014): Einfluss der Erfahrung des Operateurs in der Hüftendoprothetik: Abhängigkeit von Operationsdauer und Komplikationsrisiko. Der Orthopäde 43(6), 522-528. DOI: 10.1007/s00132-014-2292-4.

Zhu Y, Zhang F, Chen W, Liu S, Zhang Q \& Zhang Y (2015): Risk factors for periprosthetic joint infection after total joint arthroplasty: a systematic review and meta-analysis. Journal of Hospital Infection 89(2), 82-89. DOI: 10.1016/j. jhin.2014.10.008. 